Léo Signorini Novaes

Adaptação osteológica para a terrestrialidade em pica-paus (Aves: Picidae)

Osteological adaptation for terrestrial habit in woodpeckers (Aves: Picidae)

São Paulo 
Léo Signorini Novaes

\section{Adaptação osteológica para a terrestrialidade em pica-paus (Aves: Picidae)}

\section{Osteological adaptation for terrestrial habit in woodpeckers (Aves: Picidae)}

Dissertação apresentada ao Instituto de Biociências da Universidade de São Paulo, para a obtenção de Título de Mestre em Zoologia

Orientador: Luís Fábio Silveira

São Paulo 
Novaes, Léo Signorini

Adaptação osteológica para a terrestrialidade em pica-paus (Aves:

Picidae). $x+65 p$.

Dissertação (Mestrado) - Instituto de Biociências da Universidade de São Paulo. Departamento de Zoologia.

1. Picidae 2. Morfologia 3. Terrestrialidade I. Universidade de São Paulo. Instituto de Biociências. Departamento de Zoologia.

Versão corrigida seguindo orientações da banca examinadora. Versão original disponível na biblioteca do Instituto de Biociências da Universidade de São Paulo e Biblioteca Digital de Teses e Dissertações da USP (BDTD).

\section{Comissão Julgadora:}


Dedicado à minha família, dos que já se foram até os que acabaram de chegar. 
"There is grandeur in this view of life, with its several powers, having been originally breathed into a few forms or into one; and that, whilst this planet has gone cycling on according to the fixed law of gravity, from so simple a beginning endless forms most beautiful and most wonderful have been, and are being, evolved."

Charles Darwin, 1859 


\section{Agradecimentos}

Ao Instituto de Biociências e o Museu de Zoologia da USP e a todos os seus professores, alunos, amigos e colegas pela formação acadêmica, pessoal e mental que me proporcionaram nesses últimos sete anos.

Ao meu orientador Luís Fábio Silveira, pelo conhecimento divido, amizade compartilhada e paciência muito além do que eu mereço.

Ao Programa de Coordenação e Aperfeiçoamento de Pessoal do Ensino Superior (CAPES).

Aos curadores, funcionários e alunos dos museus que compartilharam de suas extensas coleções, sem as quais teria sido impossível completar o trabalho: Paul R. Sweet e Lydia Garetano (AMNH), Helen James e Gary Graves (NMNH), Janet Hinshaw (UMMZ) e, claro, Luís Fábio Silveira e a equipe do MZUSP.

À Barbara e ao Gabriel pelos cafés da manhã, tarde, noite e madrugada.

Ao casal Erica e Chicão por me ensinarem que ciência pode ser coisa séria, mas cientista não precisa ser sério o tempo todo.

Aos veteranos Marina Somenzari e Marco Antônio Rego por terem sido os primeiros a me receber no Museu e permanecerem presentes ao longo de toda a minha formação, incluindo os surtos e desesperos e crises existenciais.

À Gláucia del Rio, pelas romarias e bom humor inextinguível.

Aos digníssimos Thiago Vernaschi e Vitor Piacentini pela irreverência e orientação simultâneas.

A todos os colegas, atuais e passados, do Laboratório de Ornitologia do MZUSP, pelo prazer de sua companhia e honra inenarrável de suas amizades. Aline Corrêa, Anna Ferraroni, Daniela Ingui, Deborah Oliveira, Erica Pacifico, Erika Machado, Fabio Schunck, Fernanda Alves, Fernanda Bocalini, Francisco Dénes, Glaucia del Rio, Luciano M. Lima, Marina Somenzari, Patrícia Lopes, Rafael Marcondes, Thiago Vernaschi, Thyago Santos, Vagner Cavarzere, Vinicius Tonetti e Vitor Piacentini. 
Ao amigo Guilherme Garbino pela introdução às alegrias da zoologia e pequenos mamíferos gondwanicos.

Aos amigos João Pedro, Maira e João Gabriel pelas infinitas risadas, pés na jaca e demonstrações de identidade na roda de paranauê.

Aos companheiros Rodrigo, João e Tiago pelos mundos impressionantes, histórias desconexas e madrugadas sem fim.

À Tatiene, por tudo.

Ao meu irmão Luis, por carregar o nome que eu dei com empenho moderado e honra indisputável (se não olhar muito de perto na luz forte).

À Magda, pela boa vontade e apoio inabaláveis; ao João, pelo bom humor e cerveja inacabáveis; ao Daniel, pelos rabiscos e causos incríveis; à Marcela, pelos conselhos e palavras infindáveis.

Aos meus avôs (que já se foram, mas permanecem) e às minhas avós (que provavelmente só se vão depois de mim).

Ao Maurício pela bossa e à Marcia pelo prumo. 


\section{Sumário}

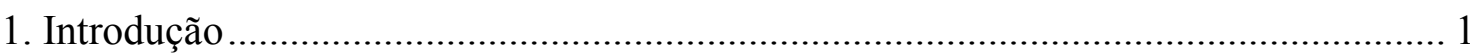

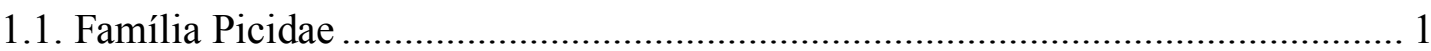

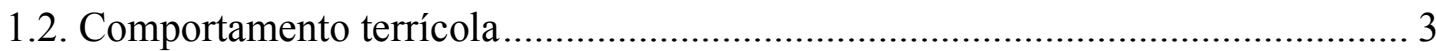

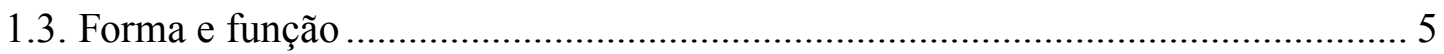

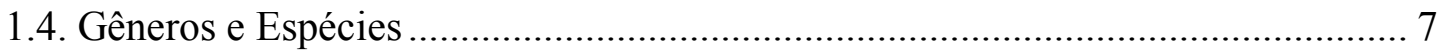

1.4.1. Gênero Colaptes Vigors, 1826 ................................................................. 7

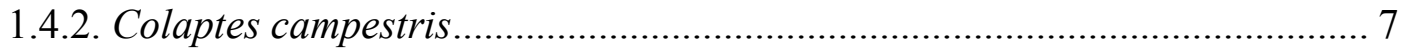

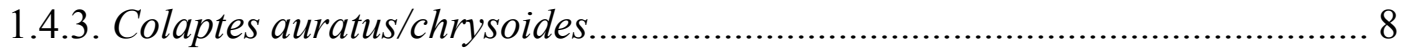

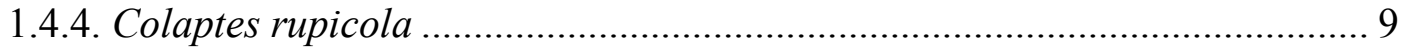

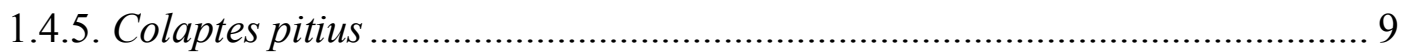

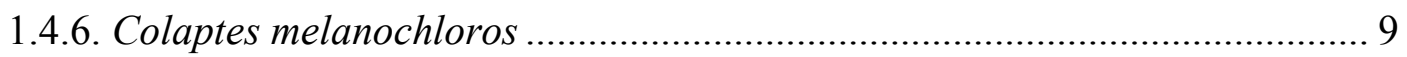

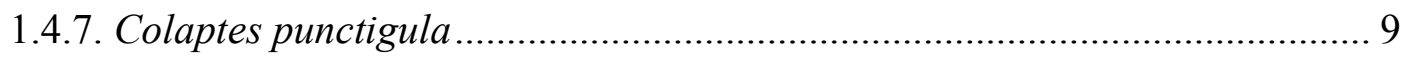

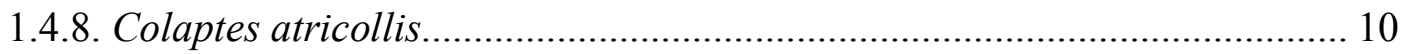

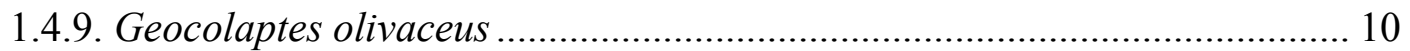

1.4.10. Dryocopus lineatus e Celeus flavescens/lugubris ................................... 10

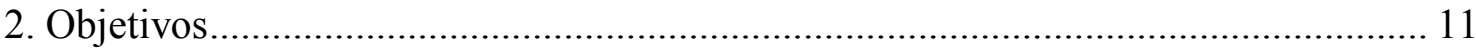

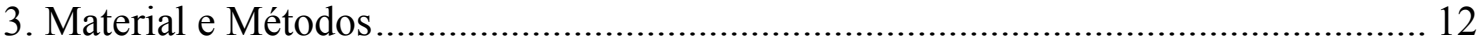

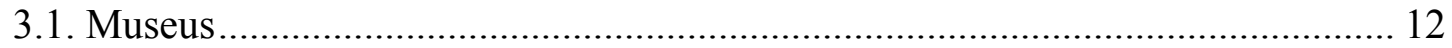

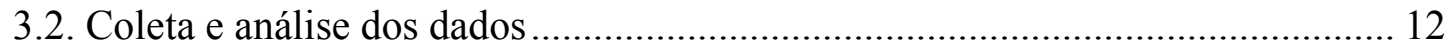

3.2.1. Definição dos táxons e informações de etiqueta ......................................... 12

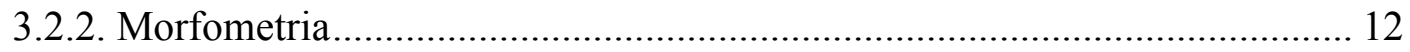

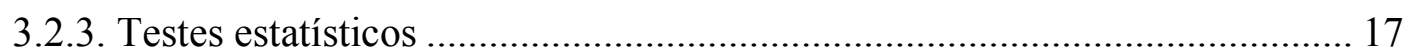

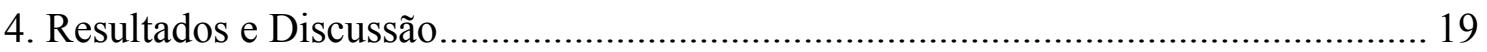

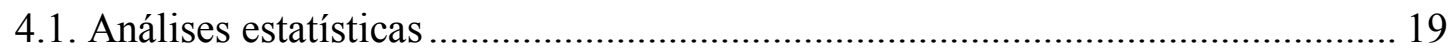

4.1.1. Fatores da análise de componente principal ............................................. 22

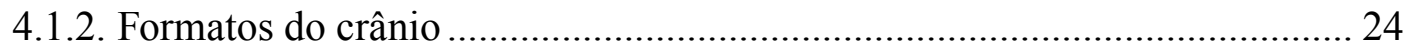




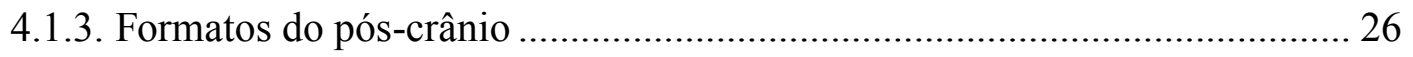

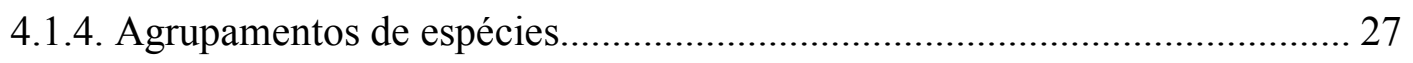

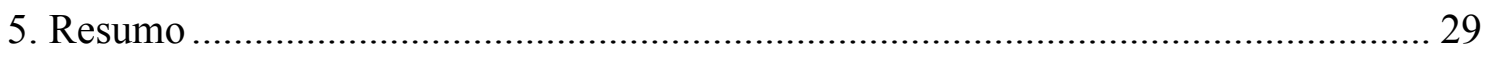

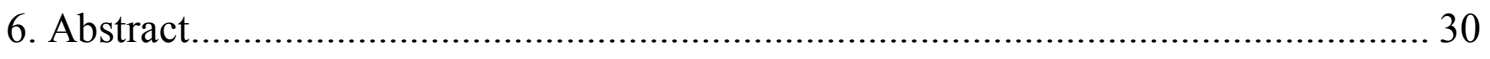

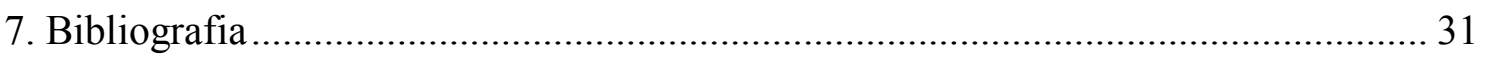

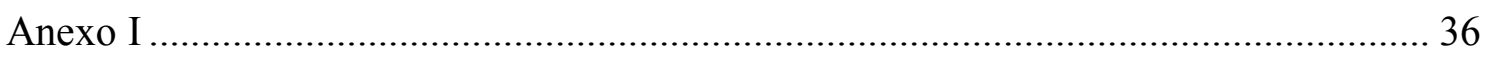

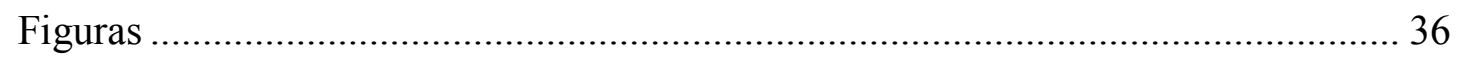

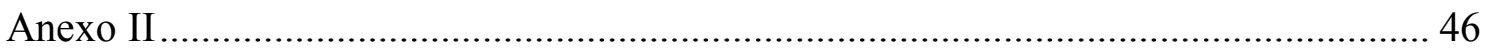

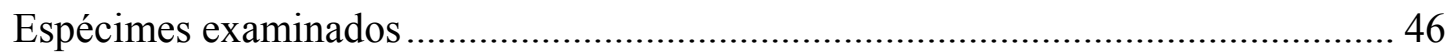

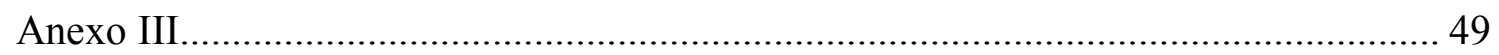

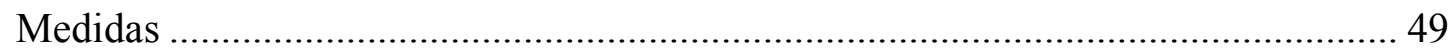

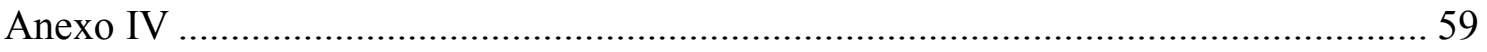

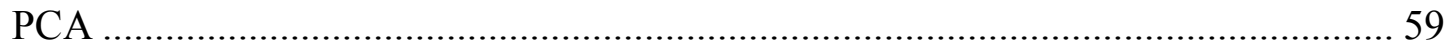




\section{Índice remissivo de figuras}

Figura 1: Distribuição das espécies dentro do gênero Colaptes. Retirado de Short, 1972. Espécies terrícolas (com exceção de C. auratus, na América do Norte) separadas no quadro esquerdo. 36

Figura 2: Distribuições aproximadas de Dryocopus lineatus (na esquerda, hachurado diagonal) e Celeus elegans e C. lugubris (na direita, hachurado diagonal e horizontal, respectivamente). Mapas elaborados a partir das informações de distribuição de espécies disponível em < http://www.natureserve.org/infonatura/>, acesso em 27 outubro 2013.

Figura 3: Filogenia proposta para a família Picidae com os gêneros e espécies utilizados nesse trabalho indicados por setas vermelhas. Números acima dos nós representam probabilidades posteriores, números abaixo dos nós denotam valores de bootstrap. Adaptado de Benz 2006. 38

Figura 4: Filogenia proposta para os gêneros Colaptes e Piculus, com os hábitos de cada espécie indicados ao lado dos terminais. Os valores de probabilidade estimada para os nós são indicados à direita de cada um, e a escala indica substituições por sítio. Adaptado de Moore et al. 2010 e Short 1971.

Figura 5: Referência de medidas utilizadas da pelve. Esquemas foram elaborados com base no exemplar MZUSP89449, C. campestris. 40

Figura 6: Referência de medidas utilizadas do crânio e ossos longos do pós-crânio. Esquemas foram elaborados com base no exemplar MZUSP89449, C. campestris. ..... 41

Figura 7: Autovalores dos fatores principais gerais extraídos. Fatores além do oitavo não foram utilizados em análises posteriores por apresentarem autovalores inferiores a 1, fatores além do décimo segundo não estão representados. 42

Figura 8: Gráfico de dispersão dos índices dos indivíduos para os fatores gerais 1 e 2. Formato dos símbolos identifica o hábito das espécies, quadrado para arborícola e círculo para terrícola.

Figura 9: Gráfico de dispersão dos índices dos indivíduos para os fatores gerais 2 e 3. Formato dos símbolos identifica o hábito das espécies, quadrado para arborícola e círculo para terrícola. 
Figura 10: Autovalores dos fatores principais do crânio extraídos. Fatores além do terceiro não foram utilizados em análises posteriores por apresentarem autovalores inferiores a 1, fatores além do décimo primeiro não estão representados. 43

Figura 11: Autovalores dos fatores principais do pós-crânio extraídos. Fatores além do terceiro não foram utilizados em análises posteriores por apresentarem autovalores inferiores a 1 , fatores além do décimo primeiro não estão representados.

Figura 12: Gráfico de dispersão dos índices para os fatores do pós-crânio 1 e 2. Formato dos símbolos identifica o hábito das espécies, quadrado para arborícola e círculo para terrícola. 44

Figura 13: Gráfico de dispersão dos índices dos indivíduos para os fatores do crânio 1 e 2. Formato dos símbolos identifica o hábito das espécies, quadrado para arborícola e círculo para terrícola. 45

Figura 14: Gráfico de dispersão dos índices dos indivíduos para os fatores do crânio 2 e 3. Formato dos símbolos identifica o hábito das espécies, quadrado para arborícola e círculo para terrícola 


\section{Introdução}

\subsection{Família Picidae}

A família Picidae, que compreende as aves popularmente conhecidas como pica-paus, faz parte da ordem Piciformes, que também inclui, dependendo do autor, as famílias Galbulidae, Bucconidae, Capitonidae, Ramphastidae e Indicatoridae (LIVEZEY \& ZUSI, 2007) ou apenas Capitonidae, Ramphastidae e Indicatoridae (WINKLER \& CHRISTIE, 2002). O primeiro agrupamento, no qual as características da ordem são um par de músculos bronqueo-traqueais na siringe, 14 vértebras cervicais, arranjo zigodáctilo dos pés e ausência do processo basipterigóide cranial (SHORT, 1982) é o utilizado nesse trabalho. A ordem é um grupo tradicionalmente aceito como monofilético (CRACRAFT, 1981; LIVEZEY \& ZUSI, 2007), com as controvérsias sobre a classificação dentro dela envolvendo a inclusão das famílias Bucconidae (joõesbobos, macurus e rapazinhos) e Galbulidae (aribambas) (WETMORE, 1960; CRACRAFT, 1981; SIMPSON \& CRACRAFT, 1981; SWIERCZEWSKI \& RAIKOW, 1981). A filogenia de Livezey \& Zusi (2007) inclui representantes de todas as ordens atuais e posiciona os Galbulidae e Bucconidae dentro da ordem.

Os pica-paus são aves com um alto grau de especialização e, portanto, facilmente identificáveis pelos seus hábitos e morfologia característicos. Seu comportamento, peculiar e quase único entre todas as aves, é o primeiro exemplo dado por Charles Darwin em seu livro "On the Origin of Species":

"[...] the woodpecker, with its feet, tail, beak and tongue so admirably adapted to catch insects under the bark of trees."

Essa especialização envolve três competências: a escalada de galhos e troncos; a escavação de ninhos e cavidades de abrigo em substratos arbóreos; e a obtenção da sua fonte de alimento por meio de uma língua altamente derivada, longa e dotada de diversos tipos de pontas modificadas. Essas três esferas comportamentais envolvem adaptações únicas dentro da ordem (tanto devido às pressões físicas envolvidas nas atividades quanto às oportunidades derivadas dessas adaptações), em todos os âmbitos dos organismos. 
A mobilidade dos pica-paus em seu habitat mostra seu impacto em vários de seus grupos musculares e ósseos, principalmente nos posteriores. Grande atenção foi dado ao longo da história do estudo dessas adatações ao pés, mais especificamente ainda ao hálux desses animais: Walter Bock cita em seu trabalho de 1959 (The Scansorial Foot of the Woodpeckers, with Comments on the Evolution of Perching and Climbing Feet in Birds, uma revisão póstuma dos manuscritos e idéias de Waldron DeWitt Miller) cinco trabalhos (um artigo e quatro livros) anteriores tratando do assunto, todos por sua vez chamando atenção para os outros inúmeros trabalhos anteriores a eles que também discutiam a fundo a função e o surgimento do arranjo zigodáctilo adaptável em Picidae, bem como as pressões adaptativas que agiram sobre esse arranjo inicial e que vieram a gerar a diversidade de aplicações desse arranjo na família atualmente (STRESEMANN, 1927; GRASSÉ, 1950; BEECHER, 1953; WALLACE, 1955; WING, 1956; BOCK \& MILLER, 1959).

O arranjo zigodáctilo, caracterizado pelos dedos I e IV voltados caudalmente e opostos aos dedos II e III voltados cranialmente, é uma adaptação que surge primeiramente como resposta ao hábito de empoleiramento, mas que passa também a permitir a escalada de superfícies verticais ao longo de algumas das linhagens de Picidae (BOCK \& MILLER, 1959; BOCK, 1999; SHORT, 1982). Esse arranjo é comum aos Piciformes, Psittaciformes, Cuculiformes e, em certa medida, Trogoniformes (que possuem um arranjo semelhante mas de mesma função: trogonídeos apresentam heterodactilia, condição na qual os dedos III e IV se voltam cranialmente e os dedos I e II caudalmente), com alguns exemplos de um arranjo semelhante, porém reversível, em Pandionidae, Musophagidae e corujas do gênero Strix. Com a exceção dos pica-paus e do gênero Micropsitta, a maioria absoluta (se não todas) as outras espécies que pertencem a esses grupos não são aves escansoriais, mas sim com hábito de empoleiramento (BOCK \& MILLER, 1959; BOCK, 1960; BOCK, 1999). Como exemplo, no caso de Micropsitta, as espécies do gênero têm hábito escansorial extremamente pronunciado, e dispõe para isso de pés com arranjo não zigodáctilo como o resto da ordem, mas sim um arranjo muito semelhante ao pamprodáctilo dos andorinhões onde os quatro dedos se voltam cranialmente, facilitando a escalada em superfícies verticais (BOCK \& MILLER, 1959; SPRING, 1965). 
Essa característica do arranjo zigodáctilo passa a ter uma importância óbvia na família dos pica-paus, onde a pressão é claramente voltada a favor de membros posteriores adaptados à escalada vertical. Adaptações nesse sentido são encontradas em várias formas diferentes na família, com várias classificações sendo propostas em função dessas adaptações. W. H. Burt separa a família toda em nove grupos de gêneros, fazendo uma gradação entre os "mais arborícolas" e os "mais terrícolas" (SPRING, 1965), ecoando a classificação semelhante usada por Garrod mais de um século antes com base na musculatura dos membros posteriores, associando a presença de determinados grupos musculares acessórios a determinados hábitos (GARROD, 1874)

Escalam galhos e troncos agilmente e utilizam seus bicos em forma de cinzel para golpear a madeira e abrirem espaços para inserirem suas longas línguas, dotadas de músculos especializados e uma secreção pegajosa onde capturam insetos que moram dentro dos troncos ou abrem espaços para nidificação (SHORT, 1982; SICK, 1997; WINKLER \& CHRISTIE, 2002). A articulação entre a maxila superior e o crânio é diferente do esperado, se curvando de um modo que faz com que, no momento do golpe na madeira, ela receba as forças como tensão, não compressão, permitindo assim que um músculo nesse local ajude a absorver e dissipar o impacto dos golpes em substratos rígidos (WINKLER \& CHRISTIE, 2002; SCHWAB, 2002). O hálux desses animais pode ser às vezes muito reduzido ou até ausente (como nos pica-paus-de-três-dedosamericano Picoides dorsalis). As penas da cauda geralmente apresentam raque rígida que ajuda no apoio do animal durante as escaladas e bicadas nos troncos, exceto em Picumninae, Nesoctitini e Jynginae (BOCK \& MILLER, 1959; SHORT, 1982; WINKLER \& CHRISTIE, 2002).

Os membros de Picidae apresentam distribuição mundial, com exceção da Antártida, áreas sem florestas do ártico, Madagascar, ilhas muito longe de áreas continentais e da Austrália (SHORT, 1982; WINKLER \& CHRISTIE, 2002). No Brasil existem 50 espécies de Picidae entre as subfamílias Picinae e Picuminae (CBRO, 2011).

\subsection{Comportamento terrícola}

O hábito arborícola da maioria dos pica-paus, apesar de ser o grande definidor e responsável pelo sucesso da família (WINKLER \& CHRISTIE, 2002), é diminuído ou até mesmo abandonado em algumas linhagens. A observação desse hábito é tão antiga 
quanto a descrição das espécies relacionadas, sendo inclusive o motivo do epíteto específico ou do nome do gênero de algumas delas: Colaptes campestris foi descrito como vivendo nos campos abertos da América do Sul, se alimentando de formigas e insetos no chão ao invés de golpear a madeira de árvores em busca de alimento (VIEILLOT, 1818). O gênero monotípico Geocolaptes, nomeado pelo naturalista britânico William John Burchell (SWAINSON \& RICHARDSON, 1832), vem do grego, geo- sendo a raiz relacionada a chão ou terra e colaptes derivado do verbo grego

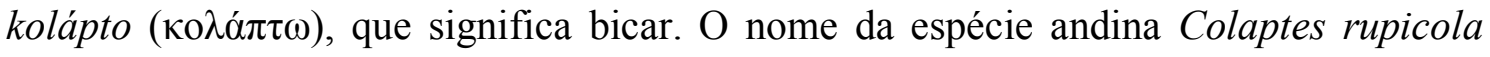
vem do latim para "habitante das rochas" (D'ORBIGNY, 1840). O abandono dos hábitos arborícolas chamou a atenção até mesmo de Charles Darwin em sua visita aos pampas, que comenta como, mesmo tendo quase todas as características dos pica-paus, C. campestris não escala nem faz ninhos em ocos de árvores, preferindo para isso barrancos às margens do rio da Prata (DARWIN, 1859).

O hábito terrícola acarreta adaptações que divergem daquelas relacionadas ao modo de vida comum dos pica-paus, como verificado em C. campestris e outras espécies de hábitos semelhantes. Nelas, ocorre derivação em diversos caracteres de adaptação à vida arborícola para adaptações mais apropriadas à vida terrícola, como redução do tamanho e densidade do crânio bem como a redução na musculatura associada ao tamborilar e ao hábito de constantes choques na madeira (SHORT, 1972; WINKLER \& CHRISTIE, 2002). Seu habitat também reflete essas mudanças, com indivíduos de C. campestris, por exemplo, preferindo campos abertos ou clareiras (SHORT, 1972; SHORT, 1982; WINKLER \& CHRISTIE, 2002).

As adaptações anatômicas relacionadas ao hábito terrícola serão o foco deste estudo, principalmente (mas não se resumindo a) as estruturas relacionadas à nidificação (bico), alimentação (crânio, maxilas e língua) e pouso e locomoção terrestre (pélvis e membros posteriores). Trabalhos anatômicos especificamente sobre pica-paus terrícolas são raros, sendo esses geralmente incluídos em estudos gerais (BOCK \& MILLER, 1959; BOCK, 1999). 


\subsection{Forma e função}

As características tratadas nesse trabalho (e, geralmente, nos outros trabalhos de morfologia) possuem atributos próprios distintos: forma e função.

Forma é facilmente definida em termos de aparência, configuração espacial, proporções e afins. A definição formal do termo utilizada nesse trabalho (BOCK \& WAHLERT, 1965) é a seguinte:

"Em qualquer sentença que descreva uma característica de um organismo, sua forma é a classe de predicados sobre composição física e a disposição, formato ou aparências desses materiais, contanto que esses predicados não façam referência ao ambiente normal do organismo."

Como o trabalho atual faz uso de ossos para determinar forma, evitam-se os problemas apontados por Boch e Wahlert com a utilização de estruturas moles (músculos ou aparelho digestivo, por exemplo), nominalmente o de variação do formato dessas estruturas pelo seu próprio funcionamento natural. O estudo de músculos, por exemplo, depende da comparação de grupos musculares não só no mesmo estágio de contração, mas também ao longo de seu contínuo de contração, que pode diferir entre os exemplares analisados. Nesses casos, forma se refere a atributos fluidos da característica em questão.

Adicionalmente, surge aqui uma dificuldade causada pelos falsos cognatos entre as línguas: forma, no português, geralmente faz referência às relações entre as medidas de um objeto independentes do tamanho desse objeto. O inglês form, tanto no uso comum quanto no específico desse tipo de trabalho, se refere às relações entre as medidas do objeto incluindo seu próprio tamanho. Sendo assim, quando um autor anglófono se utiliza desse termo, o significado é distinto do esperado para o termo semelhante em português mas simultaneamente mais próximo do utilizado nesse trabalho: tamanho como característica integral das diferenças observadas entre as linhagens (BOOKSTEIN, 1989).

Função é um termo mais difícil de ser definido objetivamente e sempre se corre o risco da articulação tender à teleologia. Do mesmo trabalho, a definição de função: 


\begin{abstract}
"Em qualquer sentença que descreva uma característica de um organismo, suas funções são a classe de predicados que incluem todas as propriedades físico-químicas decorrentes de sua forma, incluindo todas as propriedades decorrentes de níveis progressivos de organização, contanto que esses predicados não façam referência ao ambiente do organismo."
\end{abstract}

Os autores frisam no trabalho o cuidado que deve ser tomado na formulação de conclusões para se evitar qualquer aspecto determinista de propósito ou finalismo. Funções são consequências naturais da forma das estruturas mas não informam essas adaptações, sendo portanto independentes dos papéis que atribuímos a elas.

A comunicação dessa informação, entretanto, se encontra subjugada à nossa linguagem e seus vícios finalistas, mas espera-se que sejam auto evidentes as instâncias nesse texto onde a facilidade de redação soe finalista: a diversidade de formas discutidas e demonstradas aqui é sempre associada a hábitos terrícolas ou arborícolas, mas não os causam direta ou indiretamente nem são adaptações para eles. 


\subsection{Gêneros e Espécies}

\subsubsection{Gênero Colaptes Vigors, 1826}

O gênero Colaptes Vigors, 1826 apresenta distribuição ampla pela América, desde o Alaska até a Argentina (Figura 1). Os indivíduos do gênero se assemelham aos de Piculus Spix, 1824, mas são inteiramente listrados no dorso e de hábito parcial ou totalmente terrícola. Suas características morfológicas são bico estreito no cume, principalmente entre as narinas, cume geralmente curvado em toda a sua extensão, ponta do bico em formato de cinzel, ossos craniais finos, projeções ósseas (para inserção muscular) no crânio muito menos desenvolvidas comparadas com as de espécies arborícolas como alguns representantes dos gêneros Piculus e Picus; parte de baixo das asas amarela ou avermelhada, junto com as hastes das penas das asas e ocasionalmente da cauda, cauda parcial ou completamente listrada em barras, sexos diferenciados pela cor malar, mas apresentando diferenças sexuais reduzidas em espécies terrícolas como C. campestris e C. rupicola (SHORT, 1972).

Mesmo dentro do gênero Colaptes as espécies podem ser agrupadas de acordo com as adaptações e derivações relacionadas ao modo de vida das espécies em questão. Espécies de hábitos terrícolas como $C$. campestris, $C$. pitius e $C$. rupicola apresentam diferenças anatômicas e osteológicas com relação às espécies arborícolas do gênero Colaptes, como tubérculos bem desenvolvidos na ulna, o processo manubrial do esterno distintamente furcado e os bicos mais largos e achatados (SHORT, 1972).

Dentro do gênero, é perceptível uma gradação na mudança do hábito arborícola para o terrícola, que vai desde o total ou predominantemente terrícola $(C$. campestris e $C$. rupicola, por exemplo) até o predominantemente arborícola (C. melanochloros) com representantes intermediários ao longo da variação morfológica e comportamental.

\subsubsection{Colaptes campestris}

Pica-pau de porte médio, barrado em marrom e creme no corpo todo, predominantemente marrom no dorso e creme no ventre. Possui o peito e as laterais da cabeça amarelo-dourados, com a coroa e nuca negras. A garganta pode ser negra (subespécie C. c. campestris, Norte da distribuição) ou branca (C. c. campestroides, Sul da distribuição), com intermediários ao longo da distribuição (CORY, 1919; SHORT, 
1982; WINKLER \& CHRISTIE, 2002). Ocorre em todo o leste da América do Sul, do Nordeste brasileiro até a Patagônia (Figura 1).

Espécie de hábitos quase exclusivamente terrícolas, o pica-pau-do-campo alimenta-se principalmente de formigas (como a maioria das espécies do gênero), passa a maior parte do tempo no chão buscando seu alimento e não nidifica em árvores, preferindo para tal ribanceiras e barrancos, ou as vezes postes de cercas quando ocorre próximo a ocupações humanas (SHORT, 1972; SHORT, 1982; ANTAS \& CAVALCANTI, 1988; WINKLER \& CHRISTIE, 2002; TUBELIS, 2007).

Quando no chão, pulam e saltam quando atravessam terrenos difíceis ou quando sobem em formigueiros, mas andam livremente quando o terreno permite. Forrageiam em grupo, ocasionalmente em companhia do pica-pau-verde-barrado (Colaptes melanochloros) (SHORT, 1969; SHORT, 1982).

\subsubsection{Colaptes auratus/chrysoides}

A espécie mais estudada de Colaptes, $C$. auratus é um pica-pau de porte médio, com garganta e coroa contrastantes, de tom cinza ou rosado (cuja intensidade varia de acordo com a subespécie), peitos negros em forma de lua crescente, barrados no dorso e com pintas negras no ventre de cor creme. Face ventral das asas e cauda de tom variável entre amarelo e róseo (novamente dependendo da subespécie). Ocorre em toda a América do Norte e Norte da América Central (Figura 1).

Forrageia no solo e em árvores, com qual frequência dependendo da subespécie. Alimenta-se principalmente de formigas, mas complementa sua dieta com cupins, larvas e adultos de coleópteros, frutos e insetos em enxames. Saltam quando se locomovem no chão e nidificam escavando ocos em árvores mortas ou podres, postes telefônicos e de cercas ou, muito raramente, em barrancos (CHAPMAN, 1892; SHORT, 1971).

A linhagem utilizada nesse trabalho, C. chrysoides, é tradicionalmente tratada como uma subespécie de C. auratus, com distribuição ao longo do limite sul da espécie nominal, e diferenças mínimas externas (o tom da face ventral das asas e cauda é dourado). Nidifica em saguaros (Carnegiea gigantea), uma espécie de cactos abundante nos ambientes áridos de sua distribuição, utilizando a seu favor a resposta dos cactos de revestir qualquer intrusão em seu tronco com uma grossa secreção impermeável 
semelhante a piche para estabelecer seus ninhos (SHORT, 1982; WINKLER \& CHRISTIE, 2002).

\subsubsection{Colaptes rupicola}

Espécie andina (Figura 1) de porte médio-grande, único picídeo em seu habitat (SHORT, 1972; SHORT, 1982). Completamente terrícola, de coloração cremeamarelada, possuindo barramento escuro no dorso e ventre liso, com coroa acinzentada. Habita áreas rochosas desprovidas de árvores, apresentando o hábito de voar e se refugiar em rochas mais altas quando assustado ou ameaçado (SHORT, 1972; SHORT, 1982; WINKLER \& CHRISTIE, 2002).

Nidifica em cavidades formadas pelas rochas de seu habitat ou em barrancos de terra (WINKLER \& CHRISTIE, 2002).

\subsubsection{Colaptes pitius}

Porte médio, coloração creme com barramento em negro ou marrom escuro, espessa no dorso e mais fina no ventre. Único pica-pau com tendências terrícolas em seu habitat, se alimentando principalmente no solo, voando para árvores quando assustado ou em perigo. Ocorre no Sul da América do Sul, nas florestas da terra do fogo. Nidifica em árvores mortas (SHORT, 1982). Nidifica em árvores mortas ou barrancos de terra (WINKLER \& CHRISTIE, 2002).

\subsubsection{Colaptes melanochloros}

Porte médio, coloração esverdeada com barramento negro no dorso e coloração creme com padrão de manchas arredondadas no pescoço e ventre, com testa negra e nuca vermelha. Alimenta-se quase que exclusivamente de formigas e cupins arborícolas e suas larvas, com registros de frutos ocasionais. Ocorre em matas do leste da América do Sul, do Uruguai até o Nordeste brasileiro. Nidifica em árvores mortas, postes, palmeiras ou cactos (WINKLER \& CHRISTIE, 2002).

\subsubsection{Colaptes punctigula}

Semelhante a C. melancholoros, mas de menor porte (é o menor pica-pau dos estudados neste trabalho) e coloração amarelada no dorso e ventre, e tons róseos no pescoço, com o padrão peitoral de manchas semelhantes a gotas muito característico. Ocorre na 
Amazônia, se alimenta de formigas arborícolas e suas larvas e nidifica em árvores vivas ou mortas (WINKLER \& CHRISTIE, 2002).

\subsubsection{Colaptes atricollis}

Semelhante a $C$. melanochloros, mas com padrão de barramento no ventre e pescoço negro. Espécie peruana, apresenta distribuição limitada à face oeste dos Andes, com hábito praticamente exclusivo arborícola mas com registros de forrageamento no solo ou próximo de arbustos. Alimenta-se de formigas e suas larvas, nidifica em árvores ou postes (WINKLER \& CHRISTIE, 2002).

\subsubsection{Geocolaptes olivaceus}

Espécie africana exclusivamente terrícola, alimentação especializada em formigas e suas larvas, mas também consome cupins e besouros. Ocorre no sul da África do Sul. Dorso cinzento e ventre creme com marcações setadas avermelhadas. Nidifica em barrancos ou beiras de estradas e pedrais, geralmente cavando um túnel (WINKLER \& CHRISTIE, 2002).

\subsubsection{Dryocopus lineatus e Celeus flavescens/lugubris}

Espécies exclusivamente arborícolas, alimentação especializada em larvas de besouros. Escolhidas por apresentarem todas as características tradicionais da família, tanto morfológicas (formatos do bico e narinas, etc.) quanto comportamentais (nidificação exclusiva em ocos de árvores, tamborilar como demarcação de território/comunicação, escalada de caules).

Apresentam distribuição ampla na América do Sul, que no caso de D. lineatus se estende até o litoral mexicano (Figura 2). 


\section{Objetivos}

O hábito terrícola em pica-paus é extremamente interessante como objeto de estudo. Não só o hábito em si, mas também as pressões evolutivas que levaram ao seu surgimento independente em mais de uma linhagem, bem como (pelo menos neste trabalho) às adaptações ósseas decorrentes dessas pressões.

O trabalho de filogenia molecular mais recente do gênero conclui que espécies de Colaptes que apresentam hábito terrícola pronunciado não formam uma linhagem única (MOORE, et al., 2010), sendo na maior parte dos casos mais próximas a espécies arborícolas ou formando um grupo monofilético cujo grupo irmão é uma espécie arborícola (Figura 3, Figura 4), além das espécies basais C. auratus e C. fernandinae apresentarem hábitos parcialmente terrícolas.

Dado que o resultado externo final é semelhante (grupos especializados em vida arborícola apresentam representantes exclusivamente terrícolas independentemente), qual o grau de semelhança entre essas adaptações? A mudança de meio de vida desses animais é possível apenas pelo mesmo conjunto de alterações ósseas? Se sim, quais as características comuns dos ambientes dessas espécies configuram essas pressões tão consistentemente? Se não, quais vias convergentes são exploradas pela plasticidade das linhagens?

Esse estudo deverá analisar a morfologia de linhagens terrícolas de pica-paus e compará-las, a fim de melhor entender os processos adaptativos que resultam nessas soluções, além de complementar os estudos, até recentemente exclusivamente moleculares, realizados com o gênero. 


\section{Material e Métodos}

\subsection{Museus}

O trabalho foi realizado com base em 49 espécimes osteológicos depositados nas seguintes instituições: American Museum of Natural History (AMNH), Nova Iorque, EUA; Smithsonian Institution National Museum of Natural History (NMNH), Washington, EUA; University of Michigan Museum of Zoology (UMMZ), Ann Harbor, EUA e Museu de Zoologia da Universidade de São Paulo (MZUSP), São Paulo, Brasil. Todos os exemplares depositados em museus no exterior foram examinados no American Museum of Natural History por empréstimo das outras instituições americanas.

\subsection{Coleta e análise dos dados}

\subsubsection{Definição dos táxons e informações de etiqueta}

A classificação taxonômica, dados de localidade e sexo de cada exemplar seguiram a identificação e dados prévios que constam em suas respectivas etiquetas. Isso se faz necessário visto a natureza dos exemplares, unida ao fato de nenhum deles fazer parte de um conjunto de aproveitamento total de espécimes (pele shmoo e esqueleto do mesmo indivíduo). Os hábitos das espécies foram baseados em todos os relatos encontrados na literatura, principalmente em Short 1972 e Short 1982 para o gênero Colaptes e Winkler \& Christie para as outras espécies.

A idade dos exemplares também segue as informações das etiquetas, mas pôde ser facilmente corroborada mediante o estudo das propriedades e características dos esqueletos, principalmente crânios.

Não foram antecipados problemas com essa metodologia pela ausência de conflitos de classificação entre os táxons no nível de espécie, já que táxons que apresentam simpatria são claramente distintos em hábito, e táxons com hábitos semelhantes são alopátricos (Figura 1).

\subsubsection{Morfometria}

As medições foram obtidas por meio de um paquímetro digital Mahr $16 \mathrm{EX}(0,01 \mathrm{~mm}$ de precisão) com interface USB e captura automática de valores. As medidas foram todas 
fundamentadas em pontos bem definidos de cada osso (todos são ápices de processos, extremos de ossos ou encontros bem delineados de outras estruturas) e homólogos entre todos os táxons estudados. Medidas que por qualquer motivo foram impossíveis em algum dos exemplares (geralmente por algum dano físico à peça ou problema na conservação do material) foram removidas da análise daquele caractere, mas não da análise de PCA. As soluções para dados faltantes e substituições de medições são discutidos a fundo na seção de PCA.

As imagens de referência (Figura 5, Figura 6) exibem em detalhe os pontos utilizados nas medições discriminadas a seguir (em estruturas pares, se assume que foram tomadas medidas do elemento esquerdo a não ser que seja especificada a alternativa). Toda a nomenclatura de estruturas segue Baumel, 1993.

Dcriscran: distância entre as extremidades craniais dorsais da Crista iliaca dorsalis.

Dcriscl: distância entre a extremidade cranial dorsal da Crista iliaca dorsalis e a extremidade dorsal do Processus spinosus da Extremitas cranialis synsacri.

Dcrislas: distância entre a extremidade cranial dorsal da Crista iliaca dorsalis e a extremidade distal do Antitrochanter.

Dcrislai: distância entre a extremidade cranial dorsal da Crista iliaca dorsalis e o Tuberculum preacetabulare.

Darts: distância entre extremidades distais de ambos Antitrochanter.

Darti: distância entre ambos Tuberculum preacetabulare.

Dproca: distância entre a extremidade distal do Antitrochanter e o Tuberculum preacetabulare.

Dpcaud: distância entre ambas extremidades caudais da Spina dorsolateralis ilii.

Dpcauas: distância entre a extremidade distal do Antitrochanter e a extremidade caudal da Spina dorsolateralis ilii.

Dpcauai: distância entre a extremidade caudal da Spina dorsolateralis ilii e o Tuberculum preacetabulare.

Dpvcaud: distância entre ambas as extremidades caudais do Processus terminalis ischii. 
Dpvcpc: distância entre a extremidade caudal da Spina dorsolateralis ilii e extremidade caudal do Processus terminalis ischii.

Dpvcai: distância entre a extremidade caudal do Processus terminalis ischii e o Tuberculum preacetabulare.

Mdcris: menor distância entre ambas Crista iliaca dorsalis.

Aecran: distância entre o Processus spinosus e o Processus ventralis da Extremitas cranialis synsacri.

Devcris: distância entre a extremidade cranial dorsal da Crista iliaca dorsalis e o Processus ventralis da Extremitas cranialis synsacri.

Cpelv: comprimento da pelve, definido aqui como a distância entre a Extremitas cranialis synsacri e a Extremitas caudalis synsacri.

Dinta: distância entre os processos internos de ambas Crista iliaca obliqua.

Eart: distância entre o processo interno da Crista iliaca obliqua e o Tuberculum preacetabulare.

Daintpc: distância entre o processo interno da Crista iliaca obliqua e a extremidade caudal do Processus terminalis ischii.

Diama: diâmetro do forame do acetábulo.

Acran: altura do crânio.

Lcran: largura do crânio.

Pcran: profundidade do crânio, definida aqui como a distância entre a articulação craniofacial da maxila superior e a Prominentia cerebellaris.

Amaxs: altura da maxila superior, definida aqui como a menor distância entre a articulação craniofacial da maxila superior e a face ventral da maxila superior.

Lmaxs: largura da maxila superior, definida aqui como a distância entre ambas articulações dos arcos jugais com os premaxilares. 
Cmaxs: comprimento da maxila superior, definida aqui como a distância entre a articulação do arco jugal com o premaxilar e o Rostrum maxillae.

Dcondp: distância entre o côndilo occipital e a Tuba auditiva comunis.

Dppteri: distância entre a Tuba auditiva comunis e o encontro dos ossos pterigóides.

Cjug: comprimento do arco jugal.

Dintn: menor distância entre as bordas internas das narinas.

Lnar: largura da narina, definida aqui como a menor distância interna entre suas bordas.

Cnar: comprimento da narina, definido aqui como a maior distância interna entre suas bordas.

Dapm: distância entre a extremidade caudal da mandíbula e o Angulus mandibulae.

Dpmed: distância entre o Angulus mandibulae e a extremidade rostral da mandíbula.

Cmaxi: comprimento da mandíbula, definido aqui como a distância entre as extremidades caudal e rostral da mandíbula.

Lamaxi: distância entre o Processus mandibulae medialis e a borda externa da articulação da mandíbula.

Aqui: altura da quilha, definida aqui como a distância entre o Apex carinae e a Spina interna rostri.

Cqui: comprimento da quilha, definida aqui como a distância entre a Spina interna rostri e a extremidade caudal da quilha.

Lproxum: distância entre o Tuberculum dorsale e a borda externa da Crista bicipitales, no ponto de encontro com o Sulcus transversus.

Acris: altura da Crista deltopectoralis, definida aqui como a distância entre o Tuberculum dorsale e a região de encontro da crista com o Corpus humeri.

Ddiag: distância entre a borda externa da Crista bicipitales e a região de encontro da Crista deltopectoralis com o Corpus humeri.

Eum: diâmetro medial do Corpus humeri. 
Cum: comprimento do úmero.

Lace: largura do acetábulo, definida aqui como a distância entre a Facies articularis acetabularis e a Crista trochanteris.

Aace: altura do acetábulo.

Ltroc: largura da tróclea femoral.

Cfem: comprimento do fêmur.

Lptbt: largura proximal do tibiotarso, incluindo a fíbula.

Etbt: diâmetro medial do tibiotarso.

Ctbt: comprimento do tibiotarso.

Culn: comprimento da ulna.

Crad: comprimento do rádio.

Ccora: comprimento do coracóide.

Apig: altura da Lamina pygostyli, definida aqui como a menor distância entre o processo dorsal do pigóstilo e a face ventral do Basis pygostyli.

Cpig: comprimento da Lamina pygostyli.

Lpig: largura do Basis pygostyli.

Lproc: largura do Processus transversus presentes lateralmente na Lamina pygostyli.

Cproc: distância entre as extremidades externa de ambos Processus transversus. 


\subsubsection{Testes estatísticos}

Com o objetivo de descrever a variação morfológica dos táxons, bem como ajudar a visualizá-la, foram utilizados diversos métodos estatísticos, todos com nível de significância $(\alpha)$ de $5 \%(\mathrm{p}=0,05)$ quando aplicável. Todas as análises foram realizadas no pacote de software estatístico IBM SPSS Statistics versão 21 (IBM corp. 2012).

Com todos os dados em mãos foram aplicados em primeiro lugar, para cada medida agrupada por espécie, o teste de Shapiro-Wilk com hipótese-nula de distribuição não-normal das medidas, onde resultados inferiores a 0,05 indicariam agrupamentos ou outros comportamentos não esperados de uma distribuição normal de valores e, portanto, uma distribuição não-normal. Casos onde esse teste retornou resultados de distribuição não-normal ou limítrofes são extremamente interessantes como demonstração da influência do tamanho amostral em testes de distribuição normal e são discutidos a fundo na seção mais apropriada à frente.

Para este estudo, a análise e descrição da morfometria dos exemplares esbarram no problema de diferenciação entre crescimento alométrico e isométrico. Diferenças de caracteres individuais entre os táxons podem representar efetivas mudanças nas relações corporais que levam a formas e funções distintas ligadas ao hábito dos animais, que representam o foco do trabalho, ou refletirem apenas diferenças de tamanho entre os indivíduos, o que passa a apresentar uma situação mais complexa.

Tamanho corporal, a priori, não é descartado como não informativo. Meu interesse, ao invés, passa a ser como o tamanho corporal participa da estruturação da forma dos animais. Principalmente em Picidae, onde tamanho corporal é mencionado várias vezes como componente de diversidades morfológica e de exploração de recursos, a interação de tamanho como componente dos outros eixos de variação de forma corporal seria o interessante. Faz-se necessário, portanto, um modo de retirar a influência do tamanho corporal da informação do resto da variação morfológica que ao mesmo tempo permita quer essa variação seja posteriormente comparada com o tamanho corporal para que elas se complementem.

A análise de componente principal (PCA, sigla em inglês para Principal Component Analysis) faz exatamente isso. A PCA é um método de análise de multi-variáveis que usa transformações ortogonais (rotações no plano de referência do conjunto de dados 
que mantém as relações internas do conjunto) da matriz de informação para traçar relações lineares que expliquem a maior variância possível nos dados. O atrativo da técnica é a simplificação do número de medidas utilizadas nessa análise morfométrica. Quando se trata da comparação de quase 60 medidas, a variação morfológica bruta se traduz numa matriz 60-dimensional, tornando a análise direta de suas correlações humanamente infactível.

Com a tradução destes 60 caracteres em alguns poucos fatores que respondem (no caso do conjunto de dados desse trabalho) por quase $90 \%$ da variância nos dados, a PCA possibilita uma comparação e demonstração muito mais simples da variedade de formas que estão sendo representadas. Visto que a variação de tamanho da amostra é considerável (envolvendo desde espécies de $20 \mathrm{~cm}$ de comprimento total como $C$. punctigula até espécies de quase $50 \mathrm{~cm}$ como as do gênero Dryocopus), é de se esperar que o primeiro fator, que tem maior peso de variação, possa ser tratado como indicador substituto do tamanho corporal dos espécimes e possua uma forte associação positiva com a maioria das medições. Não só isso, como as transformações do espaço amostral são ortogonais e os fatores são necessariamente ortogonais entre si em todas as dimensões da análise, todos os fatores subsequentes apresentam variação independente desse primeiro eixo, gerando eixos de diversidade morfológica não afetados pelo tamanho corporal. 


\section{Resultados e Discussão}

\subsection{Análises estatísticas}

A análise de normalidade de distribuição dos dados não auxilia em nada a posterior PCA, mas confirma uma das características das medidas morfométricas utilizadas: mesmo sendo variáveis de caráter contínuo dentro de um táxon particular, as pressões de manutenção de função em cada uma delas engendram necessariamente uma limitação na distribuição nos valores. Dado que a função de cada osso e músculo depende de outras incontáveis configurações normalmente, e que essas limitações são ainda mais agudas quando as funções envolvidas são altamente especializadas (voo em aves no geral ou o hábito de escalar e bicar dos pica-paus especificamente), é de se esperar que a seleção envolvida nesse caso seja extremamente estabilizadora. Tão estabilizadora, de fato, que as variâncias de cada medida para os táxons individuais vão ser baixas o suficiente para tornar qualquer teste visual (como Shapiro-Wilk ou, para amostragens consideravelmente maiores do que o factível para esse tipo de trabalho, Kolmogorov-Smirnov) redundante.

Complicando esse tipo de análise, existe ainda a questão do tamanho de amostragem das medições. São dois os fatos inescapáveis da aplicação de métodos estatísticos a problemas empíricos: primeiro, que o modelo que descreve a coisa não é a coisa em si (o conflito entre o númeno abstrato e o fenômeno concreto inevitável em qualquer exercício cientifico) e, segundo, que amostragens raramente tem as dimensões ideais. $\mathrm{O}$ tamanho pequeno da amostragem dos táxons tem várias causas, entre elas a simples inexistência de exemplares disponíveis para estudo. Essa tem, por sua vez, raízes na tradição de priorizar o depósito de peles em detrimento do de esqueletos completos ou preparações úmidas (WOOD \& SCHNELL, 1986; LIVEZEY, 2003; OLSON, 2003). Mesmo com a crescente importância de trabalhos osteológicos para diversas áreas da ornitologia, mantem-se a dificuldade de equiparar a diversidade de táxons depositados em preparações relevantes a esse tipo de trabalho. Com uma amostra pequena o suficiente, testes dessa natureza (principalmente Shapiro-Wilk nesse trabalho, mas geralmente verdadeiro para outros de mesma função) são extremamente sensíveis a erros de falso positivo sem a contrapartida de serem muito informativos nos casos de aceitação da hipótese nula de distribuição normal dos valores (SHAPIRO \& WILK, 1965; SHAPIRO, et al., 1968; RAZALI \& WAH, 2011). 
Dado que PCA é um método geométrico, distribuição normal dos valores é preferível mas não indispensável (como seria no caso da utilização do método para fins de modelagem estatística ou regressão). Mesmo com esse caveat, a maioria das medições apresenta distribuições normais para cada táxon, com menos de 7\% dos 418 casos válidos (cada caso sendo definido como a propriedade de distribuição de uma medida para cada táxon estudado. Foram excluídos da análise casos como o de Colaptes atricollis, com um único exemplar, ou Colaptes rupícola, com três exemplares mas com problemas na mesma medida em dois desses exemplares, por exemplo) apresentando distribuição não-normal. Se aplicada a correção Holm-Bonferroni (HOLM, 1979) para realização repetida de testes, menos de 1\% dos casos apresenta distribuição não-normal. É possível prosseguir com razoável convicção de que os valores apresentam distribuição normal para a aplicação da PCA (JOLICOEUR \& MOSIMANN, 1960; MONTEIRO, 2013).

Os valores das medições não podem ser utilizados diretamente numa análise como PCA, precisando antes ser convertidas para logaritmos para eliminar conflitos decorrentes do crescimento alométrico dos animais. Todas as análises desse ponto em diante foram feitas com base nesses dados devidamente transformados.

A análise de componente principal pode ser realizada a partir da regressão de duas matrizes: a de covariância ou a de correlação de variáveis. O uso de uma em detrimento da outra não é necessariamente certo ou errado, dependendo da interpretação realizada posteriormente e o tipo de conjunto de dados disponíveis. No caso específico dessa análise, foi utilizada a matriz de correlação pela sua propriedade de padronização dos dados em contraste à propriedade de maximização de variância da matriz de covariância. Como o interesse primário dessa análise era a determinação das medidas que melhor correspondem à variação de tamanho corporal, a utilização da matriz de correlação é mais interessante por eliminar o máximo possível a atribuição indevida de peso às medições com alta variância. A padronização da variância e a utilização da tabela de correlação faz com que o primeiro fator busque a maior concordância de variação entre as variáveis sem dar importância indevida às que tem maiores variâncias, correspondendo o máximo possível com tamanho corporal e eliminando o menos possível a informação de formato dos ossos (MONTEIRO, 2013). 
Nos casos de medidas faltantes nos exemplares (geralmente resultado de esqueletos danificados pelo tempo), foram estimadas as medições faltantes como a média das medições disponíveis de todos os outros indivíduos da espécies (como na maioria dos casos de dados faltantes em C. campestris, por exemplo) ou, especificamente no caso de medidas faltantes em C. atricollis, a substituição pela média das medidas disponíveis de todos os indivíduos do gênero. 


\subsubsection{Fatores da análise de componente principal}

Os oito fatores de interesse extraídos (Tabela 9) foram escolhidos primeiramente em função de seus autovalores (Figura 7) superiores a 1 e depois por análise das variáveis com maior correlação com cada autovetor (Tabela 10). As variáveis com maior correlação para cada fator são as variáveis com a maior variância nessa dimensão, e representam, portanto, a maior variância de formas nesse eixo. Sendo assim, o PCA passa a ser um ótimo indicador tanto da diversidade morfológica dos caracteres analisado quanto dos eixos e associações dessa diversidade para cada exemplar medido (Tabela 11).

O fator 1 apresenta correlação positiva e alta com quase todas as variáveis, confirmando a hipótese do primeiro fator poder responder pelo tamanho corporal dos exemplares. Não só isso, a relação das medidas com o primeiro fator é o primeiro indicador da mudança da relação entre as medidas conforme o tamanho corporal varia, apesar de não ser um indicador direto. Esse é o princípio das diferenças entre as formas e funções dos esqueletos estudados, mas talvez não o mais importante. O que é importante do primeiro fator para o resto da análise é a característica compartilhada entre todos os fatores extraídos: a ortogonalidade que eles apresentam entre si mesmos faz com que suas influências nas medidas sejam progressivamente eliminadas (obviamente não sem deixar resquícios e ruídos, mas eliminando o suficiente para possibilitar essa análise). Eliminada (ou grandemente reduzida) a influência do tamanho corporal, os fatores subsequentes contém apenas a indicação de variação das medidas independentemente de tamanho corporal.

Os fatores seguintes dão indícios, em seus índices, de medidas que configuram eixos de maior diversidade e, por consequência, de formas. A natureza do trabalho faz com que os eixos não discriminem características ou razões únicas, mas sim conjuntos de medidas que respondem por variações progressivamente reduzidas do conjunto de dados e que reagem em conjunto com a variação de forma corporal. $\mathrm{O}$ fator 2 , como exemplo, mostra tanto valores referentes a narina quanto a maxila inferior e o pigóstilo.

Mesmo nos casos onde a PCA não aponta variação suficiente para a criação de um eixo adicional essas relações podem ser exploradas se forem utilizados subseções dos dados. Repetir o processo do mesmo modo, mas separando as variáveis em crânio, pelve e 
membros/restante do pós-crânio resulta nas mesmas relações da super-análise mas com maior definição posterior no resultado. Os fatores resultantes dessas análises parciais estão, portanto, contidos nos da super-análise mas sem a vantagem de uma visualização simples.

Removida a influência do primeiro fator, os seguintes podem ser compreendidos como definidores de formato. $\mathrm{O}$ segundo e terceiro fatores gerais apresentam informações sobre as três classes de medidas tomadas (crânio, pelve e restante do pós-crânio) discutidas a seguir, mas apenas o primeiro e o segundo apresentam valores que separam exemplares por hábito de modo estatisticamente significante.

Reiterando que o PCA aponta, no conjunto de dados, os eixos de maior variância das variáveis e lembrando que as espécies analisadas compreendem extremos morfológicos dentro da família, não é surpreendente que análise geral não separe por hábitos diretamente. A diversidade de formas entre os gêneros provavelmente supera a diversidade de formas entre os hábitos, mas o que é interessante é o segundo fator isolar características que, apesar de relativas a aparelhos distintos, agrupa esses exemplares de acordo com seu hábito apesar de sua classificação em gêneros distintos (Figura 8). O segundo fator parece indicar um eixo de variação que diz respeito ao tamanho e posicionamento das narinas, comprimento do jugal e tamanho do pigóstilo e seus processos de inserção das rectrizes. O terceiro contém informação sobre tamanho da quilha, formato da face occipital do crânio (e potencialmente da posição do forame magno) e espessura de alguns dos ossos longos do pós-crânio. 


\subsubsection{Formatos do crânio}

Os eixos de variação da análise geral e da análise isolada do crânio concordam em vários fatores, principalmente no referente ao tamanho e posição das narinas e formato do bico. Ambas concordam fortemente com a associação das medidas de posicionamento e tamanho das narinas (estão entre as cinco correlações maiores em ambas) e a análise isolada do crânio coloca entre os maiores valores associados as medidas de largura e altura da maxila superior, que têm valores relativamente altos na análise geral mas não chegam aos mais altos.

Os valores, quando plotados num gráfico de dispersão (Figura 8, Figura 9, Figura 13 e Figura 14), mostram o comportamento desses eixos de variação com mais clareza. Conforme o hábito das linhagens tende à terrestrialidade, as maxilas superiores vão ficando mais estreitas e baixas, com lmaxs e amaxs apresentando correlação positiva com o segundo fator da análise de crânio que coloca os exemplares arborícolas em sua porção superior, as narinas ficam maiores e mais próximas, com cnar, lnar e dintn apresentando forte correlação com os segundos fatores tanto da análise geral quanto da isolada do crânio, mas com sinais invertidos. Não é um efeito incomum de PCAs consecutivas apresentarem fatores semelhantes com sentido inverso, significa apenas que a rotação da matriz de dados se deu em sentidos opostos nas análises sem prejudicar a simetria dos dados resultantes. A simples observação dos gráficos de dispersão é suficiente para estabelecer essa relação inversa, com os exemplares arborícolas concentrados nos valores superiores do segundo fator da análise do crânio (Figura 13) mas nos valores mais baixos do segundo fator da análise geral (Figura 8).

Voltando à variação de formas, ambas as análises concordam em atribuir narinas pequenas e separadas às linhagens arborícolas e narinas maiores e mais próximas (e, como a maxila superior também fica mais achatada, voltadas para cima) às linhagens terrícolas. Ambas as análises também concordam na diferenciação do comprimento do jugal nas linhagens, com cjugal apresentando o mesmo comportamento de índices com sinais invertidos nas análises mas descrevendo o mesmo fenômeno, o de espécies arborícolas possuírem jugais mais curtos que os terrícolas. A análise isolada do crânio também traz a tona duas relações além das apontadas pela análise geral: a altura do crânio e a espessura da articulação da maxila inferior. Tanto acran quanto lamaxi são 
maiores em espécies arborícolas, indicando um crânio mais alto e uma articulação mais robusta.

Todos esses indícios tocam na grande diferença entre essas linhagens: a seleção envolvida no hábito de golpear madeira. Crânios mais altos, bicos mais robustos e narinas menores nas espécies que se alimentam de larvas enterradas na madeira e cavam ninhos em árvores contra bases mais delicadas e narinas maiores e voltadas para cima em linhagens que se alimentam primariamente de formigas e cupins, fazem seus ninhos em madeira morta, barrancos ou formigueiros e cupinzeiros. 


\subsubsection{Formatos do pós-crânio}

Os eixos de variação da análise geral e da análise do pós-crânio apresentam concordância em duas propriedades: formato do pigóstilo e seus processos laterais e tamanho da quilha. $\mathrm{O}$ formato do pigóstilo acompanha a variação da medida lpig, cpig e apig. apig e cpig aparentam acompanhar a variação de tamanho, não apresentando correlação forte com nenhum fator além do primeiro. lpig apresenta correlação alta tanto com o segundo fator da análise geral quanto da análise de pós-crânio isolada, apontando para a tendência de linhagens arborícolas apresentarem pigóstilos mais largos que linhagens terrícolas. Ainda no pigóstilo, as medidas de cproc e lproc apresentam comportamento semelhante, com a mesma associação de processos mais largos e longos em linhagens arborícolas.

O tamanho da quilha aparece dentro do terceiro fator geral mas na análise isolada do pós crânio aparece inserido no segundo fator, juntamente com as informações do pigóstilo. Como parte da análise isolada ele indica a variação de tamanho entre linhagens como favorecendo a maior superfície da quilha nas linhagens terrícolas e menor nas arborícolas.

No caso do pós-crânio, um eixo de variação corresponde a modificações no formato corporal associadas a funções relacionadas porém distintas: o uso das rectrizes no apoio corporal dos animais enquanto escalam, evidenciado na diferença de tamanho do pigóstilo e de seus processos onde vai ocorrer a inserção dessa rectrizes, e o próprio hábito de voo associado com o tamanho da quilha, maior nas linhagens terrícolas que, possivelmente, decolam direto do chão em voos explosivos ao invés de poderem usar o impulso de queda livre de aves que iniciam o voo de alturas maiores. 


\subsubsection{Agrupamentos de espécies}

Mais importante que a separação de espécies em grupos de hábitos semelhantes é a localização relativa desses grupos no espaço de variação morfológica determinada pela análise de componentes. A distinção de hábitos, apesar de evidente nas análises geral e parciais, é apenas a confirmação da hipótese quase trivial de convergência de formas semelhantes para funções semelhantes.

A começar pelas espécies C. campestris e C. punctigula. Pelo estudo de Moore et al. 2010, essas duas espécies formam uma linhagem monofilética dentro do gênero. Que elas não apresentam convergência de formas não é surpresa se consideradas as profundas diferenças de hábito alimentar e reprodutivo das espécies, mas chama atenção a intensidade dessa diferença. C. campestris está morfologicamente muito mais próximo de C. rupicola, com quem compartilha várias similaridades de hábito, e $C$. melanochloros, com quem só compartilha certos hábitos alimentares. Não apenas isso, mas C. campestris divide parte do espaço morfológico com C. rupícola, encapsulando a variação da outra espécie em sua amplitude maior (provavelmente como consequência de seu espaço amostral maior), gerando um par de espécies que, apresentando uma distribuição discreta de formas com suas espécies irmãs respectivas, não possuem uma distribuição discreta de formas entre si.

A outra dupla de espécies em questão, C. rupicola e $C$. pitius, tem também uma relação semelhante com G. olivaceus: as duas espécies irmãs são morfologicamente similares entre si mas são também similares a G. olivaceus, uma espécie de outro gênero, uma espécies inclusive que aparenta ser o extremo terrícola nos eixos de diversidade das análises.

C. melanochloros chama a atenção também por ser uma espécie arborícola morfologicamente mais próxima das outras espécies terrícolas do gênero do que de espécies arborícolas dentro e fora do gênero. D. lineatus e as espécies de Celeus também são mais próximas entre si do que $C$. melanochloros é próxima das espécies terrícolas, mesmo tendo teoricamente hábitos semelhantes.

Essa proximidade de C. melanochloros (e, em menor medida, de C. atricollis e $C$. chrysoides) com outras espécies terrícolas sugere, portanto, que o fator de pressão seletiva não é a utilização de árvores em si, mas sim os hábitos alimentares e de 
nidificação. Como o gênero Colaptes é quase todo composto por espécies mirmecófagas (principalmente depois da revisão de Moore et al. 2010), a aparente incongruência de $C$. melanochloros e as outras espécies arborícolas do gênero compartilhando características morfológicas com espécies terrícolas é na verdade somente a semelhança de várias espécies de um gênero com adaptações relacionadas ao abandono parcial de árvores como substrato de exploração alimentar e de abrigo, condição da qual uma das espécies, C. punctigula, se afastou posteriormente.

Essas adaptações ao abandono das árvores, portanto, aparentam não só terem acontecido mais de duas vezes, independentemente, mas também seguido vias congruentes quando na direção da terrestrialidade a partir da posição ancestral de diminuição de ênfase na dependência de árvores observada nas linhagens basais do gênero. O mesmo efeito não se observa no sentido de retomada dessa dependência do substrato como observado em C. punctigula, com sua posição no espaço morfológico afastada tanto do resto de seu gênero como também das outras linhagens de hábitos semelhantes.

Finalmente, a parte que talvez seja a mais interessante dos resultados é o tamanho relativo do espaço morfológico explorado pelas linhagens. Conclusões nesse sentido são complicadas pela pequena amostragem do trabalho, mas mesmo se encarados como resultados preliminares as proporções permanecem: as linhagens terrícolas ocupam um espaço de variação morfológica muito menor do que o ocupado pelas linhagens arborícolas. Essa diferença de liberdade (por falta de um termo melhor) de formas parece inusitada dado o pressuposto do hábito característico dos pica-paus ser altamente especializado e, por consequência, limitado em suas potenciais formas e soluções.

A confluência de formas semelhantes num espaço ainda mais limitado quando linhagens dentro dos pica-paus passam a explorar quase que exclusivamente formigas e cupins, como é o caso com todas essas linhagens terrícolas tratadas aqui, parece deixar ainda mais improvável essa limitação adicional, quando parece que o esperado seria um relaxamento dessas limitações dado que as linhagens estão se afastando de uma adaptação extremamente específica em prol de comportamentos mais generalistas. $\mathrm{O}$ que me parece, entretanto, é que essa exploração exclusiva de formigas e cupins não é um relaxamento das pressões do modo de vida ancestral da família mas sim a pressão adicional de uma nova especialização alimentar, desligada em função mas não totalmente desligada em forma das limitações antigas. 


\section{Resumo}

Os pica-paus (família Picidae) são um grupo bem definido e caracterizado por adaptações ligadas ao modo de vida arborícola como membros posteriores próprios para escalada de apoios verticais, crânio e maxilas robustos utilizados para golpear madeira rapidamente e com força e cauda com penas rígidas utilizadas como apoio na escalada. Dentro da família, entretanto, existem espécies que não só apresentam hábito terrícola como algumas em especial que abandonam totalmente o hábito arborícola. O gênero com maior incidência desses casos é Colaptes Vigors, 1825, onde todos os representantes estão associados com a alimentação especializada em formigas e cupins e suas larvas e as linhagens exclusivamente terrícolas nidificam em barrancos ou buracos no chão. Além dele, existe o gênero monotípico africano Geocolaptes Gmelin, 1788, que apresenta as mesmas características de habitat mas relações filogenéticas distante. $\mathrm{O}$ objetivo deste trabalho foi o de analisar a relação entre as formas dos exemplares em busca de similaridades e diferenças relacionadas ao hábito e comportamento das linhagens e a possível independência do surgimento dessas alterações na filogenia do grupo. Foram analisados 49 exemplares de esqueleto pertencentes aos dois gêneros com representantes terrícolas bem como exemplares dos gêneros Dryocopus e Celeus como comparação a linhagens adaptadas ao hábito arborícola, depositados na coleção do MZUSP e em coleções estrangeiras. O tratamento dos dados por meio de Análise de Componente Principal (PCA) mostrou correlação entre o hábito de vida das linhagens e atributos do crânio (altura do crânio, formato do bico e tamanho e posicionamento das narinas) e do pós-crânio (tamanho e formato do pigóstilo e tamanho da quilha). É possível que estas alterações na forma das linhagens tenham duas pressões distintas, a exploração de um recurso diferente na alimentação (formigas e cupins) e a alteração nos modos de locomoção dos indivíduos (pigóstilo para o apoio das rectrizes na escalada e quilha no esforço de decolagem a partir do chão). Os resultados sugerem a possibilidade dessas adaptações terem surgido independentemente mas gerado resultados extremamente semelhantes em forma, mas também demonstram a necessidade de um estudo incorporando mais táxons para uma comparação mais representativa. 


\section{Abstract}

Woodpeckers (family Picidae) are a well-defined group, traditionally characterized by their unique morphological specializations for climbing and excavating in trees, like posterior limbs and the tail adapted for support and a robust cranium and beak for hammering on wood. Among the species in the family, however, there are not only some that stray from this highly specialized behavior and develop ground-based behavior, but also a few that completely abandon trees. The genus with most of these cases, Colaptes Vigors, 1825, contains species that specialize in feeding on ants ant termites and their larvae, building nests in banks, holes in the ground or even termite hills. Besides them, the monotipical African genus Geocolaptes Gmelin, 1788 shows the same feeding and nesting habits but is much more distantly related. This work aims at analyzing relations between the shapes of the species' skeletons and looking for similarities and differences that correlated with their habitats and behavior and whether or not the similar solutions occurred independently throughout the family's evolutionary history. 49 skeleton specimens were utilized, belonging to the two ground dwelling and the Dryocopus and Celeus genera. Principal Component Analysis showed correlation between feeding and nesting habits and several measures of the skull (skull height, beak shape and nostrils' shape and positioning) and postcrania (size and shape of the pygostyle and size of the keel). It is a possibility that these changes in shape derive from two distinct selective pressures: the exploration of a different food source (ants and termites) and the change in the way the organisms move (pygostyle as a support in climbing and the keel relating to the strain of taking off). The results suggest that these adaptations came about independently but generated extremely similar shapes, while also demonstrating the need for further study with the inclusion of more taxa for a more representative comparison. 


\section{Bibliografia}

ANTAS, P. D. T. Z.; CAVAlCANTI, R. B. Aves Comuns Do Planalto Central. $2^{\text {a }}$ Edição. ed. Brasília: UNB, 1988.

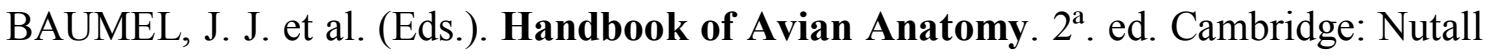
Ornithological Club, 1993. (publication n. 23).

BEECHER, W. J. Feeding adaptations and systematics in the avian order Piciformes. Journal of the Washington Academy of Sciences, v. 43, p. 293-299, 1953.

BENZ, B. W.; ROBBINS, M. B.; PETERSON, A. T. Evolutionary history of woodpeckers and allies (Aves: Picidae): Placing key taxa on the phylogenetic tree. Molecular Phylogenetics and Evolution, n. 40, p. 389-399, 2006.

BOCK, W. J. Secondary Articulation of the Avian Mandible. The Auk, v. 77, n. 1, p. 19-55, 1960.

BOCK, W. J. Functional and evolutionary morphology of woodpeckers. Ostrich, v. 70, n. 1, p. 23-31, 1999.

BOCK, W. J.; MILLER, W. D. The scansorial foot of the woodpeckers, with comments on the evolution of perching and climbing feet in birds. American Museum Novitates, New York, v. 1931, p. 9-45, 1959.

BOCK, W.; WAHLERT, G. Adaptation and the Form-function complex. Evolution, v. 19, n. 3, p. 269-299, 1965.

BOOKSTEIN, F. L. "Size and Shape": A Comment on Semantics. Systematic Zoology, v. 38, n. 2 , p. $173-180,1989$.

CBRO. Lista das aves do Brasil, 18 dezembro 2011. Disponivel em: $<$ http://www.cbro.org.br>. Acesso em: 3 fevereiro 2011.

CHAPMAN, F. M. On the Color-Pattern of the Upper Tail-Coverts in Colaptes auratus. The Auk, v. 9, n. 1, Article XXI, 1892.

CORY, C. B. Catalogue of Birds of the Americas and Adjacent Islands. Chicago: Field Museum of Natural History, v. XIII, part II, nº 2, 1919. 
CRACRAFT, J. Toward a phylogenetic classification of the recent birds of the world (Class: Aves). The Auk, n. 98, p. 681-714, Outubro 1981.

DARWIN, C. R. On the Origin of Species by Means of Natural Selection, or the Preservation of Favoured Races in the Struggle for Life. $1^{\text {a }}$ Edição. ed. Londres: John Murray, 1859.

D'ORBIGNY, A. Voyage dans L'Amérique Méridionale: Le Bresil, La République Orientale de L'Uruguay, La République Argentine, La Patagonie, La République du Chili, La République de Bolivia, La République du Pérou. Paris: Bertrand, P., v. IV-3 Oiseaux, 1840.

GARROD, A. H. On certain muscles of birds and their value in classification. Part II. Proceedings of the Zoological Society of London, v. 42, n. 1, 1874.

GRASSÉ, P.-P. Traité de zoologie. Paris: [s.n.], v. XV: Oiseaux, 1950.

HOLM, S. A simple sequentially rejective multiple test procedure. Scandinavian journal of statistics, v. 6, n. 2, p. 65-70, 1979.

JOLICOEUR, P.; MOSIMANN, J. E. Size and shape variation in the painted turtle. A principal component analysis. Growth, v. 24, n. 4, p. 339-354, 1960.

LIVEZEY, B. C. Avian spirit collections: attitudes, importance and prospects. Bulletin of The British Ornithologists' Club, v. 123A, p. 35-51, 2003.

LIVEZEY, B. C.; ZUSI, R. L. Higher-order phylogeny of modern birds (Theropoda, Aves: Neornithes) based on comparative anatomy. II. Analysis and discussion. Zoological Journal of the Linnean Society, v. 149, n. 1, 2007. ISSN 1096-3642.

MONTEIRO, L. R. Morphometrics and the comparative method: studying the evolution of biological shape. Italian Journal of Mammalogy, v. 24, n. 1, p. 1-7, 2013.

MOORE, W. S.; OVERTON, L. C.; MIGLIA, K. J. Mitochondrial DNA based phylogeny of the woodpecker genera Colaptes and Piculus, and implications for the history of woodpecker diversification in South America. Molecular Phylogenetics and Evolution, 2010. 
OLSON, S. Development and uses of avian skeleton collections. Bulletin of The British Ornithologists' Club, v. 123A, p. 26-34, 2003.

PETERS, J. L. Check-list of Birds of the World. Cambridge: Harvard University Press, v. VI, 1948.

RAZALI, N. M.; WAH, Y. B. Power comparisons of shapiro-wilk, kolmogorovsmirnov, lilliefors and anderson-darling tests. Journal of Statistical Modeling and Analytics, v. 2, n. 1, p. 21-33, 2011.

ROHLF, F. J. Morphometrics. Annual Review of Ecology and Systematics, v. 21, p. 299-316, 1990.

SCHWAB, I. R. Cure for a headache. British Journal of Ophthalmology, v. 86, n. 6, p. 843, 2002.

SHAPIRO, S. S.; WILK, M. B. An analysis of variance test for normality (complete samples). Biometrika, v. 52, n. 3/4, p. 591-611, 1965.

SHAPIRO, S. S.; WILK, M. B.; CHEN, H. J. A comparative study of various tests for normality. Journal of the American Statistical Association, v. 63, n. 324, p. 13431372, 1968.

SHORT, L. L. Foraging association of Green-barred Flickers and Campo Flickers in Argentina. Wilson Bulletim, v. 81, p. 468-470, 1969.

SHORT, L. L. Reversed Sexual Dimorphism In Tail Length And Foraging Differences In Woodpeckers. Bird-Banding, v. 41, n. 2, p. 85-168, 1970.

SHORT, L. L. The evolution of terrestrial woodpeckers. American Museum novitates, v. $2467,1971$.

SHORT, L. L. Systematics and Behavior of South American Flickers (Aves, Colaptes). Bulletin of the American Museum of Natural History, New York, v. 149, Article 1, 1972.

SHORT, L. L. A zoogeographic analysis of the South American Chaco avifauna. Bulletin of the American Museum of Natural History, New York, v. 154, p. 163-352, 1975. 
SHORT, L. L. Woodpeckers of the world. Greenville: Delaware Museum of Natural History, 1982. 676 p. Monograph Series 4.

SICK, H. Ornitologia Brasileira. Rio de Janeiro: Nova Fronteira, 1997. 912 p.

SIMPSON, S. F.; CRACRAFT, J. The Psylogenetic Relantionships of the Piciformes (Class AVES). The Auk, v. 98, p. 481-494, 1981.

SPRING, L. Climbing and pecking adaptations in some North American woodpeckers. The Condor, v. 67, n. 6, p. 457-488, 1965.

STEINHEIMER, F. D. Charles Darwin's bird collection and ornithological knowledge during the voyage of H.M.S. Beagle, 1831-1836. Journal of Ornithology, v. 145, n. 4, p. 300-320, (appendix [pp. 1-40]), 2004.

STRESEMANN, E. Aves. In: KÜKENTHAL, W.; KRUMBACH, T. Handbuch der Zoologie. Berlin: [s.n.], v. 7, 1927.

SWAINSON, W.; RICHARDSON, J. Fauna Boreali-Americana. Londes: John Murray, v. 2: The Birds, 1832.

SWIERCZEWSKI, E. V.; RAIKOW, R. J. Hind limb morphology, phylogeny, and classification of the Piciformes. The Auk, v. 98, n. 3, p. 466-480, 1981.

TEST, F. H. Relation of Wing and Tail Color of the Woodpeckers Colaptes Auratus and C. Cafer to their Food. The Condor, v. 71, n. 2, 1969.

TUBELIS, D. P. Fruit consumption by Colaptes campestris (Aves, Picidae) at Emas National Park, Brazil. Biotemas, Florianópolis, v. 20, n. 4, p. 131-133, 2007. ISSN 0103-1643.

VIEILlOT, L. J. P. Le Pic de Champs. In: Nouveau dictionnaire d'histoire naturelle, appliquee aux arts, a l'agriculture, a l'economie rurale et domestique, a la medecine, etc. Par une societe de naturalistes et d'agriculteurs. Paris: Deterville, v. XXVI, 1818. p. 101-102.

WALLACE, G. J. An introduction to ornithology. New York: [s.n.], 1955.

WETMORE, A. A classification for the birds of the world. Smithsonian Miscellaneous Collection, v. 139, p. 1-37, 1960. 
WING, L. W. Natural history of birds. New York: [s.n.], 1956.

WINKLER, H.; CHRISTIE, D. A. Family Picidae (Woodpeckers). In: DEL HOYO, J.; ELLIOTT, A.; SARGATAL, J. Handbook of the Birds of the World Volume 7: Jacamars to Woodpeckers. Barcelona: Lynx Edicions, 2002. p. 296-555.

WOOD, D. S.; SCHNELL, G. D. Revised world inventory of avian skeletal specimens, 1986. Norman: Aerican Ornithologists' Union and Oklahoma Biological Survey, 1986. 296 p. 
Anexo I

Figuras

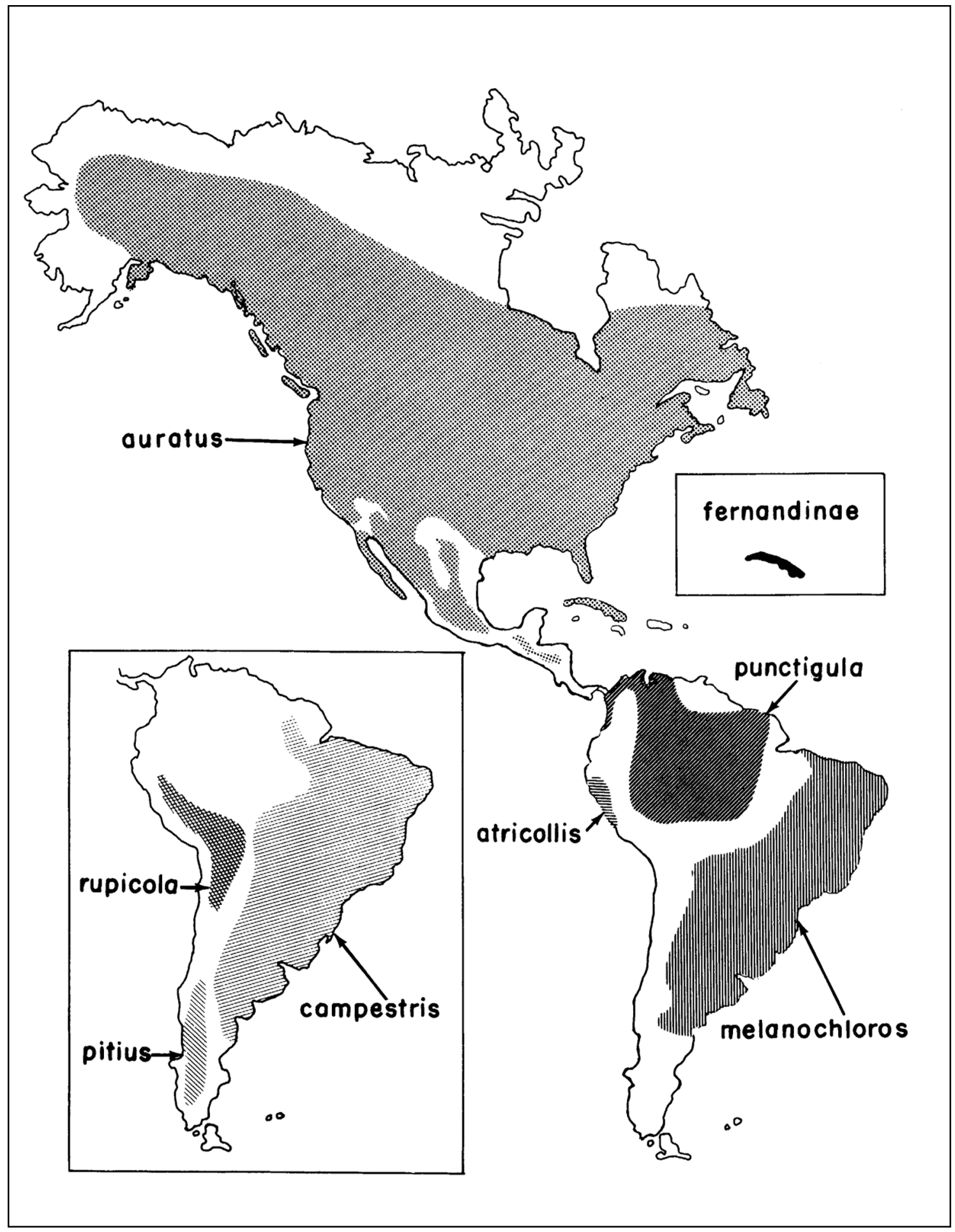

Figura 1: Distribuição das espécies dentro do gênero Colaptes. Retirado de Short, 1972. Espécies terrícolas (com exceção de C. auratus, na América do Norte) separadas no quadro esquerdo. 


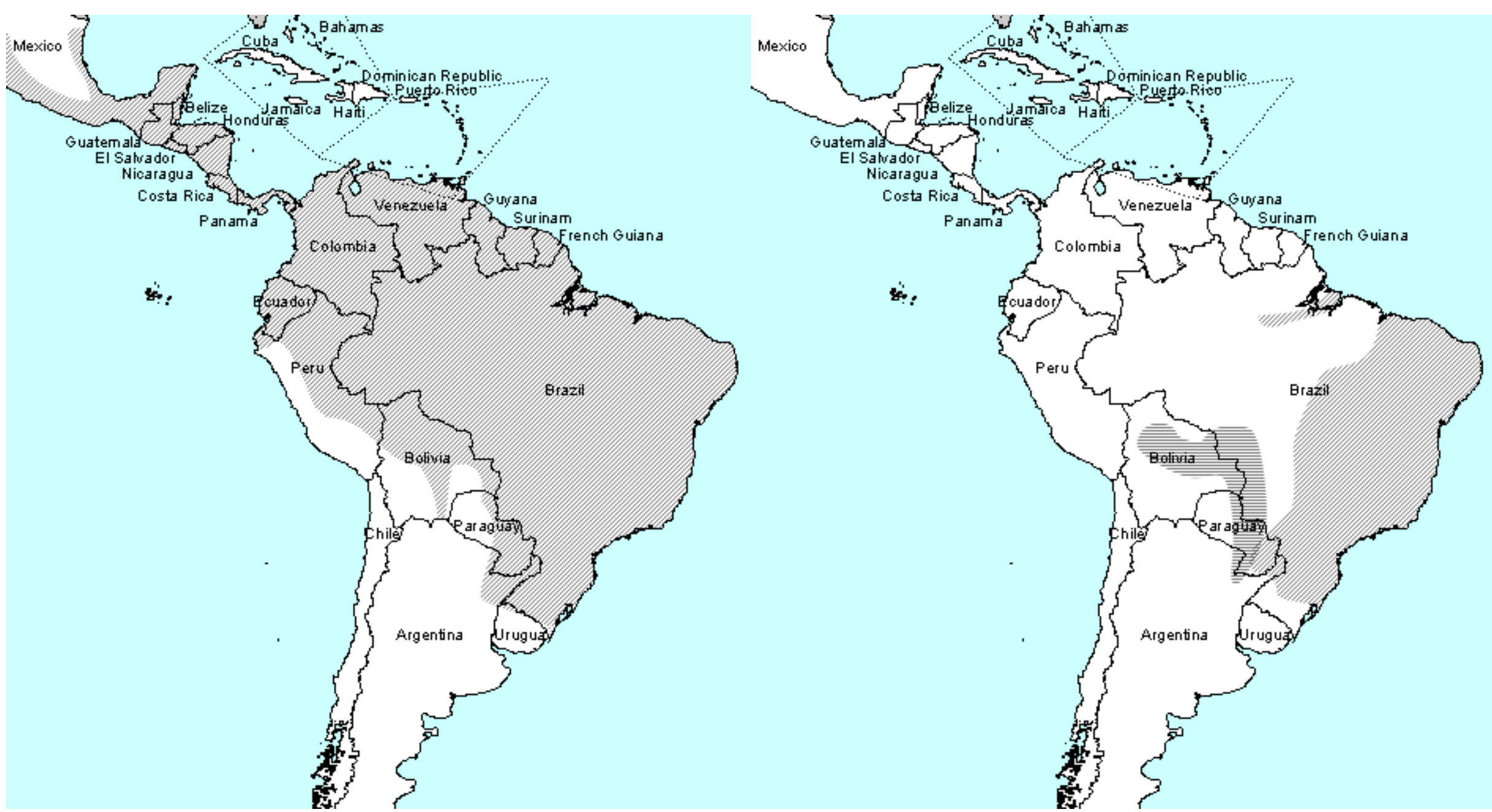

Figura 2: Distribuições aproximadas de Dryocopus lineatus (na esquerda, hachurado diagonal) e Celeus elegans e C. lugubris (na direita, hachurado diagonal e horizontal, respectivamente). Mapas elaborados a partir das informações de distribuição de espécies disponível em $<$ http://www.natureserve.org/infonatura/>, acesso em 27 outubro 2013. 


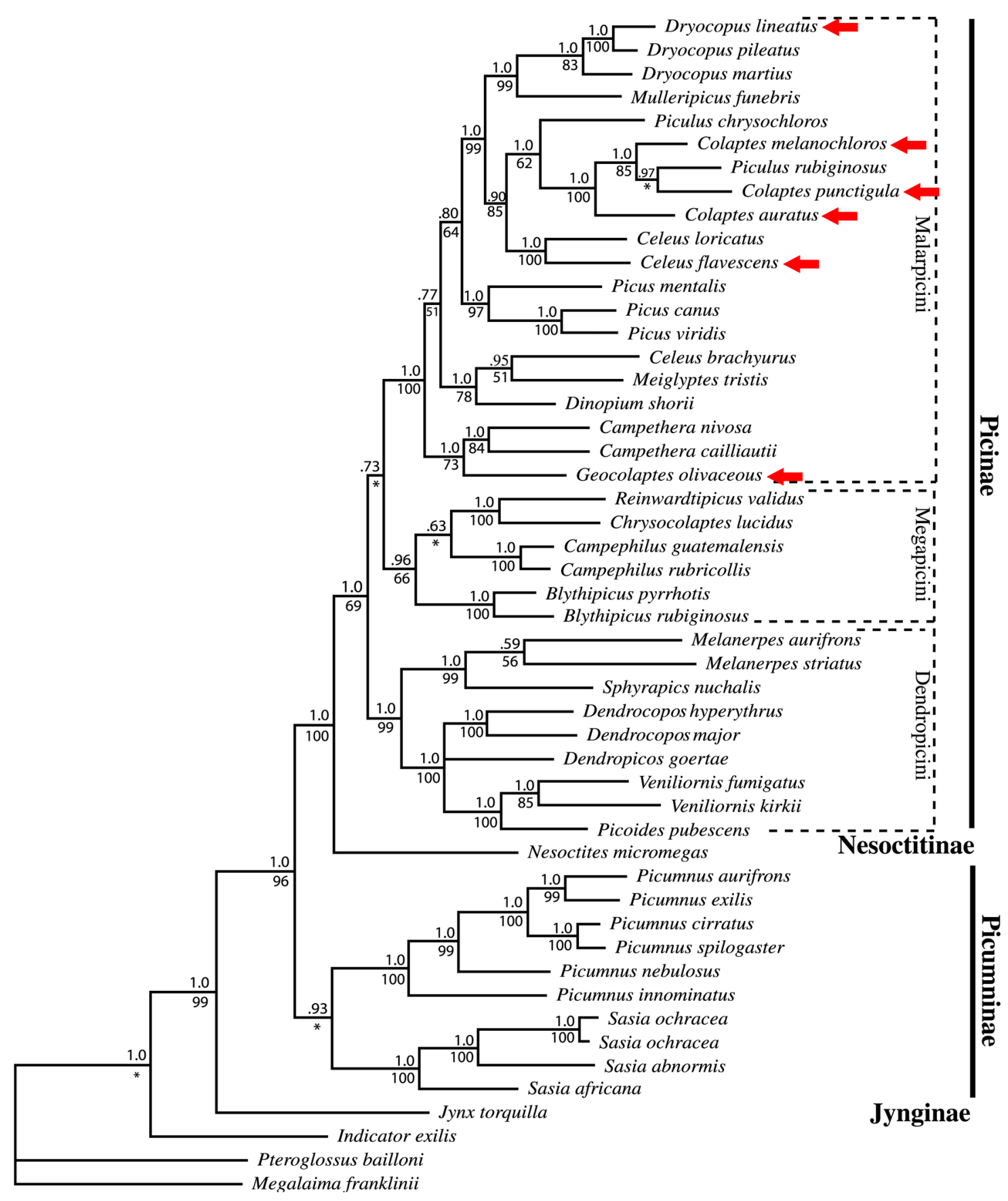

Figura 3: Filogenia proposta para a família Picidae com os gêneros e espécies utilizados nesse trabalho indicados por setas vermelhas. Números acima dos nós representam probabilidades posteriores, números abaixo dos nós denotam valores de bootstrap. Adaptado de Benz 2006. 


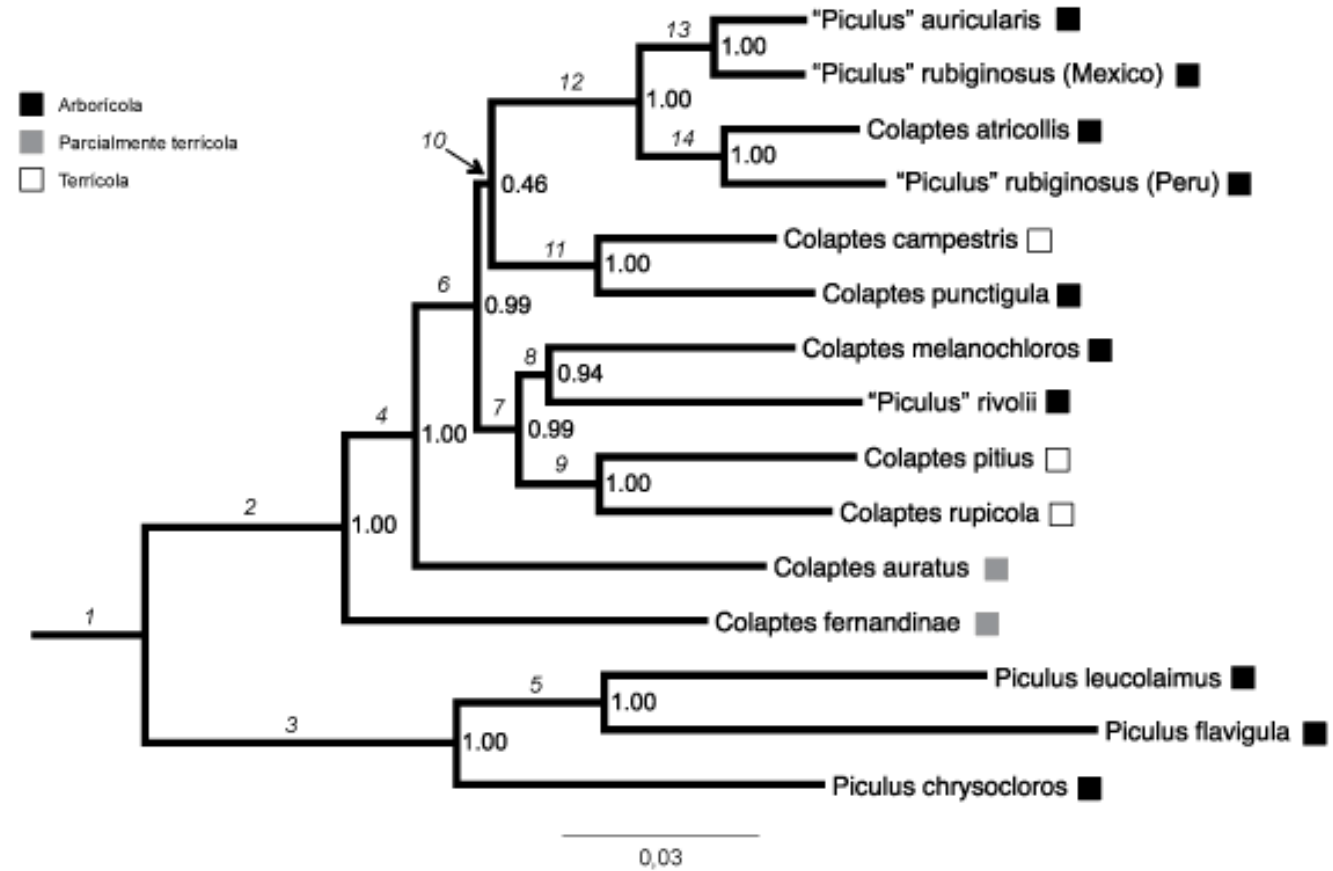

Figura 4: Filogenia proposta para os gêneros Colaptes e Piculus, com os hábitos de cada espécie indicados ao lado dos terminais. Os valores de probabilidade estimada para os nós são indicados à direita de cada um, e a escala indica substituições por sítio. Adaptado de Moore et al. 2010 e Short 1971. 

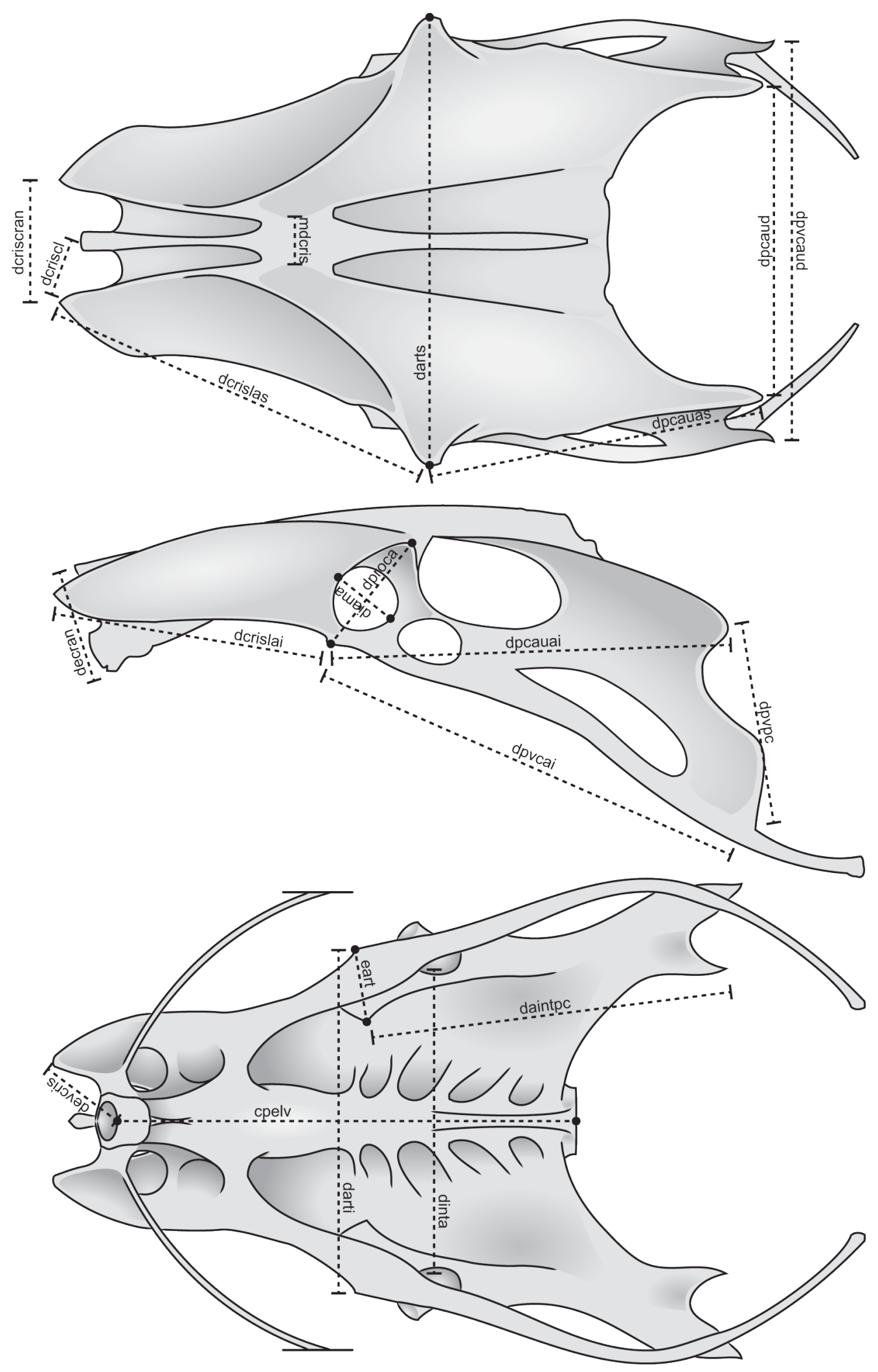

Figura 5: Referência de medidas utilizadas da pelve. Esquemas foram elaborados com base no exemplar MZUSP89449, C. campestris. 

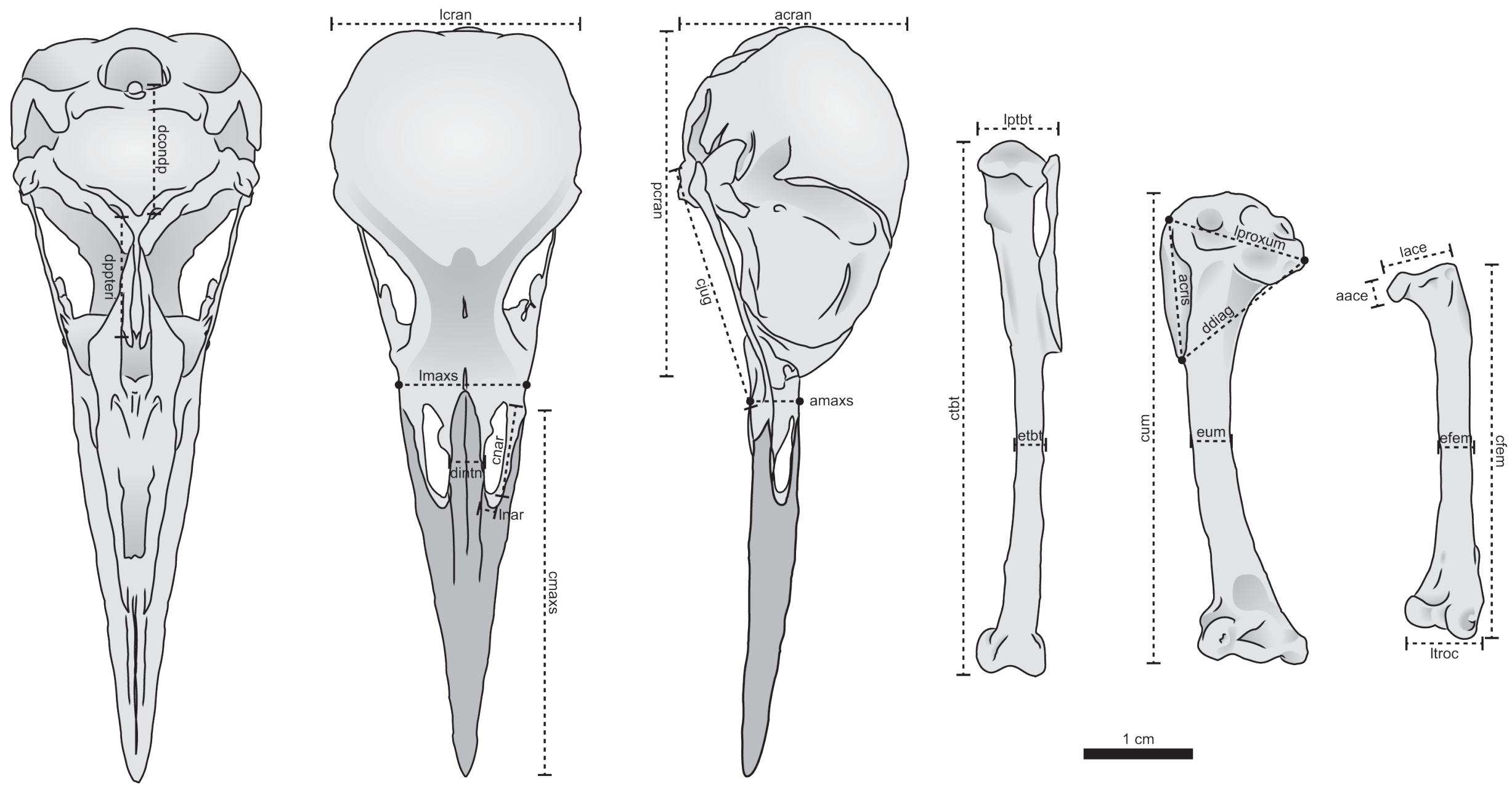

Figura 6: Referência de medidas utilizadas do crânio e ossos longos do pós-crânio. Esquemas foram elaborados com base no exemplar MZUSP89449, $C$. campestris. 


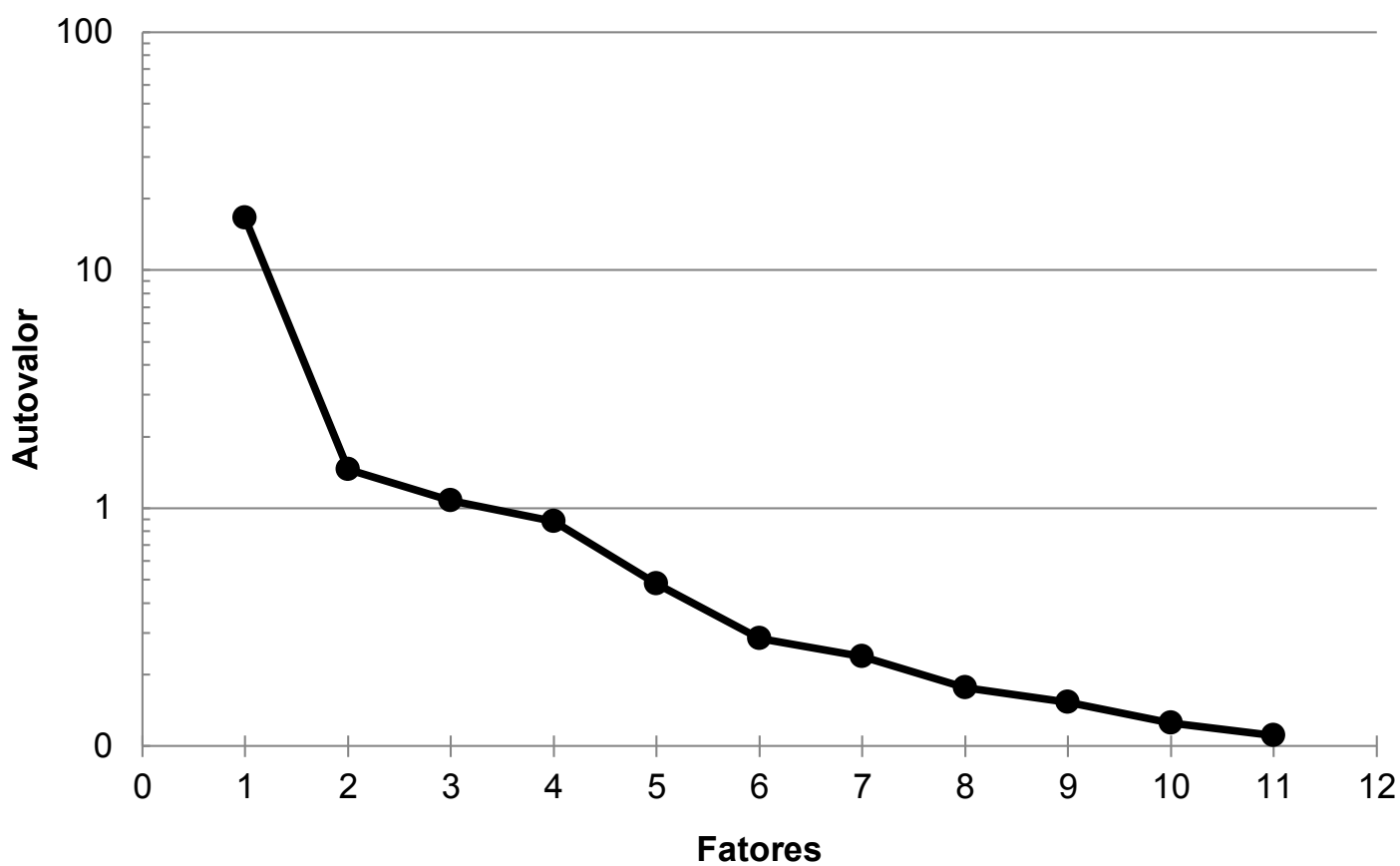

Figura 7: Autovalores dos fatores principais gerais extraídos. Fatores além do oitavo não foram utilizados em análises posteriores por apresentarem autovalores inferiores a 1, fatores além do décimo segundo não estão representados.

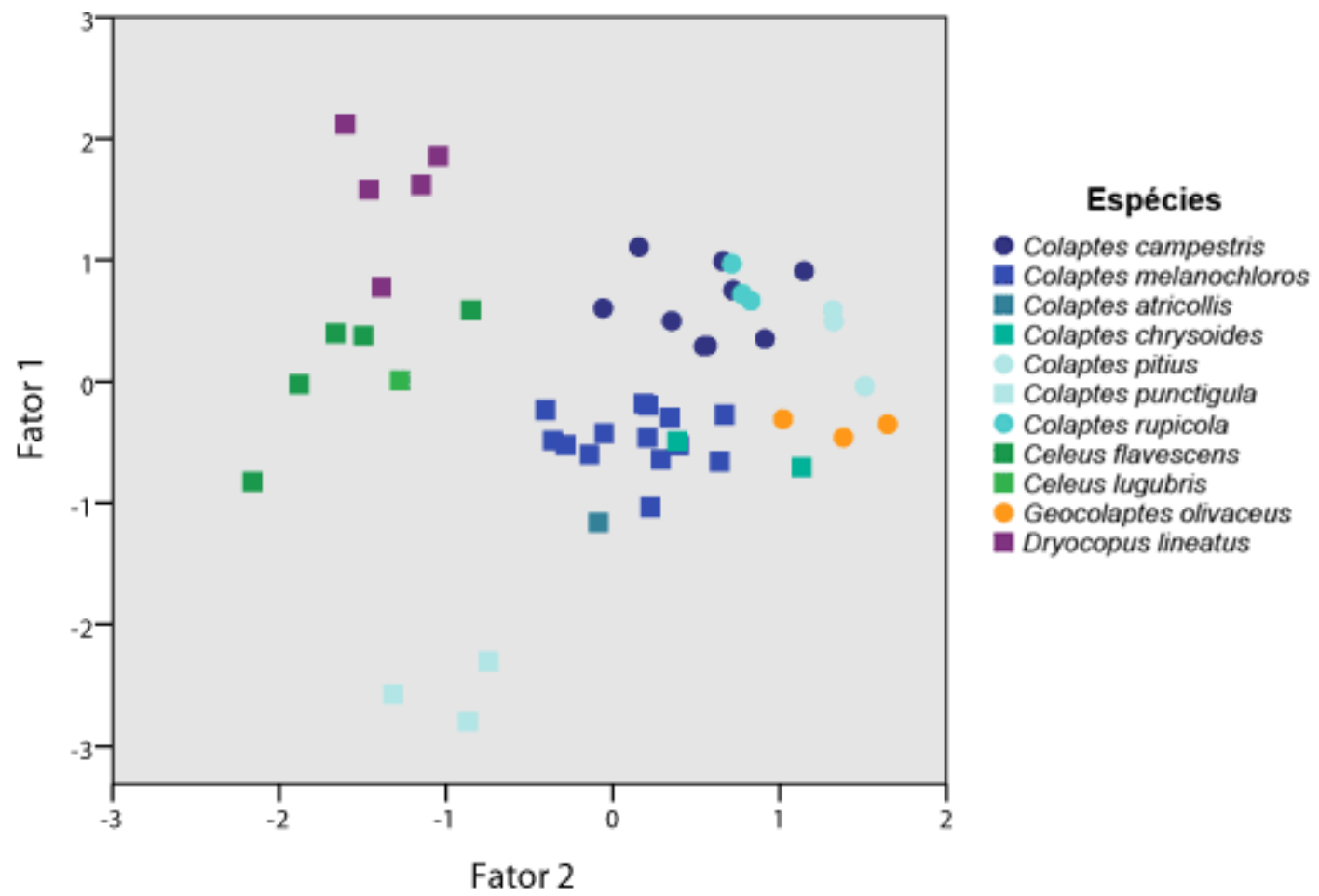

Figura 8: Gráfico de dispersão dos índices dos indivíduos para os fatores gerais 1 e 2 . Formato dos símbolos identifica o hábito das espécies, quadrado para arborícola e círculo para terrícola. 


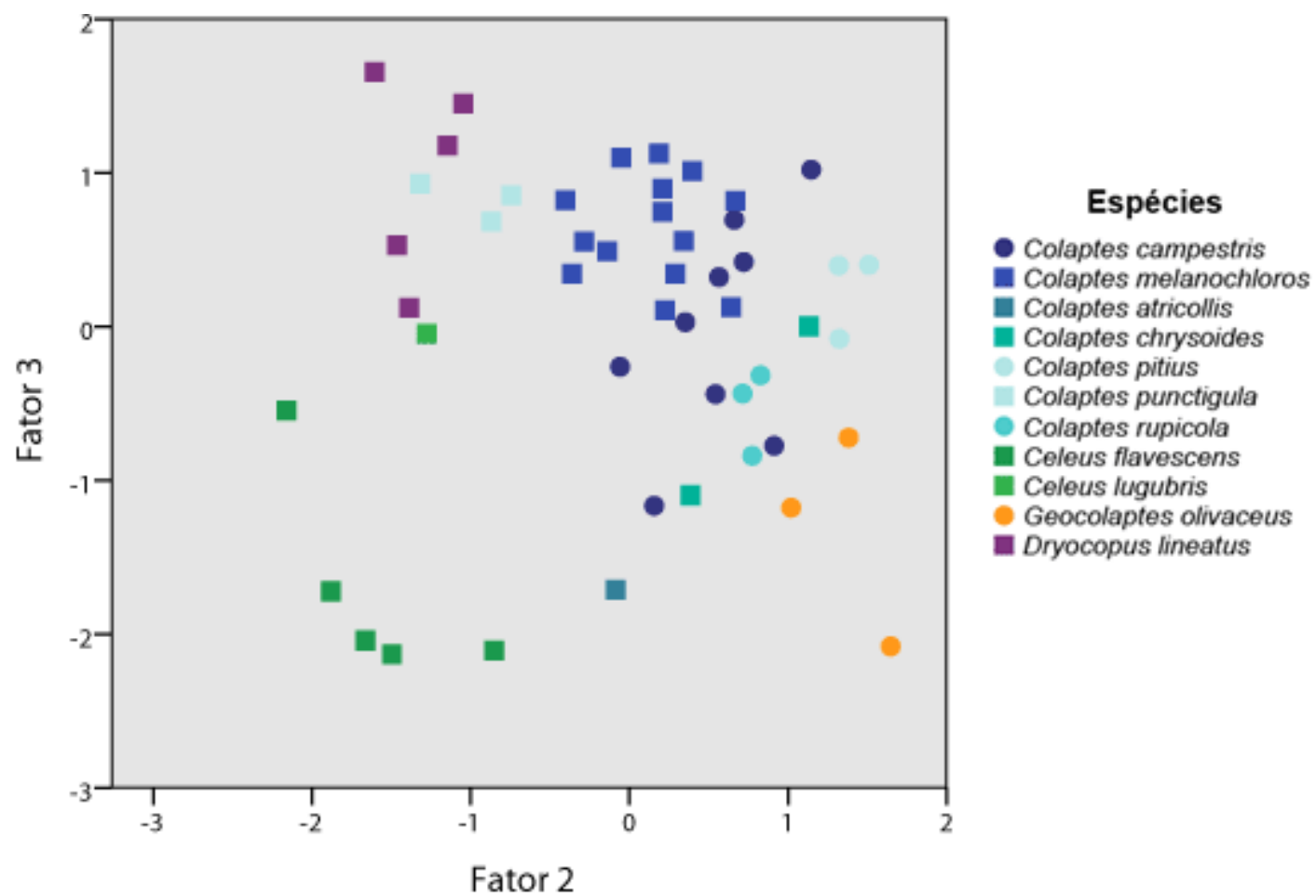

Figura 9: Gráfico de dispersão dos índices dos indivíduos para os fatores gerais 2 e 3. Formato dos símbolos identifica o hábito das espécies, quadrado para arborícola e círculo para terrícola.

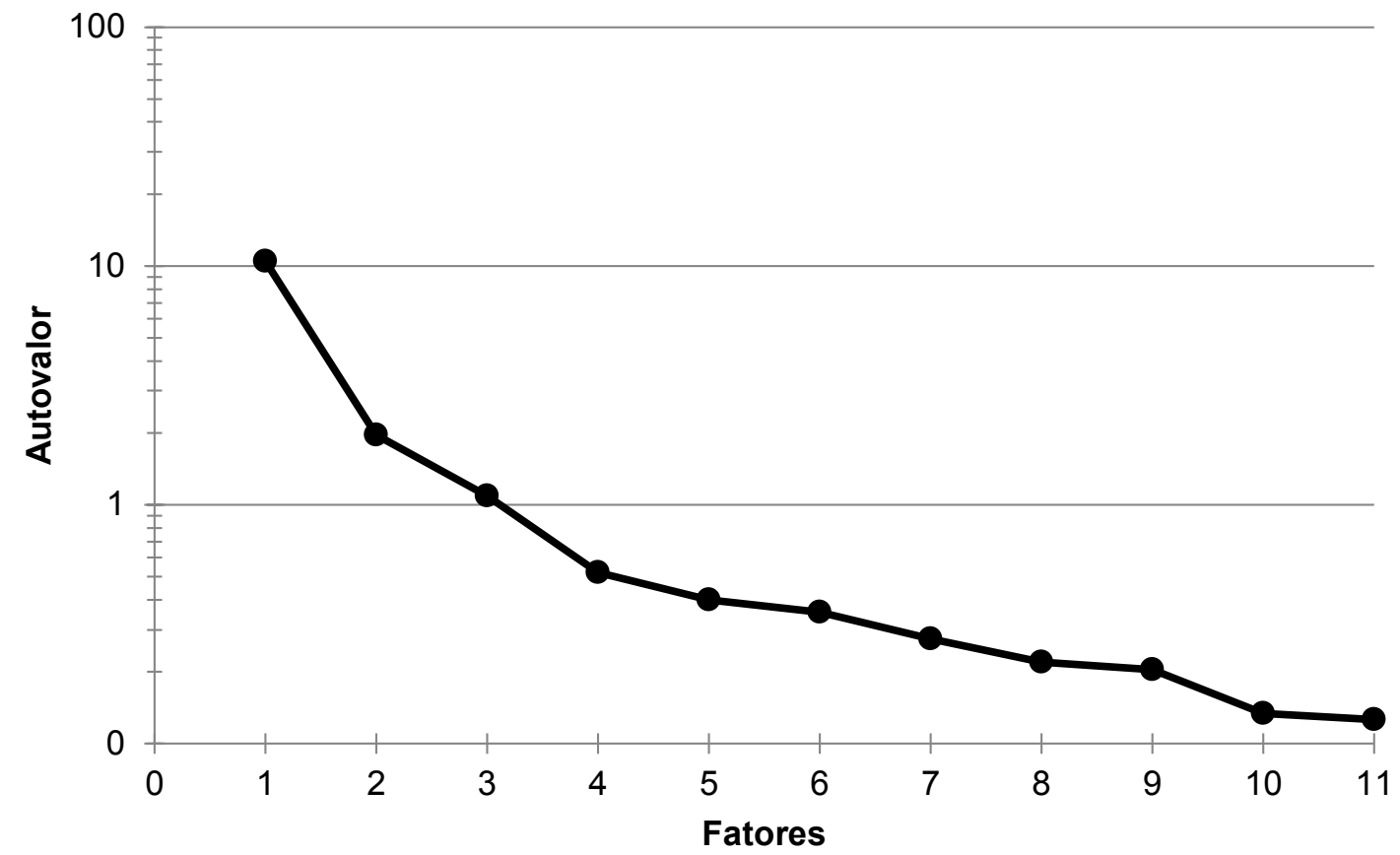

Figura 10: Autovalores dos fatores principais do crânio extraídos. Fatores além do terceiro não foram utilizados em análises posteriores por apresentarem autovalores inferiores a 1, fatores além do décimo primeiro não estão representados. 


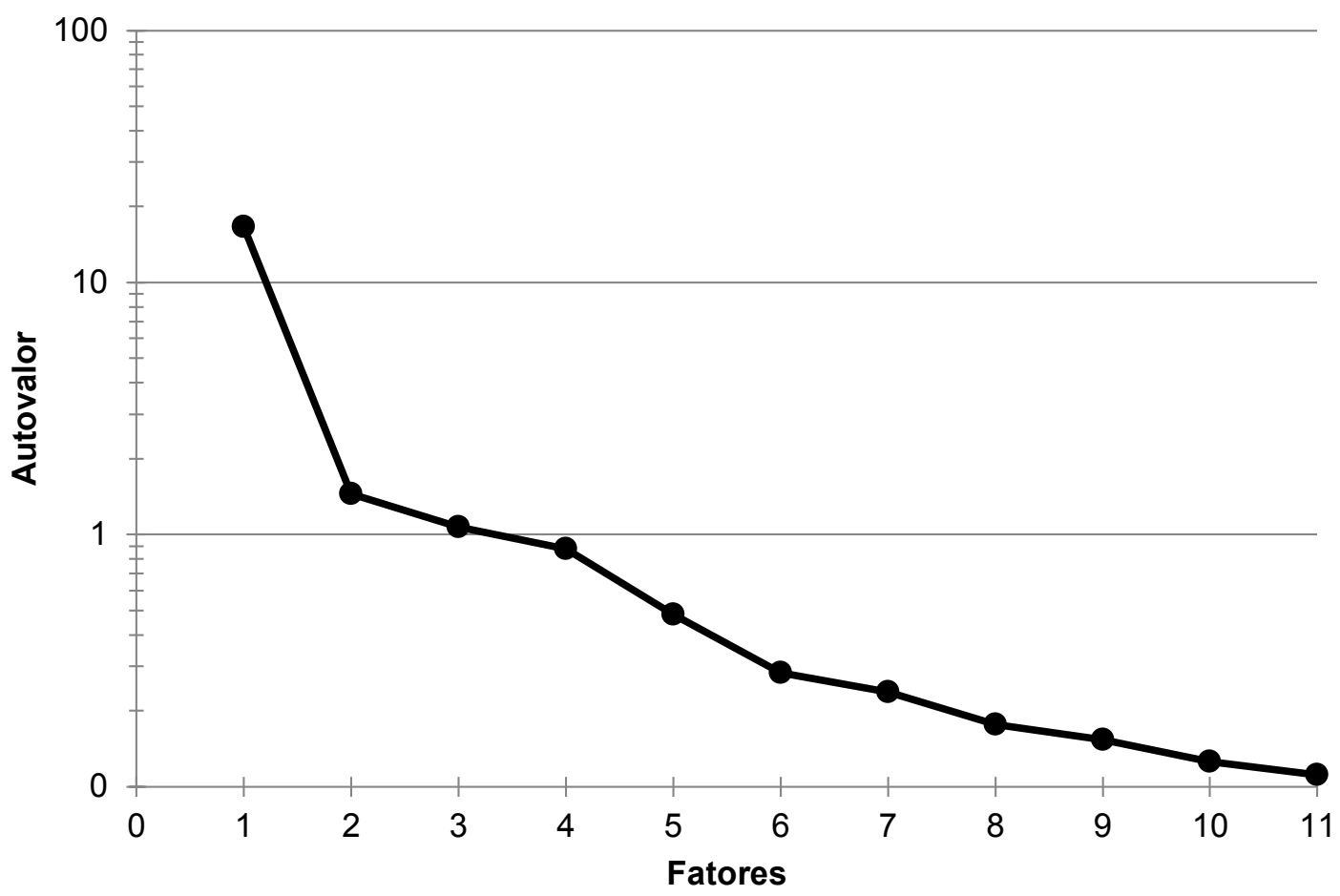

Figura 11: Autovalores dos fatores principais do pós-crânio extraídos. Fatores além do terceiro não foram utilizados em análises posteriores por apresentarem autovalores inferiores a 1 , fatores além do décimo primeiro não estão representados.

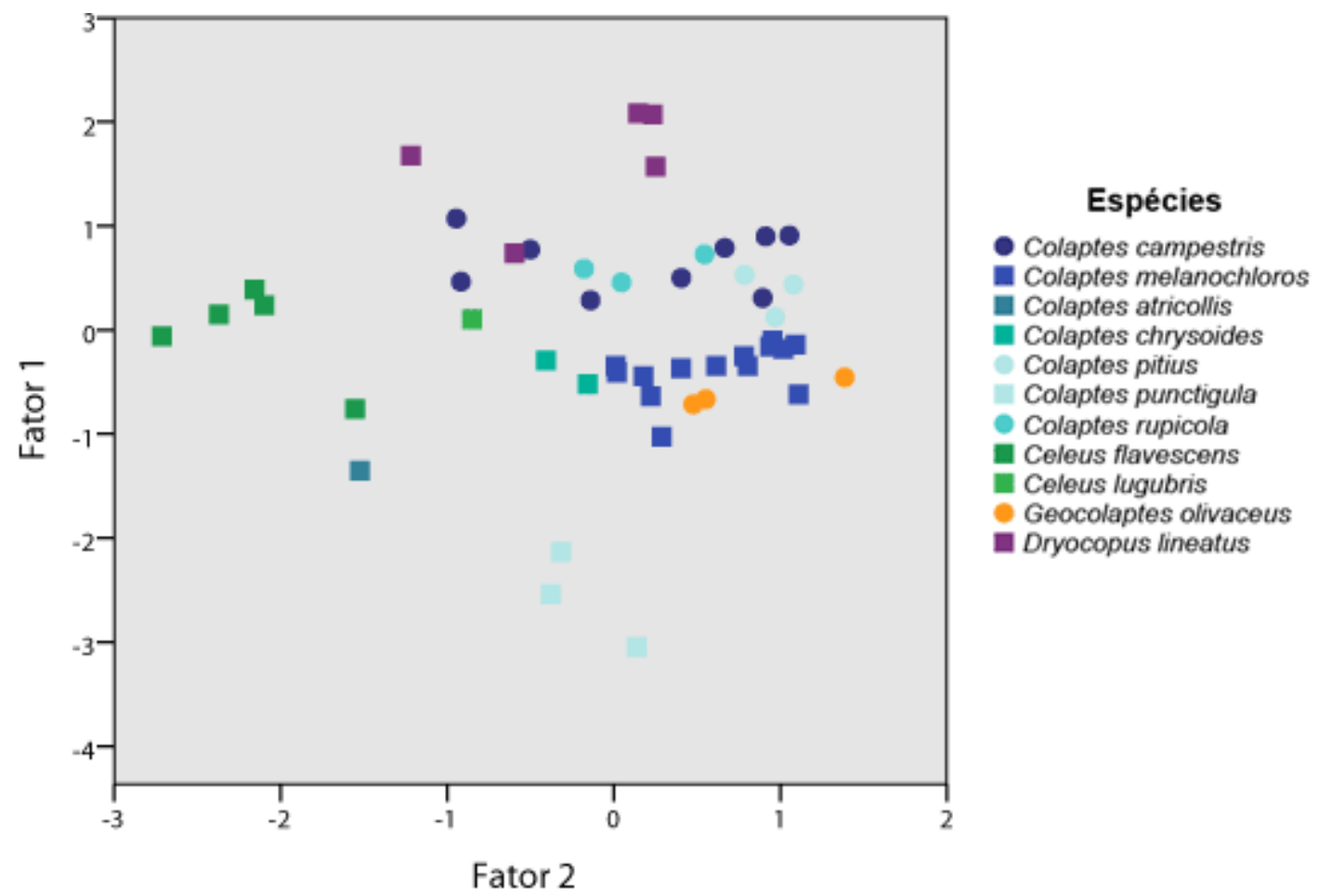

Figura 12: Gráfico de dispersão dos índices para os fatores do pós-crânio 1 e 2. Formato dos símbolos identifica o hábito das espécies, quadrado para arborícola e círculo para terrícola. 


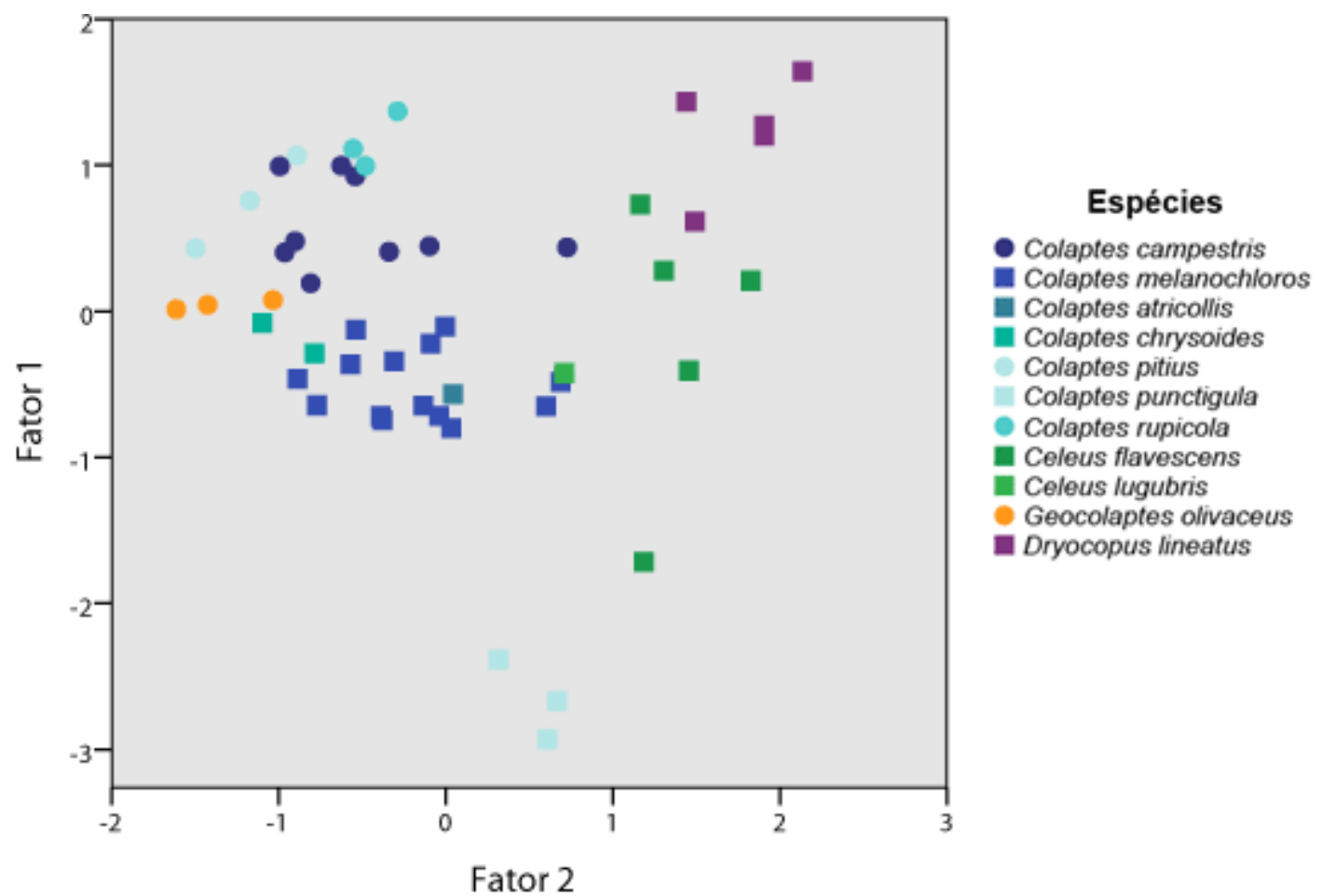

Figura 13: Gráfico de dispersão dos índices dos indivíduos para os fatores do crânio 1 e 2 . Formato dos símbolos identifica o hábito das espécies, quadrado para arborícola e círculo para terrícola.

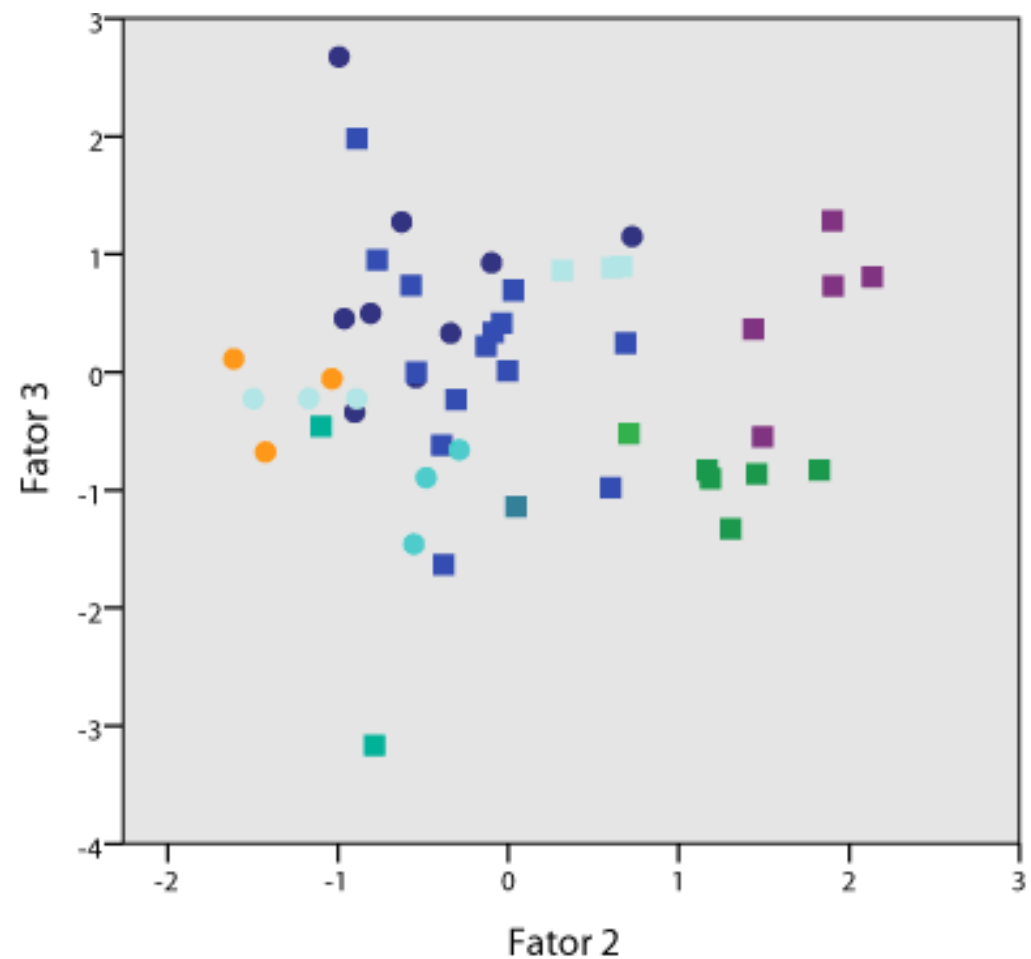

\section{Espécies}

- Colaptes campestris - Colaptes melanochloros Colaptes atricollis

Colaptes chrysoides

Colaptes pitius

Colaptes punctigula

- Colaptes rupicola

Celeus flavescens

Celeus lugubris

- Geocolaptes olivaceus

Dryocopus lineatus

Figura 14: Gráfico de dispersão dos índices dos indivíduos para os fatores do crânio 2 e 3 . Formato dos símbolos identifica o hábito das espécies, quadrado para arborícola e círculo para terrícola. 
Anexo II

Espécimes examinados

\begin{tabular}{lcccc}
\hline \multirow{2}{*}{ Espécies } & \multicolumn{3}{c}{ Sexo } & \multirow{2}{*}{ Total } \\
\cline { 2 - 4 } & $\mathbf{M}$ & $\mathbf{F}$ & $\mathbf{I}$ & \\
\hline Colaptes campestris & 4 & 4 & 1 & 9 \\
Colaptes melanochloros & 5 & 8 & 1 & 14 \\
Colaptes atricollis & 1 & - & - & 1 \\
Colaptes chrysoides & 2 & - & - & 2 \\
Colaptes pitius & 1 & 2 & - & 3 \\
Colaptes punctigula & - & 2 & 1 & 3 \\
Colaptes rupicola & 2 & - & 1 & 3 \\
Celeus flavescens & 1 & 3 & 1 & 5 \\
Celeus lugubris & 1 & - & - & 1 \\
Geocolaptes olivaceus & 2 & 1 & - & 3 \\
Dryocopus lineatus & 1 & - & 4 & 5 \\
\hline Total: & \multicolumn{3}{c}{} \\
\hline \hline
\end{tabular}

Tabela 1: Exemplares estudados separados em espécie e sexo do indivíduo. Subespécies diferentes estão todas inclusas em suas respectivas espécies.

\begin{tabular}{lccccc}
\hline \multirow{2}{*}{ Espécies } & \multicolumn{4}{c}{ Instituição } & \multirow{2}{*}{ Total } \\
\cline { 2 - 5 } & MZUSP & AMNH & NMNH & UMMZ & \\
\hline Colaptes campestris & 3 & 2 & 4 & 0 & 9 \\
Colaptes melanochloros & 0 & 2 & 4 & 8 & 14 \\
Colaptes atricollis & 0 & 1 & 0 & 0 & 1 \\
Colaptes chrysoides & 0 & 2 & 0 & 0 & 2 \\
Colaptes pitius & 0 & 2 & 0 & 1 & 3 \\
Colaptes punctigula & 0 & 1 & 0 & 2 & 3 \\
Colaptes rupicola & 0 & 2 & 0 & 1 & 3 \\
Celeus flavescens & 4 & 1 & 0 & 0 & 5 \\
Celeus lugubris & 0 & 1 & 0 & 0 & 1 \\
Geocolaptes olivaceus & 0 & 1 & 0 & 2 & 3 \\
Dryocopus lineatus & 1 & 4 & 0 & 0 & 5 \\
\hline Total: & \multicolumn{5}{c}{} \\
\hline \hline
\end{tabular}

Tabela 2: Exemplares estudados separados em espécie e instituição de depósito. Subespécies diferentes estão todas inclusas em suas respectivas espécies. Os códigos da identificação de tombo seguem a nomenclatura delineada anteriormente (AMNH: American Museum of Natural History; UMMZ: University of Michigan Museum of Zoology; NMNH: National Museum of Natural History; MZUSP: Museu de Zoologia da USP). 


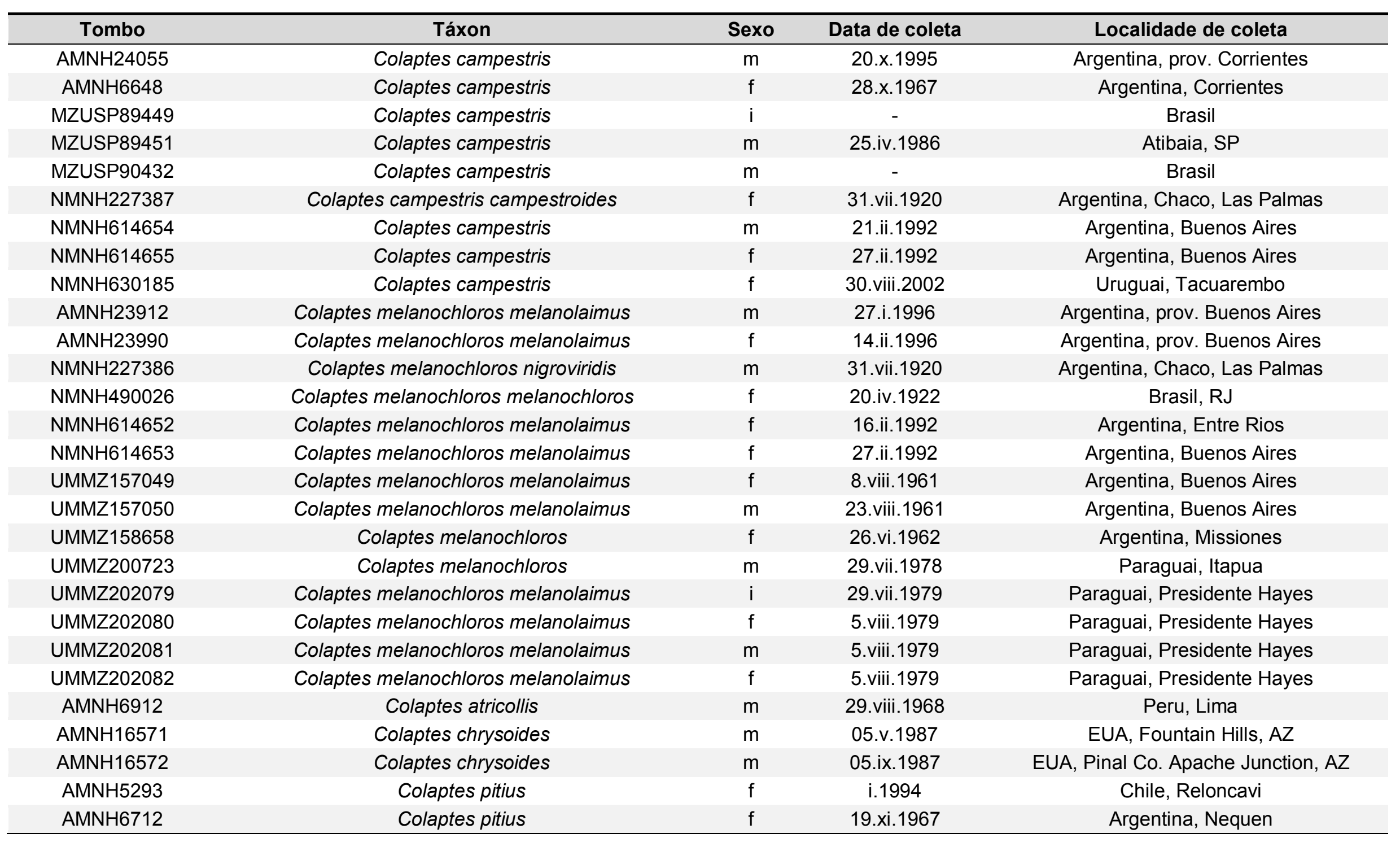




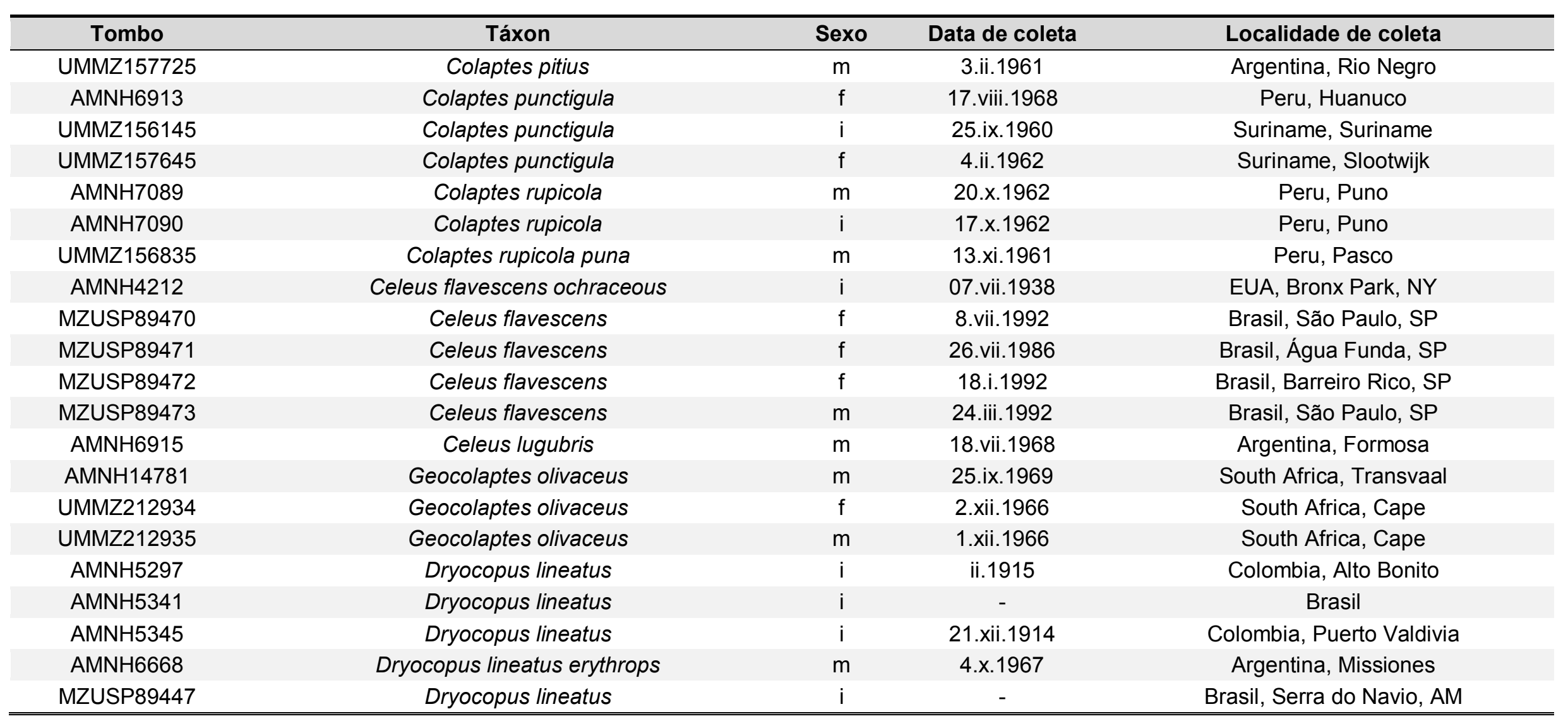

Tabela 3: Número tombo, classificação taxonômica, sexo, data e local de coleta dos espécimes estudados. Todas as informações foram retiradas das etiquetas depositadas junto com os espécimes. Os códigos da identificação de tombo seguem a nomenclatura delineada anteriormente (AMNH: American Museum of Natural History; UMMZ: University of Michigan Museum of Zoology; NMNH: National Museum of Natural History; MZUSP: Museu de Zoologia da USP). 
Anexo III

Medidas

\begin{tabular}{|c|c|c|c|c|c|c|c|c|c|c|}
\hline Tombo & dcriscran & dcriscl & dcrislas & dcrislai & darts & darti & dproca & dpcaud & dpcauas & dpcauai \\
\hline AMNH24055 & 9,36 & 5,49 & 21,29 & 17,71 & 26,13 & 23,33 & 7,86 & 18,15 & 21,21 & 24,61 \\
\hline AMNH6648 & 7,99 & 4,46 & 22,56 & 17,85 & 26,39 & 23,30 & 7,91 & 17,66 & 19,41 & 23,93 \\
\hline MZUSP89449 & 6,99 & 3,58 & 21,48 & 17,76 & 24,08 & 21,42 & 7,04 & 16,87 & 19,74 & 22,57 \\
\hline MZUSP89451 & 8,34 & 4,47 & 22,26 & 18,59 & 24,04 & 20,29 & 7,07 & 17,69 & 19,04 & 23,00 \\
\hline MZUSP90432 & 8,23 & 4,48 & 20,73 & 17,42 & 23,59 & 19,35 & 6,93 & 21,56 & 20,60 & 23,10 \\
\hline NMNH227387 & 8,88 & 4,74 & 20,77 & 16,73 & 24,24 & 20,64 & 7,42 & 16,91 & 18,58 & 22,88 \\
\hline NMNH614654 & 8,15 & 5,39 & 22,68 & 18,48 & 26,17 & 22,34 & 7,21 & 18,43 & 20,25 & 23,80 \\
\hline NMNH614655 & 7,52 & 4,41 & 23,26 & 19,37 & 24,95 & 22,80 & 7,30 & 20,13 & 18,74 & 22,41 \\
\hline NMNH630185 & 7,28 & 4,15 & 21,47 & 17,67 & 23,93 & 20,23 & 6,76 & 17,14 & 18,26 & 21,72 \\
\hline AMNH23912 & 6,34 & 3,49 & 18,44 & 15,13 & 20,97 & 18,53 & 5,99 & 15,72 & 17,58 & 20,12 \\
\hline AMNH23990 & 7,73 & 4,25 & 18,38 & 15,04 & 21,65 & 18,38 & 6,20 & 18,54 & 16,91 & 20,08 \\
\hline NMNH227386 & 7,65 & 4,11 & 18,68 & 15,71 & 22,10 & 19,23 & 6,01 & 16,61 & 17,55 & 19,91 \\
\hline NMNH490026 & 7,51 & 3,63 & 19,24 & 16,09 & 22,07 & 19,95 & 5,83 & 18,66 & 17,44 & 19,81 \\
\hline NMNH614652 & 7,14 & 4,17 & 19,19 & 15,76 & 22,80 & 18,53 & 6,05 & 17,18 & 16,91 & 20,35 \\
\hline NMNH614653 & 7,21 & 4,39 & 19,87 & 16,07 & 22,83 & 20,86 & 6,70 & 17,47 & 18,58 & 20,99 \\
\hline UMMZ157049 & 6,62 & 3,41 & 19,81 & 16,24 & 22,60 & 19,39 & 6,17 & 19,82 & 16,37 & 20,03 \\
\hline UMMZ157050 & 5,99 & 2,98 & 19,12 & 15,74 & 22,30 & 19,46 & 6,38 & 14,29 & 18,29 & 21,35 \\
\hline UMMZ158658 & 7,52 & 4,72 & 20,79 & 16,30 & 22,51 & 19,26 & 6,60 & 15,95 & 17,91 & 21,47 \\
\hline UMMZ200723 & 7,98 & 4,54 & 19,73 & 16,67 & 22,02 & 18,72 & 6,27 & 16,95 & 17,98 & 20,58 \\
\hline UMMZ202079 & 6,57 & 3,55 & 18,94 & 15,74 & 22,12 & 18,96 & 6,27 & 16,52 & 18,47 & 21,41 \\
\hline UMMZ202080 & 6,55 & 4,26 & 19,85 & 16,83 & 23,03 & 20,41 & 6,60 & 17,00 & 19,11 & 20,73 \\
\hline UMMZ202081 & 7,61 & 4,23 & 19,39 & 15,39 & 22,61 & 19,53 & 6,76 & 15,96 & 18,75 & 22,20 \\
\hline UMMZ202082 & 6,63 & 4,47 & 20,00 & 16,39 & 22,37 & 19,99 & 6,67 & 15,50 & 18,36 & 21,50 \\
\hline AMNH6912 & 6,44 & 3,32 & 16,83 & 14,77 & 20,13 & 18,16 & 5,35 & 15,48 & 17,18 & 19,38 \\
\hline
\end{tabular}




\begin{tabular}{|c|c|c|c|c|c|c|c|c|c|c|}
\hline Tombo & dcriscran & dcriscl & dcrislas & dcrislai & darts & darti & dproca & dpcaud & dpcauas & dpcauai \\
\hline AMNH16571 & 7,46 & 4,29 & 18,69 & 14,66 & 21,91 & 18,14 & 6,58 & 15,68 & 16,82 & 19,70 \\
\hline AMNH16572 & 6,49 & 3,82 & 18,66 & 14,86 & 21,45 & 17,34 & 5,87 & 12,27 & 16,53 & 19,24 \\
\hline AMNH5293 & 8,56 & 4,54 & 20,74 & 18,09 & 23,60 & 19,89 & 6,61 & 18,64 & 19,16 & 21,76 \\
\hline AMNH6712 & 7,05 & 4,17 & 21,84 & 18,63 & 23,82 & 20,65 & 6,92 & 18,75 & 19,12 & 21,18 \\
\hline UMMZ157725 & 7,25 & 3,75 & 19,73 & 15,99 & 21,82 & 18,11 & 6,66 & 14,52 & 17,34 & 20,66 \\
\hline AMNH6913 & 4,95 & 3,12 & 16,73 & 14,19 & 18,61 & 16,79 & 5,49 & 13,16 & 14,95 & 16,84 \\
\hline UMMZ156145 & 5,71 & 3,65 & 15,76 & 12,81 & 18,22 & 16,53 & 5,20 & 13,95 & 14,55 & 17,37 \\
\hline UMMZ157645 & 6,07 & 3,16 & 15,80 & 13,16 & 18,85 & 16,82 & 5,54 & 13,39 & 15,27 & 17,17 \\
\hline AMNH7089 & 7,31 & 4,07 & 21,97 & 17,53 & 24,78 & 21,46 & 7,27 & 20,38 & 18,50 & 22,46 \\
\hline AMNH7090 & 8,25 & 4,88 & 21,76 & 18,10 & 24,90 & 22,63 & 6,99 & 20,54 & 17,84 & 21,53 \\
\hline UMMZ156835 & 8,15 & 5,64 & 21,95 & 18,68 & 25,76 & 22,52 & 7,25 & 17,78 & 18,85 & 22,46 \\
\hline AMNH4212 & 7,69 & 4,00 & 19,12 & 15,11 & 23,80 & 20,71 & 6,07 & 15,65 & 19,07 & 22,06 \\
\hline MZUSP89470 & 7,55 & 4,32 & 21,62 & 17,66 & 24,63 & 19,65 & 7,16 & 17,03 & 18,01 & 21,27 \\
\hline MZUSP89471 & 7,27 & 3,79 & 21,93 & 16,50 & 26,05 & 21,63 & 7,52 & 18,00 & 19,25 & 23,62 \\
\hline MZUSP89472 & 8,48 & 4,82 & 21,39 & 16,73 & 24,97 & 20,65 & 7,49 & 17,11 & 20,11 & 22,58 \\
\hline MZUSP89473 & 7,70 & 4,79 & 21,52 & 16,75 & 24,57 & 20,53 & 7,63 & 17,74 & 20,74 & 23,45 \\
\hline AMNH6915 & 7,49 & 4,81 & 20,32 & 16,18 & 24,12 & 19,76 & 7,78 & 16,25 & 18,81 & 21,90 \\
\hline AMNH14781 & 7,59 & 3,53 & 19,18 & 17,59 & 22,14 & 19,96 & 6,13 & 16,85 & 17,68 & 19,67 \\
\hline UMMZ212934 & 7,27 & 4,18 & 20,21 & 16,38 & 23,62 & 21,57 & 6,26 & 17,66 & 17,74 & 20,21 \\
\hline UMMZ212935 & 7,71 & 4,03 & 19,68 & 16,85 & 22,85 & 19,56 & 6,27 & 19,91 & 16,48 & 18,73 \\
\hline AMNH5297 & 10,27 & 6,08 & 25,40 & 21,75 & 28,57 & 23,56 & 10,07 & 21,52 & 24,26 & 26,49 \\
\hline AMNH5341 & 8,49 & 4,92 & 20,55 & 16,54 & 25,69 & 20,40 & 7,98 & 18,51 & 20,73 & 23,39 \\
\hline AMNH5345 & 8,18 & 4,76 & 22,47 & 18,24 & 28,69 & 24,60 & 8,52 & 20,19 & 22,33 & 26,49 \\
\hline AMNH6668 & 8,09 & 4,25 & 22,15 & 18,94 & 28,88 & 22,49 & 9,55 & 20,85 & 23,88 & 28,15 \\
\hline MZUSP89447 & 8,21 & 4,18 & 22,77 & 19,45 & 27,57 & 23,76 & 9,04 & 22,64 & 24,61 & 26,66 \\
\hline
\end{tabular}

Tabela 4: Medidas referentes à pelve, primeira parte. Todas as medidas estão em milímetros. Traços representam medidas não disponíveis no momento do estudo (na maior parte dos casos devido a danos do espécime). Abreviações das nomenclaturas seguem o padrão delineado na seção 3.2.1. 


\begin{tabular}{|c|c|c|c|c|c|c|c|c|c|c|c|}
\hline Tombo & dpvcaud & dpvcpc & dpvcai & mdcris & aecran & devcris & cpelv & dinta & eart & daintpc & diama \\
\hline AMNH24055 & 24,82 & 14,43 & 28,33 & 5,12 & 8,58 & 9,19 & 26,46 & 15,76 & 4,03 & 23,74 & 3,46 \\
\hline AMNH6648 & - & 13,93 & 26,36 & 4,35 & 7,84 & 7,64 & 25,91 & 16,83 & 3,67 & 22,08 & 3,16 \\
\hline MZUSP89449 & 26,43 & 12,01 & 23,92 & 3,87 & 7,48 & 7,30 & 29,19 & 14,23 & 3,29 & 21,62 & 3,18 \\
\hline MZUSP89451 & 26,68 & 12,76 & 24,59 & 3,72 & - & - & 30,02 & 13,86 & 3,54 & 22,42 & 2,93 \\
\hline MZUSP90432 & 29,46 & 10,56 & 23,66 & 3,64 & 8,27 & 9,23 & 26,48 & 13,38 & 3,67 & 23,24 & 2,97 \\
\hline NMNH227387 & 27,47 & 13,85 & 25,31 & 4,67 & 7,54 & 8,04 & 30,51 & 14,76 & 3,44 & 22,71 & 3,16 \\
\hline NMNH614654 & 28,96 & 14,16 & 26,87 & 4,38 & - & - & 28,21 & 14,30 & 4,45 & 22,98 & 3,40 \\
\hline NMNH614655 & 29,90 & 12,95 & 25,80 & 3,51 & 7,45 & 8,21 & 28,40 & 15,27 & 3,92 & 22,57 & 3,93 \\
\hline NMNH630185 & 23,69 & 13,04 & 24,20 & 4,21 & - & - & 25,36 & 14,47 & 3,74 & 20,92 & 3,16 \\
\hline AMNH23912 & 20,31 & 10,37 & 22,36 & 3,41 & 6,38 & 6,85 & 23,24 & 12,61 & 3,07 & 19,72 & 2,84 \\
\hline AMNH23990 & 25,71 & 11,23 & 22,28 & 5,18 & 6,13 & 6,95 & 22,50 & 12,78 & 3,27 & 20,01 & 2,81 \\
\hline NMNH227386 & 24,68 & 11,43 & 20,66 & 3,75 & 6,96 & 6,92 & 24,55 & 12,89 & 3,40 & 19,82 & 3,08 \\
\hline NMNH490026 & - & - & - & 3,57 & 6,47 & 7,38 & 24,75 & - & 4,11 & 20,62 & 2,90 \\
\hline NMNH614652 & 24,82 & 12,13 & 23,26 & 3,78 & 7,15 & 7,16 & 23,20 & 12,13 & 3,79 & 20,69 & 2,90 \\
\hline NMNH614653 & 26,68 & 11,92 & 22,29 & 3,43 & 6,74 & 7,03 & 24,18 & 13,55 & 3,41 & 21,06 & 2,96 \\
\hline UMMZ157049 & 24,91 & 12,45 & 22,29 & 3,56 & 7,34 & 7,28 & 26,21 & 12,04 & 3,73 & 19,96 & 2,99 \\
\hline UMMZ157050 & - & 12,83 & 23,45 & 3,72 & - & - & - & 14,82 & 3,88 & 20,05 & 2,80 \\
\hline UMMZ158658 & - & - & - & 3,86 & 7,66 & 8,20 & 26,92 & 13,21 & 3,63 & 21,37 & 2,77 \\
\hline UMMZ200723 & 25,12 & 11,54 & 20,61 & 3,99 & 7,14 & - & 25,65 & 12,94 & 3,35 & 19,93 & 2,96 \\
\hline UMMZ202079 & 24,75 & 11,02 & 22,70 & 3,38 & 7,51 & 7,13 & 26,06 & 12,76 & 3,47 & 21,57 & 2,92 \\
\hline UMMZ202080 & 25,22 & 11,55 & 21,73 & 3,43 & 7,67 & 7,05 & 24,98 & 13,39 & 3,95 & 21,72 & 2,79 \\
\hline UMMZ202081 & 26,76 & 12,32 & 23,63 & 3,27 & - & - & 27,96 & 12,93 & 3,60 & 21,94 & 2,98 \\
\hline UMMZ202082 & 27,35 & 12,00 & 22,06 & 2,98 & - & - & 27,72 & 13,49 & 3,55 & 21,14 & 2,92 \\
\hline AMNH6912 & - & 12,27 & 21,99 & 4,05 & 6,32 & 6,65 & 21,66 & 13,20 & 3,23 & 19,18 & 2,49 \\
\hline AMNH16571 & 24,62 & 12,49 & 21,62 & 3,79 & 6,80 & 7,22 & 22,63 & 12,61 & 3,68 & 18,83 & 2,78 \\
\hline AMNH16572 & 24,19 & 12,05 & 22,73 & 2,77 & 6,72 & 7,02 & 21,93 & 12,48 & 2,70 & 19,01 & 2,79 \\
\hline
\end{tabular}




\begin{tabular}{|c|c|c|c|c|c|c|c|c|c|c|c|}
\hline Tombo & dpvcaud & dpvcpc & dpvcai & mdcris & aecran & devcris & cpelv & dinta & eart & daintpc & diama \\
\hline AMNH5293 & - & 13,01 & 24,62 & 4,36 & 7,77 & 7,97 & 28,54 & 14,80 & 3,58 & 21,88 & 3,14 \\
\hline AMNH6712 & 28,51 & 12,75 & 24,48 & 3,37 & 7,59 & 7,30 & 29,46 & 14,29 & 4,08 & 22,10 & 2,87 \\
\hline UMMZ157725 & 24,64 & 12,18 & 22,80 & 3,85 & 7,32 & 6,97 & 28,61 & 12,66 & 3,77 & 20,34 & 2,86 \\
\hline AMNH6913 & 22,04 & 10,03 & 17,72 & 3,72 & 5,34 & 5,55 & 20,01 & 11,60 & 3,38 & 17,18 & 2,70 \\
\hline UMMZ156145 & 23,57 & 10,02 & 18,62 & 2,90 & 5,54 & 6,03 & 19,85 & 12,14 & 2,62 & 17,10 & 2,11 \\
\hline UMMZ157645 & 24,29 & 9,01 & 17,97 & 2,88 & 5,77 & 5,79 & 22,89 & 12,05 & 3,09 & 16,74 & 2,61 \\
\hline AMNH7089 & 30,22 & 14,42 & 25,53 & 2,43 & 7,77 & 8,20 & 25,34 & 15,13 & 3,71 & 22,41 & 3,51 \\
\hline AMNH7090 & 35,58 & 12,59 & 23,62 & 3,39 & 7,40 & 7,85 & 25,97 & 15,85 & 4,34 & 21,69 & 3,25 \\
\hline UMMZ156835 & 27,51 & 14,39 & 27,58 & 4,15 & 7,66 & 8,51 & 25,78 & 16,21 & 4,29 & 21,36 & 3,51 \\
\hline AMNH4212 & 26,45 & 12,46 & 22,23 & 3,97 & 7,21 & 7,07 & 23,35 & 14,98 & 2,94 & 20,64 & 3,39 \\
\hline MZUSP89470 & 24,74 & 12,56 & 24,42 & 4,52 & 8,72 & 9,00 & 27,69 & 12,40 & 4,04 & 20,26 & 3,10 \\
\hline MZUSP89471 & 32,05 & 13,88 & 25,47 & 4,32 & 8,48 & 8,05 & 25,76 & 15,54 & 4,10 & 21,80 & 3,14 \\
\hline MZUSP89472 & - & 13,10 & 23,76 & 4,77 & 8,69 & 8,35 & 29,20 & 13,07 & 4,03 & 22,01 & 3,55 \\
\hline MZUSP89473 & 29,46 & 14,23 & 22,80 & 5,07 & 7,91 & 8,99 & 28,18 & 13,47 & 3,86 & 21,85 & 3,30 \\
\hline AMNH6915 & 25,88 & 13,91 & 25,74 & 4,43 & 7,95 & 7,03 & 26,47 & 13,26 & 3,76 & 21,26 & 2,94 \\
\hline AMNH14781 & 26,36 & 10,99 & 20,76 & 4,55 & 8,57 & 9,40 & 21,48 & 14,35 & 2,98 & 19,16 & 2,91 \\
\hline UMMZ212934 & 27,96 & 11,37 & 24,72 & 5,09 & - & - & 22,26 & 14,17 & 3,67 & 20,41 & 2,80 \\
\hline UMMZ212935 & 28,87 & 10,87 & 21,05 & 4,36 & 6,69 & 7,25 & 24,88 & 12,71 & 3,80 & 19,69 & 3,13 \\
\hline AMNH5297 & 24,42 & 15,72 & 28,91 & 2,96 & 10,13 & 11,39 & 28,73 & 13,78 & 5,26 & 27,82 & 3,94 \\
\hline AMNH5341 & 25,10 & 13,55 & 26,29 & 4,02 & - & - & 27,39 & 14,93 & 4,21 & 23,22 & 3,23 \\
\hline AMNH5345 & 30,33 & 15,62 & 29,99 & 3,88 & 8,90 & 7,92 & 29,65 & 16,91 & 4,88 & 26,19 & 3,59 \\
\hline AMNH6668 & 29,47 & 13,86 & 29,49 & 4,09 & 8,63 & 8,34 & 29,21 & 15,17 & 4,77 & 27,48 & 3,76 \\
\hline MZUSP89447 & 26,23 & 12,08 & 27,75 & 4,09 & - & - & 25,61 & 15,65 & 4,84 & 25,47 & - \\
\hline
\end{tabular}

Tabela 5: Medidas referentes à pelve, segunda parte. Todas as medidas estão em milímetros. Traços representam medidas não disponíveis no momento do estudo (na maior parte dos casos devido a danos do espécime). Abreviações das nomenclaturas seguem o padrão delineado na seção 3.2.1. 


\begin{tabular}{|c|c|c|c|c|c|c|c|c|c|c|c|c|c|c|c|c|}
\hline Tombo & acran & Icran & pcran & amaxs & Imaxs & cmaxs & dcondp & dppteri & cjug & dintn & Inar & cnar & dapm & dpmed & cmaxi & lamaxi \\
\hline AMNH24055 & 9,75 & 3,52 & 33,16 & 5,89 & 12,41 & 28,83 & 12,34 & 3,12 & 18,82 & 2,65 & 3,52 & 9,86 & 23,59 & 31,33 & 52,75 & 6,09 \\
\hline AMNH6648 & 9,99 & 4,14 & 2,44 & 5,22 & 2,72 & 30,05 & 12,32 & & 0,50 & 2,54 & 3,82 & 10,43 & 24,12 & 29,43 & 52,97 & 5,94 \\
\hline MZUSP89449 & 19,57 & 2,84 & 29,84 & 4,53 & 1,19 & - & 95 & ,38 & 9,72 & 2,68 & 3,13 & 8,39 & - & & - & 5,17 \\
\hline MZUSP89451 & 19,74 & 3,26 & 31,67 & 5,24 & 2,56 & - & 12,19 & 4,13 & 18,44 & 2,85 & 2,50 & 7,61 & - & - & - & 5,92 \\
\hline MZUSP90432 & 19,58 & 22,39 & 29,83 & 4,89 & 11,02 & 26,18 & 12,25 & 3,30 & 20,43 & 2,70 & 3,30 & 9,68 & - & - & - & 5,87 \\
\hline NMNH227387 & 19,51 & 22,82 & 30,72 & 5,20 & 2,19 & 28,72 & 11,61 & 3,34 & 7,92 & 2,70 & 3,51 & 9,44 & 22,54 & 27,83 & 49,70 & 5,98 \\
\hline NMNH614654 & 19,93 & 24,04 & 31,87 & 5,83 & 12,72 & 31,59 & 11,49 & 4,04 & 19,03 & 2,57 & 3,91 & 10,50 & 23,86 & 29,18 & 52,34 & 6,48 \\
\hline NMNH614655 & 18,91 & 22,73 & 30,51 & 4,78 & 12,83 & 29,38 & 12,52 & 2,84 & 9,47 & 2,78 & 4,02 & 9,44 & 2,89 & ,83 & 48,26 & 5,81 \\
\hline NMNH630185 & 19,01 & 23,11 & 30,54 & 5,29 & 11,49 & 28,91 & 11,84 & 3,82 & 18,94 & 2,91 & 2,99 & 8,97 & 23,58 & 27,78 & 50,72 & 6,25 \\
\hline AMNH & 17,97 &, 09 & 27,48 & 4,89 & & 5,64 & & & 79 & 60 & 3,02 & 8,30 & ,48 & & 3,67 & 5,44 \\
\hline AMNH23990 & 17,92 & 21,38 & 27,94 & 3,97 & 10,46 & 26,90 & 10,36 & 4,35 & 19,05 & 2,45 & 3,05 & 8,83 & 23,72 & 24,32 & 47,22 & 5,75 \\
\hline NMNH227386 & 18,13 & 21,21 & 28,17 & 4,64 & & 25,41 & & & 6,46 & 39 & 3,08 & 7,62 & ,29 & & 4,63 & 50 \\
\hline NMNH490026 & 18,90 & 21,73 & 28,23 & 4,78 & 11,70 & 23,53 & 11,27 & 2,59 & 16,22 & 2,84 & 3,13 & 7,03 & 20,29 & 22,84 & 42,35 & 5,48 \\
\hline NMNH614652 & 18,38 & 1,55 & 27,34 & 4,63 & 11,20 & 25,12 & 10,35 & 6 & 7,15 & 2,20 & 3,05 & 8,25 & 22,14 & 2,19 & 43,96 & 5,27 \\
\hline NMNH614653 & 18,49 & 20,86 & 29,13 & 4,80 & 11,90 & 24,91 & 11,27 & 2,88 & 18,12 & 2,64 & 3,27 & 8,22 & 22,79 & 22,44 & 44,92 & 5,49 \\
\hline UMMZ157049 & 17,89 & 21,46 & 27,53 & 5,09 & 10,85 & 23,94 & 10,61 & 75 & 16,85 & 2,33 & 2,91 & 7,77 & 19,67 & 23,64 & 44,57 & 5,35 \\
\hline UMMZ157050 & 18,01 & 21,30 & 27,39 & 4,93 & 10,14 & 25,42 & 10,42 & 3,84 & 17,09 & 2,39 & 3,36 & 8,32 & 22,98 & 22,58 & 45,06 & 5,31 \\
\hline UMMZ158658 & 19,36 & 22,30 & 28,67 & 4,45 & 12,01 & 24,43 & 10,60 & - & 6,46 & 3,00 & 2,90 & 7,66 & - & - & - & - \\
\hline UMMZ200723 & 19,33 & 21,97 & 29,17 & 5,01 & 11,95 & 26,16 & 10,66 & 3,04 & 17,50 & 2,94 & 4,65 & 7,94 & - & - & - & - \\
\hline UMMZ202079 & 18,65 & 21,27 & 28,53 & 4,53 & 11,40 & 28,81 & 10,43 & 3,4 & 18,44 & 2,41 & 3,03 & 9,24 & 20,68 & 27,00 & 47,04 & 5,33 \\
\hline UMMZ202080 & 19,13 & 22,08 & 29,20 & 4,87 & 11,70 & 27,43 & 11,37 & 3,09 & 18,26 & 2,67 & 2,88 & 8,61 & 21,14 & 27,08 & 47,34 & 5,61 \\
\hline UMMZ202081 & 18,76 & 21,67 & 29,18 & 4,76 & 11,46 & 28,61 & 11,20 & 3,38 & 17,34 & 2,73 & 2,98 & 8,79 & 20,88 & 26,63 & 47,10 & 5,53 \\
\hline UMMZ202082 & 18,23 & 20,59 & 28,25 & 4,81 & 11,08 & 25,61 & 10,41 & 3,24 & 16,83 & 2,61 & 3,02 & 8,47 & 20,65 & 24,96 & 45,15 & 5,38 \\
\hline AMNH6912 & 18,22 & 22,33 & 27,62 & 5,23 & 10,89 & 22,29 & 11,18 & 2,48 & 17,65 & 2,77 & 2,91 & 8,21 & 19,82 & 25,38 & 44,62 & 5,27 \\
\hline AMNH16571 & 17,90 & 22,47 & 28,97 & 4,55 & 10,89 & 27,10 & 12,31 & 1,63 & 15,76 & 2,08 & 3,25 & 9,06 & 20,54 & 28,45 & 45,17 & 5,76 \\
\hline AMNH16572 & 18,45 & 22,39 & 28,91 & 4,71 & 10,84 & 30,53 & 11,64 & 2,83 & 17,62 & 2,13 & 3,43 & 10,08 & 20,79 & 27,12 & 45,65 & 5,76 \\
\hline
\end{tabular}




\begin{tabular}{|c|c|c|c|c|c|c|c|c|c|c|c|c|c|c|c|c|}
\hline Tombo & acran & Icran & pcran & amaxs & Imaxs & cmaxs & dcondp & dppteri & cjug & dintn & Inar & cnar & dapm & dpmed & cmaxi & lamaxi \\
\hline AMNH5293 & - & - & - & - & - & - & - & - & - & - & - & - & - & - & - & - \\
\hline AMNH6712 & 19,93 & 23,59 & 31,73 & 5,16 & 12,95 & - & - & 2,89 & 19,09 & 2,82 & 3,85 & 10,71 & 24,44 & 32,24 & 55,51 & 6,16 \\
\hline UMMZ157725 & 19,74 & 23,56 & 29,85 & 4,77 & 10,89 & 31,71 & 12,29 & 2,98 & 18,41 & 2,17 & 3,59 & 10,22 & 23,12 & 29,50 & 52,18 & 5,43 \\
\hline AMNH6913 & 16,34 & 19,43 & 24,84 & 3,88 & 9,58 & 19,97 & - & - & 15,06 & 2,07 & 2,63 & 6,14 & 17,90 & 17,84 & 35,61 & 4,87 \\
\hline UMMZ156145 & 15,91 & 19,19 & 24,13 & 3,72 & 9,99 & 17,41 & 9,09 & 3,73 & 15,10 & 2,39 & 2,50 & 5,93 & 18,43 & 15,99 & 33,91 & 4,61 \\
\hline UMMZ157645 & 15,82 & 17,88 & 23,25 & 3,27 & 9,82 & 17,57 & 9,29 & - & 14,79 & 2,32 & 2,51 & 5,74 & 16,94 & 17,18 & 33,57 & 4,74 \\
\hline AMNH7089 & 19,87 & 23,77 & 29,90 & 6,11 & 12,39 & 33,49 & 12,16 & 2,25 & 20,77 & 3,89 & 3,65 & 9,53 & 25,36 & 31,49 & 56,56 & 5,73 \\
\hline AMNH7090 & 19,23 & 24,26 & 29,86 & 5,61 & 12,50 & 34,96 & 12,01 & 2,56 & 19,97 & 3,65 & 3,41 & 9,49 & - & - & - & - \\
\hline UMMZ156835 & 20,27 & 24,34 & 31,55 & 6,21 & 13,10 & 34,98 & 13,28 & 2,89 & 19,43 & 4,05 & 3,75 & 9,67 & - & - & - & - \\
\hline AMNH4212 & 17,94 & 20,75 & 26,93 & 4,22 & 10,81 & 18,95 & 10,33 & 2,65 & 14,38 & 2,79 & 2,65 & 6,06 & 18,75 & 19,37 & 37,94 & 4,92 \\
\hline MZUSP89470 & 18,97 & 22,70 & 28,50 & 4,88 & 12,97 & 23,24 & 10,97 & 2,60 & 16,13 & 3,51 & 2,72 & 7,62 & 21,75 & 22,10 & 42,47 & 5,83 \\
\hline MZUSP89471 & 20,28 & 23,43 & 30,05 & 5,12 & 13,93 & 36,28 & 11,85 & 2,60 & 19,07 & 4,27 & 2,72 & 7,50 & 23,12 & 31,92 & 52,93 & 5,86 \\
\hline MZUSP89472 & 19,72 & 22,45 & 29,69 & 5,70 & 12,63 & 33,00 & 11,74 & 2,45 & 17,19 & 3,84 & 2,90 & 7,14 & - & - & 49,62 & 6,22 \\
\hline MZUSP89473 & 19,94 & 23,32 & 30,47 & 5,94 & 12,65 & - & 11,06 & 2,67 & 16,64 & 4,11 & 2,44 & 8,18 & 22,73 & - & - & 6,14 \\
\hline AMNH6915 & 18,25 & 22,21 & 26,66 & 5,05 & 12,30 & 22,95 & 11,25 & 2,97 & 15,50 & 3,10 & 2,96 & 8,51 & - & - & - & - \\
\hline AMNH14781 & 18,75 & 22,02 & 29,72 & 4,57 & 11,20 & 27,93 & 11,72 & 2,61 & 18,12 & 2,16 & 3,44 & 10,71 & 21,93 & 28,45 & 49,61 & 5,39 \\
\hline UMMZ212934 & 17,97 & 21,43 & 28,99 & 5,24 & 11,40 & 30,90 & 12,01 & 3,45 & 15,23 & 2,36 & - & - & 22,92 & 29,19 & 51,19 & 5,42 \\
\hline UMMZ212935 & 18,44 & 21,50 & 30,23 & 4,69 & 11,09 & 29,55 & 12,05 & 3,18 & 18,72 & 2,21 & 3,50 & 10,43 & 22,29 & 26,37 & 48,16 & 5,11 \\
\hline AMNH5297 & - & - & - & - & - & - & - & - & 19,83 & 7,36 & 3,26 & 9,28 & 21,95 & 35,81 & 56,12 & 7,71 \\
\hline AMNH5341 & 21,24 & 23,63 & 29,77 & 5,22 & 13,98 & 29,58 & 12,30 & 2,92 & 16,57 & 4,40 & 2,99 & 9,05 & 21,50 & 28,44 & 49,20 & 6,15 \\
\hline AMNH5345 & 23,21 & 24,55 & 32,52 & 5,54 & 15,42 & 31,39 & 11,99 & - & 18,39 & 5,13 & 3,18 & 9,24 & 21,77 & 30,76 & 51,89 & 6,60 \\
\hline AMNH6668 & 22,92 & 24,65 & 32,57 & 5,49 & 15,21 & 34,84 & 12,70 & 3,45 & 17,73 & 5,44 & 3,35 & 9,77 & 26,05 & 26,59 & 51,84 & 6,29 \\
\hline MZUSP89447 & 22,85 & 25,45 & 32,34 & 6,14 & 14,47 & 33,00 & 11,69 & 4,47 & 16,02 & 5,45 & 3,11 & 9,99 & - & - & - & 5,93 \\
\hline
\end{tabular}

Tabela 6: Medidas referentes ao crânio e maxilas. Todas as medidas estão em milímetros. Traços representam medidas não disponíveis no momento do estudo (na maior parte dos casos devido a danos do espécime). Abreviações das nomenclaturas seguem o padrão delineado na seção 3.2.1. 


\begin{tabular}{|c|c|c|c|c|c|c|c|c|c|c|}
\hline Tombo & aqui & cqui & Iproxum & acris & ddiag & eum & cum & culn & crad & ccora \\
\hline AMNH24055 & 16,82 & 40,17 & 13,73 & 15,76 & 16,16 & 4,25 & 45,20 & 52,63 & 47,47 & 33,92 \\
\hline AMNH6648 & 17,13 & 39,77 & 12,82 & 13,58 & 14,98 & 4,40 & 44,09 & 51,43 & 45,63 & 35,04 \\
\hline MZUSP89449 & 14,74 & 36,08 & 13,88 & 11,96 & 15,14 & 3,72 & 43,02 & 50,03 & 45,43 & 32,68 \\
\hline MZUSP89451 & 16,38 & 40,77 & 13,06 & 14,45 & 15,33 & 4,09 & 44,22 & 51,74 & 46,67 & 33,68 \\
\hline MZUSP90432 & - & - & 13,33 & 13,57 & 14,23 & 3,91 & 41,48 & 48,34 & 43,38 & 32,49 \\
\hline NMNH227387 & 15,46 & 34,97 & 12,47 & 13,60 & 14,24 & 3,74 & 41,75 & 49,38 & 44,57 & 32,79 \\
\hline NMNH614654 & 16,57 & 38,39 & 12,88 & 13,54 & 15,07 & 4,24 & 44,03 & 52,16 & 46,42 & 34,30 \\
\hline NMNH614655 & 16,37 & 38,33 & 12,57 & 14,32 & 14,72 & 4,19 & 44,31 & 50,97 & 45,59 & 34,39 \\
\hline NMNH630185 & 15,38 & 36,42 & 12,53 & 12,44 & 14,28 & 3,79 & 42,00 & 46,13 & 43,16 & 32,86 \\
\hline AMNH23912 & 12,50 & 31,55 & 10,29 & 12,43 & 11,69 & 3,34 & 34,79 & 40,27 & 37,51 & 27,32 \\
\hline AMNH23990 & 13,24 & 31,74 & 10,77 & 11,65 & 11,70 & 3,44 & 36,72 & 43,12 & 38,91 & 28,92 \\
\hline NMNH227386 & 13,58 & 33,44 & 10,19 & 12,58 & 12,97 & 3,52 & 36,89 & 43,77 & 40,12 & 29,95 \\
\hline NMNH490026 & 15,15 & 31,54 & 10,75 & 12,69 & 12,57 & 3,64 & 38,49 & 44,02 & 39,55 & 30,10 \\
\hline NMNH614652 & 14,20 & 32,92 & 11,20 & 12,11 & 12,82 & 3,40 & 37,51 & 42,99 & 38,80 & 28,59 \\
\hline NMNH614653 & 15,95 & 34,55 & 10,95 & 12,64 & 13,39 & 3,52 & 38,92 & 46,83 & 41,06 & 30,24 \\
\hline UMMZ157049 & 14,51 & 30,69 & 11,27 & 12,43 & 12,83 & 3,67 & 37,83 & 44,22 & 39,45 & 28,81 \\
\hline UMMZ157050 & 14,32 & 32,87 & 10,79 & 12,63 & 13,38 & 4,66 & 38,20 & 44,02 & 39,59 & 29,77 \\
\hline UMMZ158658 & 16,53 & 35,26 & 12,20 & 11,40 & 13,54 & 4,01 & 38,76 & 44,54 & 39,57 & 30,10 \\
\hline UMMZ200723 & 14,89 & 34,82 & 11,63 & 11,88 & 13,34 & 3,91 & 39,34 & 46,87 & - & 31,95 \\
\hline UMMZ202079 & 13,70 & 33,67 & 10,68 & 12,62 & 13,17 & 3,32 & 37,94 & 44,31 & 39,08 & 30,38 \\
\hline UMMZ202080 & 14,73 & 35,90 & 11,55 & 12,54 & 12,60 & 3,64 & 38,43 & 45,38 & 40,52 & 30,29 \\
\hline UMMZ202081 & 14,69 & 36,48 & 11,31 & 12,02 & 13,24 & 3,54 & 39,97 & 47,95 & 43,03 & 31,90 \\
\hline UMMZ202082 & 14,57 & 34,36 & 10,47 & 12,18 & 13,15 & 3,61 & 38,55 & 45,07 & 40,58 & 29,73 \\
\hline AMNH6912 & 9,85 & 26,69 & 9,28 & 10,10 & 11,58 & 3,13 & 32,97 & 35,58 & 31,86 & 26,69 \\
\hline AMNH16571 & 15,03 & 31,86 & 11,73 & 12,28 & 13,12 & 3,42 & 38,43 & 45,66 & 40,49 & 30,42 \\
\hline AMNH16572 & 13,85 & 31,16 & 10,92 & 12,86 & 13,04 & 3,51 & 37,15 & 45,37 & 39,95 & 28,95 \\
\hline
\end{tabular}




\begin{tabular}{|c|c|c|c|c|c|c|c|c|c|c|}
\hline Tombo & aqui & cqui & Iproxum & acris & ddiag & eum & cum & culn & crad & ccora \\
\hline AMNH5293 & 18,44 & 38,00 & - & - & - & - & - & - & - & 33,86 \\
\hline AMNH6712 & 17,67 & 37,00 & 12,31 & 12,80 & 14,70 & 4,13 & 41,64 & 47,62 & 42,73 & 34,18 \\
\hline UMMZ157725 & 15,67 & 35,34 & 12,14 & 12,67 & 13,39 & 3,63 & 40,49 & 46,45 & 41,45 & 32,06 \\
\hline AMNH6913 & 11,65 & 25,79 & 9,00 & 9,81 & 9,49 & 2,83 & 30,44 & 35,65 & 32,17 & 24,86 \\
\hline UMMZ156145 & 10,35 & 25,14 & 7,90 & 8,01 & 8,83 & 2,54 & 27,86 & 32,31 & 28,88 & 21,86 \\
\hline UMMZ157645 & 9,77 & 25,60 & 8,42 & 8,02 & 9,55 & 2,88 & 29,27 & 34,17 & 30,37 & 23,85 \\
\hline AMNH7089 & 13,95 & 31,35 & 13,16 & 14,79 & 15,12 & 3,63 & 41,54 & 46,85 & 42,23 & 33,80 \\
\hline AMNH7090 & 15,14 & 32,86 & 12,45 & 14,28 & 14,66 & 3,69 & 41,86 & 48,27 & 43,44 & 32,88 \\
\hline UMMZ156835 & 15,04 & 34,13 & 12,76 & 14,33 & 15,63 & 3,92 & 43,46 & 49,75 & 44,38 & 33,81 \\
\hline AMNH4212 & 11,51 & 27,19 & 10,18 & 11,95 & 12,03 & 3,37 & 34,79 & 40,74 & 35,53 & 26,66 \\
\hline MZUSP89470 & 12,01 & 30,02 & 11,53 & 11,54 & 13,13 & 3,53 & 39,04 & 43,86 & 39,38 & 28,27 \\
\hline MZUSP89471 & 14,21 & 32,54 & 12,52 & 13,37 & 14,59 & 4,03 & 40,45 & 46,21 & 39,99 & 31,58 \\
\hline MZUSP89472 & 12,09 & 31,64 & 11,70 & 12,48 & 13,72 & 3,85 & 39,78 & 45,12 & 40,45 & 29,34 \\
\hline MZUSP89473 & 13,74 & 33,21 & 11,26 & 12,95 & 14,26 & 3,88 & 40,45 & 43,97 & 40,82 & 30,90 \\
\hline AMNH6915 & 13,16 & 32,09 & 10,94 & 12,71 & 13,47 & 3,70 & 38,85 & 44,50 & 39,63 & 28,82 \\
\hline AMNH14781 & 13,92 & 32,27 & 10,10 & 10,49 & 18,16 & 10,91 & 36,13 & 41,57 & 35,24 & 28,77 \\
\hline UMMZ212934 & 14,56 & 31,85 & 11,05 & 9,58 & 11,96 & 3,12 & 36,86 & 42,37 & 37,74 & 30,78 \\
\hline UMMZ212935 & 14,41 & 32,84 & 11,09 & 10,96 & 12,67 & 3,18 & 35,71 & 40,61 & 35,40 & 29,86 \\
\hline AMNH5297 & 16,43 & 39,81 & 14,03 & 15,10 & 16,48 & 4,73 & 47,63 & 53,89 & 49,21 & 37,41 \\
\hline AMNH5341 & 15,58 & 35,00 & 12,45 & 14,06 & 14,94 & 3,91 & 42,07 & 49,53 & 42,97 & 31,58 \\
\hline AMNH5345 & 18,16 & 39,57 & 13,76 & 15,82 & 16,14 & 4,43 & 47,53 & 55,83 & 49,78 & 35,46 \\
\hline AMNH6668 & 19,28 & 40,32 & 14,40 & 16,94 & 17,50 & 4,58 & 51,83 & 61,24 & 55,04 & 37,09 \\
\hline MZUSP89447 & 17,16 & 38,61 & 15,03 & 17,15 & 16,98 & 4,42 & 47,88 & 57,17 & 51,37 & 36,59 \\
\hline
\end{tabular}

Tabela 7: Medidas referentes à quilha, cintura escapular e membros anteriores. Todas as medidas estão em milímetros. Traços representam medidas não disponíveis no momento do estudo (na maior parte dos casos devido a danos do espécime). Abreviações das nomenclaturas seguem o padrão delineado na seção 3.2.1. 


\begin{tabular}{|c|c|c|c|c|c|c|c|c|c|c|c|c|}
\hline Tombo & lace & aace & Itroc & cfem & Iptbt & etbt & ctbt & apig & cpig & Ipig & Iproc & cproc \\
\hline AMNH24055 & 7,06 & 2,99 & 6,79 & 33,91 & 8,58 & 2,36 & 50,60 & 7,65 & 18,92 & 11,80 & 3,25 & 13,82 \\
\hline AMNH6648 & 6,88 & 2,80 & 7,16 & 34,98 & 8,83 & 6,08 & 50,42 & 7,14 & 18,95 & 10,98 & 3,12 & 13,07 \\
\hline MZUSP89449 & 6,84 & 3,03 & 6,91 & 33,42 & - & 2,69 & 48,04 & 6,13 & 17,69 & 10,16 & 3,50 & 10,22 \\
\hline MZUSP89451 & 7,15 & 3,14 & 6,71 & 34,16 & 8,04 & 2,69 & 48,75 & - & - & - & - & - \\
\hline MZUSP90432 & 6,75 & 2,74 & 7,03 & 31,92 & 8,27 & 2,50 & 46,61 & 6,63 & 15,83 & 8,41 & 2,48 & 11,40 \\
\hline NMNH227387 & 6,64 & 2,76 & 6,90 & 33,48 & 8,46 & 5,31 & 50,12 & - & - & - & - & - \\
\hline NMNH614654 & 7,14 & 2,95 & 7,20 & 33,88 & 8,84 & 6,14 & 49,91 & 7,32 & 18,56 & 11,76 & 2,88 & 12,69 \\
\hline NMNH614655 & 7,39 & 2,92 & 7,11 & 34,26 & 8,57 & 5,30 & 50,33 & - & - & - & - & - \\
\hline NMNH630185 & 6,53 & 2,79 & 6,89 & 33,10 & 8,47 & 5,55 & 47,16 & 6,59 & 16,93 & 10,09 & 2,52 & 11,40 \\
\hline AMNH23912 & 5,58 & 2,38 & 5,41 & 27,58 & 6,80 & 5,30 & 41,03 & 5,89 & 13,37 & 9,26 & 2,21 & 10,63 \\
\hline AMNH23990 & 5,93 & 2,60 & 6,09 & 28,25 & 6,87 & 4,66 & 42,72 & 6,59 & 15,87 & 9,91 & 1,89 & 10,98 \\
\hline NMNH227386 & 6,25 & 2,34 & 6,78 & 28,43 & 7,33 & 5,07 & 41,77 & 6,24 & 15,71 & 9,70 & 2,62 & 10,86 \\
\hline NMNH490026 & 6,30 & 2,45 & 6,56 & 29,96 & 7,45 & 4,73 & 42,41 & - & - & - & - & - \\
\hline NMNH614652 & - & 2,31 & 5,85 & 29,68 & 7,80 & 4,56 & 43,31 & 6,23 & 15,03 & 9,68 & 1,55 & 9,27 \\
\hline NMNH614653 & 6,01 & 2,45 & 6,35 & 29,96 & 7,41 & 4,56 & 44,41 & 5,81 & 16,77 & 10,66 & 2,05 & 10,46 \\
\hline UMMZ157049 & 6,60 & 2,68 & 6,27 & 29,30 & 7,86 & 4,51 & 43,22 & 6,12 & 16,09 & 9,75 & 2,36 & 11,01 \\
\hline UMMZ157050 & 6,08 & 2,60 & 6,03 & 28,65 & 7,80 & 5,12 & 42,61 & - & - & - & - & - \\
\hline UMMZ158658 & 6,64 & 2,64 & 6,53 & 28,73 & 8,12 & 5,68 & 41,48 & 5,74 & 17,24 & 11,00 & - & - \\
\hline UMMZ200723 & 6,14 & 2,26 & 6,33 & 30,06 & 7,48 & 5,49 & 44,14 & 6,53 & 16,35 & 10,93 & 2,25 & 11,29 \\
\hline UMMZ202079 & 6,08 & 2,50 & 6,12 & 28,91 & 7,50 & 4,68 & 41,59 & 5,98 & 15,85 & 10,97 & 2,57 & 10,65 \\
\hline UMMZ202080 & 6,22 & 2,58 & 6,77 & 29,53 & 8,03 & 5,42 & 43,41 & 6,50 & 16,03 & 10,94 & 2,03 & 9,96 \\
\hline UMMZ202081 & 6,40 & 2,55 & 6,68 & 29,92 & 7,75 & 5,26 & 44,30 & - & - & - & - & - \\
\hline UMMZ202082 & 6,17 & 2,58 & 6,43 & 29,31 & 7,26 & 5,28 & 41,88 & 6,39 & 16,34 & 9,61 & 2,32 & 10,83 \\
\hline AMNH6912 & 5,38 & 2,25 & 5,91 & - & 6,90 & 3,90 & 39,45 & 5,71 & - & 9,43 & 2,67 & 10,26 \\
\hline AMNH16571 & 6,04 & 2,33 & 5,69 & 29,40 & 7,41 & 4,09 & 41,74 & 6,28 & 16,60 & 10,44 & 3,24 & 11,82 \\
\hline AMNH16572 & 5,76 & 2,32 & 5,79 & 29,17 & - & - & 43,30 & 5,75 & 16,37 & 9,82 & 2,72 & 10,61 \\
\hline
\end{tabular}




\begin{tabular}{|c|c|c|c|c|c|c|c|c|c|c|c|c|}
\hline Tombo & lace & aace & Itroc & cfem & Iptbt & etbt & ctbt & apig & cpig & Ipig & Iproc & cproc \\
\hline AMNH5293 & 6,71 & 2,68 & 6,63 & 33,67 & - & - & - & - & - & - & - & - \\
\hline AMNH6712 & 6,62 & 2,62 & 6,82 & 32,87 & 8,22 & 5,40 & 46,48 & 6,97 & 19,38 & 11,09 & 2,94 & 12,55 \\
\hline UMMZ157725 & 6,34 & 2,50 & 6,57 & 33,32 & 8,31 & 4,57 & 47,39 & 6,75 & 17,63 & 10,64 & 1,88 & 11,00 \\
\hline AMNH6913 & 5,23 & 1,90 & 5,41 & 24,93 & 6,65 & 3,83 & 35,14 & 4,74 & 12,45 & 8,87 & 1,85 & 8,04 \\
\hline UMMZ156145 & 4,92 & 1,38 & 5,05 & 22,69 & 5,97 & 4,40 & 31,59 & 4,54 & 10,47 & 8,46 & 1,44 & 7,43 \\
\hline UMMZ157645 & 5,18 & 2,04 & 5,32 & 23,35 & 6,17 & 4,28 & 33,19 & - & - & - & - & - \\
\hline AMNH7089 & 6,59 & 2,98 & 7,40 & 33,30 & 8,72 & 5,26 & 44,37 & 7,68 & 17,44 & 10,70 & 2,75 & 11,26 \\
\hline AMNH7090 & 7,07 & 3,35 & 7,23 & 33,48 & 8,57 & 5,48 & 46,21 & 7,08 & 18,44 & 10,87 & 3,37 & 11,57 \\
\hline UMMZ156835 & 7,30 & 2,99 & 8,47 & 33,24 & 8,43 & 5,92 & 46,08 & 7,63 & 18,04 & 11,72 & 2,35 & 11,51 \\
\hline AMNH4212 & 6,58 & 2,66 & 5,99 & 27,86 & 7,19 & 4,38 & 39,80 & 6,74 & 15,36 & 10,16 & 2,92 & - \\
\hline MZUSP89470 & 7,31 & 2,85 & 7,10 & 32,55 & - & 2,74 & 45,46 & - & - & - & - & - \\
\hline MZUSP89471 & 7,58 & 3,01 & 7,00 & 33,17 & 7,26 & 3,12 & 45,76 & 6,45 & 17,37 & 12,02 & 4,48 & - \\
\hline MZUSP89472 & 7,55 & 3,01 & 7,39 & 32,20 & - & 3,06 & 47,14 & - & - & - & - & - \\
\hline MZUSP89473 & 7,22 & 2,91 & 7,32 & 32,67 & - & 2,92 & 45,94 & 6,23 & 17,61 & 12,24 & 3,82 & 12,65 \\
\hline AMNH6915 & 7,05 & 2,78 & 7,20 & 31,18 & 8,72 & 5,56 & 44,15 & 6,76 & 18,10 & 10,84 & - & - \\
\hline AMNH14781 & 6,05 & 2,51 & 6,24 & 29,88 & 7,40 & 4,50 & 41,55 & 6,20 & 14,87 & 9,19 & 1,94 & 9,80 \\
\hline UMMZ212934 & 6,36 & 2,49 & 6,49 & 31,17 & 7,32 & 4,89 & 43,73 & 5,99 & 14,86 & 8,45 & 2,36 & 9,07 \\
\hline UMMZ212935 & 6,45 & 2,30 & 6,61 & 29,71 & 7,38 & 4,59 & 40,95 & - & - & - & - & - \\
\hline AMNH5297 & 9,47 & 3,54 & 9,37 & 38,79 & 11,43 & 7,17 & 52,18 & 9,82 & 25,59 & 13,62 & - & - \\
\hline AMNH5341 & 7,20 & 2,75 & 7,36 & 30,92 & 8,71 & 5,22 & 42,24 & 7,45 & 20,99 & 14,22 & 3,50 & 14,67 \\
\hline AMNH5345 & 8,12 & 3,40 & 8,01 & 35,51 & 9,52 & 5,87 & 47,83 & 8,00 & 20,22 & 14,00 & 3,54 & 14,53 \\
\hline AMNH6668 & 8,59 & 3,47 & 8,34 & 36,29 & 10,18 & 6,25 & 47,87 & 8,48 & 22,70 & 14,91 & 4,32 & 16,30 \\
\hline MZUSP89447 & - & - & - & 34,35 & 8,85 & 3,20 & 45,28 & - & - & - & - & - \\
\hline
\end{tabular}

Tabela 8: Medidas referentes aos membros posteriores. Todas as medidas estão em milímetros. Traços representam medidas não disponíveis no momento do estudo (na maior parte dos casos devido a danos do espécime). Abreviações das nomenclaturas seguem o padrão delineado na seção 3.2.1. 
Anexo IV

PCA

\begin{tabular}{|c|c|c|c|c|c|c|c|c|}
\hline Medida & Fator 1 & Fator 2 & Fator 3 & Fator 4 & Fator 5 & Fator 6 & Fator 7 & Fator 8 \\
\hline cum & 0,9721 & 0,0390 & 0,1096 & 0,0968 & 0,0237 & $-0,1134$ & $-0,0293$ & 0,0327 \\
\hline darts & 9579 & $-0,1721$ & $-0,0298$ & $-0,0165$ & 0,0695 & 0,0906 & 0,0212 & 0,0764 \\
\hline cfem & 9494 & 0,0924 & $-0,1$ & ,0029 & 0163 & 765 & 423 & 001 \\
\hline ccora & 0,9446 & 0,2201 & 0,1392 & 0,0364 & 0,0414 & $-0,0690$ & $-0,0015$ & $-0,0008$ \\
\hline dcrislas & 0,9407 & $-0,0110$ & $-0,0208$ & 0,0141 & 0,0990 & 0,0120 & 0,0710 & $-0,0990$ \\
\hline Iproxum & 0,9354 & 0,0907 & & & 0,0749 & $-0,1648$ & $-0,0147$ & $-0,0468$ \\
\hline culn & 0,9335 & 0,0571 & 0,1967 & 0,1350 & 0,0121 & $-0,1331$ & $-0,0477$ & 0,0595 \\
\hline cpig & 0,9332 & $-0,0 s$ & & $-0,0345$ & $-0,1436$ & $-0,0869$ & & 0,0411 \\
\hline apig & ,9326 & $-0,0583$ & 0,0963 & $-0,0925$ & $-0,1200$ & 0,0605 & 0,0072 & $-0,0221$ \\
\hline acran & 0,9324 & $-0,1189$ & 0,0618 & $-0,0079$ & $-0,0502$ & $-0,0197$ & $-0,1351$ & $-0,0222$ \\
\hline daintpc & 0,9276 & $-0,1$ & 734 & 0,0409 & 584 & & 107 & 692 \\
\hline crad & 274 & 0,0 & 122 & 146 & & -0 & 162 & 439 \\
\hline dpcauai & 0,9221 & $-0,2393$ & 0,0768 & 44 & 0,0672 & $-0,0159$ & $-0,0733$ & 0,0978 \\
\hline Icran & & & & & & & & 0,0805 \\
\hline pcran & 0,9202 & 0,2423 & $-0,0$ & 887 & $-0,0$ & 317 & 068 & 0,0568 \\
\hline lace & 0,9198 & $-0,3055$ & $-0,0220$ & 0,0223 & 0,0538 & 0,0532 & 405 & $-0,0896$ \\
\hline dpvcai & & $-0,0765$ & & & & & 284 & 730 \\
\hline Itroc & 0,9126 & $-0,1$ & & $-0,1$ & & & & \\
\hline dcrislai & 0,9110 & 0,0946 & 195 & 0,0441 & 0,0 & & 126 & -0 \\
\hline dproca & 02 & $-0,2809$ & 375 & & 072 & & & 0047 \\
\hline ddiag & 0,9101 & 0,1304 & $-0,1029$ & 0,0914 & & 857 & 695 & $-0,0303$ \\
\hline aace & & $-0,1$ & $-0,0$ & 284 & 357 & 368 & 742 & \\
\hline ctbt & 0,8914 & 0,2030 & $-0,0$ & 0,1640 & $-0,0094$ & 479 & 474 & 284 \\
\hline Iptbt & $0,8 \varepsilon$ & & & & & & & \\
\hline acris & & & & & & & & \\
\hline Imaxs & 0,8845 & $-0,2 \varepsilon$ & & & & & & \\
\hline dpcauas & 0,8821 & $-0,2814$ & 0,0625 & & -0 & 304 & 214 & 050 \\
\hline darti & 0,8780 & $-0,0690$ & $-0,0120$ & $-0,0632$ & 220 & & 059 & 243 \\
\hline cproc & 0,8745 & $-0,2908$ & $-0,0155$ & 302 & & 999 & 345 & 547 \\
\hline cmaxi & 0,8659 & 0,4006 & -0 & 860 & & & 075 & \\
\hline aecran & 0,8651 & $-0,2005$ & $-0,1675$ & 0,1160 & $-0,1488$ & 0,1251 & $-0,1176$ & $-0,1476$ \\
\hline lamaxi & 0,8543 & $-0,1106$ & 0,0229 & $-0,0262$ & $-0,2439$ & $-0,0526$ & 0,1330 & $-0,1089$ \\
\hline cqui & 0,8408 & 0,2519 & 0,2543 & 0,3111 & $-0,0120$ & $-0,0743$ & 342 & $-0,0508$ \\
\hline diama & 0,8362 & $-0,1818$ & $-0,0091$ & $-0,0812$ & 0,0789 & 0,0783 & 0,0251 & $-0,0268$ \\
\hline dpmed & 0,8261 & 0,3718 & $-0,1391$ & & $-0,0635$ & $-0,0678$ & $-0,0532$ & $-0,0726$ \\
\hline amaxs & 0,8179 & 0,0284 & $-0,2084$ & $-0,1870$ & $-0,0372$ & $-0,0622$ & 0,0347 & 0,0984 \\
\hline cmaxs & 0,8150 & 0,3427 & $-0,1288$ & $-0,1490$ & 0,0460 & $-0,1137$ & $-0,0576$ & 0,0188 \\
\hline dpvcpc & 0,8143 & $-0,1477$ & $-0,0564$ & $-0,2090$ & $-0,1232$ & $-0,0730$ & 0,0995 & 0,2598 \\
\hline dcondp & & & $-0,2503$ & $-0,1015$ & $-0,0748$ & $-0,1052$ & $-0,0048$ & $-0,0056$ \\
\hline dcriscran & 0,7982 & $-0,0427$ & $-0,1535$ & 0,1068 & $-0,1782$ & 0,1429 & 0,3185 & $-0,1338$ \\
\hline eart & 0,7886 & $-0,2263$ & 0,1306 & $-0,1426$ & 0,0667 & 0,0427 & 0,1055 & $-0,0829$ \\
\hline aqui & 0,7884 & 0,3248 & 0,2912 & 0,1809 & $-0,0248$ & $-0,0428$ & $-0,0035$ & 0,0116 \\
\hline Ipig & 0,7876 & $-0,4082$ & 0,1363 & $-0,0891$ & $-0,1510$ & $-0,0762$ & $-0,1052$ & 0,1642 \\
\hline
\end{tabular}




\begin{tabular}{ccccccccc}
\hline Medida & Fator 1 & Fator 2 & Fator 3 & Fator 4 & Fator 5 & Fator 6 & Fator 7 & Fator 8 \\
\hline devcris & 0,7875 & $-0,1080$ & $-0,3125$ & 0,1124 & $-0,1720$ & 0,2192 & 0,0015 & $-0,3104$ \\
dpcaud & 0,7516 & 0,0011 & $-0,0410$ & $-0,0517$ & 0,2586 & 0,2224 & 0,1076 & $-0,2945$ \\
dapm & 0,7514 & 0,4325 & $-0,1341$ & $-0,0193$ & 0,1512 & $-0,0352$ & 0,0346 & 0,0763 \\
cpelv & 0,7426 & $-0,0807$ & 0,1135 & 0,1553 & 0,1307 & $-0,2617$ & 0,1697 & $-0,0723$ \\
dinta & 0,7307 & 0,0751 & $-0,0519$ & $-0,1263$ & 0,2246 & 0,2787 & $-0,1721$ & 0,3849 \\
Iproc & 0,7245 & $-0,3915$ & $-0,2928$ & $-0,0529$ & 0,0356 & $-0,2079$ & $-0,0778$ & 0,1717 \\
dintn & 0,7002 & $-0,5523$ & 0,0293 & $-0,2729$ & 0,0584 & 0,0788 & $-0,0818$ & $-0,1289$ \\
dcriscl & 0,6945 & $-0,0904$ & $-0,0226$ & $-0,0617$ & $-0,1954$ & 0,0872 & 0,5340 & $-0,0926$ \\
cnar & 0,6376 & 0,6236 & $-0,0348$ & $-0,0211$ & $-0,1825$ & 0,0670 & $-0,0245$ & 0,0469 \\
cjug & 0,5966 & 0,5566 & $-0,0111$ & $-0,0726$ & 0,2397 & $-0,0650$ & $-0,0221$ & $-0,1956$ \\
dpvcaud & 0,5303 & 0,1145 & $-0,2863$ & $-0,2993$ & 0,5519 & 0,1399 & 0,0659 & 0,0571 \\
eum & 0,5171 & 0,1806 & $-0,1366$ & 0,2076 & $-0,2627$ & 0,4461 & $-0,4943$ & $-0,0751$ \\
Inar & 0,4314 & 0,6717 & 0,1543 & $-0,1832$ & $-0,1707$ & 0,1247 & 0,0995 & 0,1270 \\
mdcris & 0,2548 & $-0,0333$ & $-0,4850$ & 0,4540 & $-0,1178$ & 0,2824 & 0,3245 & 0,4109 \\
etbt & 0,1116 & 0,1917 & 0,6196 & $-0,5067$ & $-0,2442$ & 0,3364 & 0,1133 & 0,1279 \\
dppteri & 0,0978 & $-0,0061$ & 0,5408 & 0,4953 & 0,3314 & 0,3144 & 0,0920 & 0,1354 \\
\hline \hline
\end{tabular}

Tabela 9: Matriz de componentes redimensionados da análise geral, mostrando os valores associados a cada medida e fator, com os cinco maiores (fundo sólido) e cinco menores (fundo hachurado) valores em evidência.

\begin{tabular}{cccccc}
\hline \multicolumn{2}{c}{ Fator 1 } & \multicolumn{2}{c}{ Fator 2 } & \multicolumn{2}{c}{ Fator 3 } \\
\hline cum & 0,9721 & Inar & 0,6717 & etbt & 0,6196 \\
darts & 0,9579 & cnar & 0,6236 & dppteri & 0,5408 \\
cfem & 0,9494 & cjug & 0,5566 & Iptbt & 0,3014 \\
ccora & 0,9446 & dapm & 0,4325 & aqui & 0,2912 \\
dcrislas & 0,9407 & cmaxi & 0,4006 & cqui & 0,2543 \\
eum & 0,5171 & cproc & $-0,2908$ & dcondp & $-0,2503$ \\
Inar & 0,4314 & lace & $-0,3055$ & dpvcaud & $-0,2863$ \\
mdcris & 0,2548 & Iproc & $-0,3915$ & Iproc & $-0,2928$ \\
etbt & 0,1116 & Ipig & $-0,4082$ & devcris & $-0,3125$ \\
dppteri & 0,0978 & dintn & $-0,5523$ & mdcris & $-0,4850$ \\
\hline \hline
\end{tabular}

Tabela 10: Maiores e menores correlações associadas a medidas nos três primeiros fatores gerais. 


\begin{tabular}{|c|c|c|c|c|c|c|c|c|c|}
\hline Tombo & Táxon & Fator 1 & Fator 2 & Fator 3 & Fator 4 & Fator 5 & Fator 6 & Fator 7 & Fator 8 \\
\hline AMNH24055 & Colaptes campestris & 1089 & 0,15689 & $-1,16498$ & 1,95655 & $-0,79476$ & $-0,38348$ & 0,65633 & 1,03735 \\
\hline AMNH6648 & Colaptes campestris & 0,91001 & 1,14749 & 1,02007 & 0,86248 & 0,6136 & & 0,19944 & 2,13721 \\
\hline MZUSP89449 & Colaptes campestris & 29037 & 54421 & 43989 & 58344 & 1,92899 & 49236 & 16235 & \\
\hline MZUSP89451 & Colaptes campestris & 0,6039 & $-0,05788$ & $-0,26196$ & 2,29265 & 1,08243 & $-1,46633$ & $-0,13382$ & $-0,89913$ \\
\hline MZUSP90432 & Colaptes campestris & 0,3508 & 0,91285 & $-0,77515$ & 1,65659 & 1,36558 & $-0,31273$ & 0,17441 & $-2,77022$ \\
\hline NMNH227387 & Colaptes campestris campestroides & 0,49971 & 0,35369 & 0,02877 & 0,51833 & $-0,40925$ & $-0,13684$ & 1,45262 & 1,12491 \\
\hline NMNH614654 & Colaptes campestris & 0,98881 & 0,6619 & 0,69428 & 0,13977 & $-0,18301$ & 0,75292 & 1,4905 & 0,81807 \\
\hline NMNH614655 & Colaptes campestris & 0,75063 & 0,72214 & 0,41925 & $-0,52204$ & 1,08343 & 0,33942 & 0,21722 & $-0,29741$ \\
\hline NMNH630185 & Colaptes campestris & 0,29499 & 0,5664 & 0,32181 & 0,6227 & $-0,34758$ & 0,16463 & 0,25232 & 0,05322 \\
\hline AMNH23912 & Colaptes melanochloros melanolaimus & $-1,03317$ & 0,22554 & 0,10679 & $-0,38293$ & $-1,23368$ & $-1,0593$ & $-0,78464$ & $-0,14586$ \\
\hline AMNH23990 & Colaptes melanochloros melanolaimus & $-0,65844$ & 0,64231 & 0,12469 & 1,09798 & 0,3627 & 0,83974 & 1,56549 & 0,4502 \\
\hline NMNH227386 & Colaptes melanochloros nigroviridis & $-0,59905$ & $-0,13876$ & 0,49105 & 0,29033 & $-0,353$ & 0,14434 & 4955 & 3373 \\
\hline NMNH490026 & Colaptes melanochloros melanochloros & $-0,48679$ & $-0,35992$ & 0,3422 & $-0,42135$ & $-0,12798$ & $-0,08326$ & 0,01707 & $-0,60419$ \\
\hline NMNH614652 & Colaptes melanochloros melanolaimus & $-0,64091$ & 0,28806 & 0,34143 & 0,06578 & & $-0,1288$ & 0,64564 & $-0,72934$ \\
\hline NMNH614653 & Colaptes melanochloros melanolaimus & $-0,29579$ & 0,34214 & 0,55706 & $-0,06819$ & 0,40904 & $-0,17665$ & 0,2076 & $-0,03378$ \\
\hline UMMZ157049 & Colaptes melanochloros melanolaimus & $-0,5211$ & $-0,2845$ & 0,55115 & 0,46542 & 0,47908 & 5199 & $-0,172$ & $-0,74042$ \\
\hline UMMZ157050 & Colaptes melanochloros melanolaimus & $-0,52614$ & 0,39946 & 1,01009 & 0,381 & 0,32961 & 0,35431 & $-1,98701$ & 1,91734 \\
\hline UMMZ158658 & Colaptes melanochloros & $-0,23419$ & $-0,40348$ & 0,82203 & 0,66937 & $-0,70032$ & 0,47771 & 0,29361 & $-0,6858$ \\
\hline UMMZ200723 & Colaptes melanochloros & $-0,27453$ & 0,66937 & 0,816 & $-0,06751$ & $-1,13033$ & 0,23991 & 0,80405 & 0,21082 \\
\hline UMMZ202079 & Colaptes melanochloros melanolaimus & $-0,46264$ & 0,2091 & 0,74452 & 0,31118 & 0,24334 & $-0,74607$ & $-0,92716$ & $-0,3258$ \\
\hline UMMZ202080 & Colaptes melanochloros melanolaimus & $-0,1966$ & 0,21132 & 0,89668 & $-0,19182$ & 0,03792 & $-0,12104$ & $-0,29069$ & $-0,78428$ \\
\hline UMMZ202081 & Colaptes melanochloros melanolaimus & $-0,18023$ & 0,18661 & 1,12482 & 0,14647 & 0,24675 & $-0,83889$ & 0,30121 & $-0,09679$ \\
\hline UMMZ202082 & Colaptes melanochloros melanolaimus & $-0,42307$ & $-0,05148$ & 1,09632 & $-0,28645$ & 0,54861 & $-0,34997$ & $-0,06819$ & $-0,13518$ \\
\hline AMNH6912 & Colaptes atricollis & $-1,15809$ & $-0,0861$ & $-1,71282$ & $-1,48032$ & $-0,32241$ & $-0,3227$ & $-0,47011$ & 0,94656 \\
\hline AMNH16571 & Colaptes chrysoides & $-0,48983$ & 0,38639 & $-1,09688$ & $-0,77222$ & $-2,37659$ & $-2,02739$ & 0,05895 & 0,37152 \\
\hline AMNH16572 & Colaptes chrysoides & $-0,70501$ & 1,13263 & 0,00099 & $-0,49738$ & $-1,63123$ & $-2,19399$ & $-1,32355$ & 0,47576 \\
\hline
\end{tabular}




\begin{tabular}{|c|c|c|c|c|c|c|c|c|c|}
\hline Tombo & Táxon & Fator 1 & Fator 2 & Fator 3 & Fator 4 & Fator 5 & Fator 6 & Fator 7 & Fator 8 \\
\hline AMNH5293 & Colaptes pitius & 0,49581 & 1,32456 & $-0,08034$ & 0,32752 & $-0,61816$ & $-0,02967$ & 0,80147 & 0,15168 \\
\hline AMNH6712 & Colaptes pitius & 0,58961 & 1,31977 & 0,39518 & $-0,80374$ & $-0,01476$ & $-0,61214$ & $-0,32138$ & $-0,17325$ \\
\hline UMMZ157725 & Colaptes pitius & $-0,03991$ & 1,51131 & 0,39988 & 0,38432 & $-1,01769$ & $-1,71787$ & 0,00167 & 0,11686 \\
\hline AMNH6913 & Colaptes punctigula & $-2,30466$ & $-0,74522$ & 0,85411 & 0,32904 & 0,47252 & $-0,18798$ & $-0,29046$ & 0,44551 \\
\hline UMMZ156145 & Colaptes punctigula & $-2,79818$ & $-0,86834$ & 0,68451 & $-0,58274$ & 0,57003 & 0,98243 & 0,51153 & $-0,20636$ \\
\hline UMMZ157645 & Colaptes punctigula & $-2,57332$ & $-1,3172$ & 0,92745 & $-0,01283$ & 1,10972 & 0,77932 & $-0,19429$ & $-0,88331$ \\
\hline AMNH7089 & Colaptes rupicola & 0,66476 & 0,82808 & $-0,31713$ & $-3,19331$ & 1,1257 & $-0,66263$ & $-1,20201$ & $-1,08869$ \\
\hline AMNH7090 & Colaptes rupicola & 0,72194 & 0,77562 & $-0,83973$ & $-2,4186$ & 1,98295 & 0,28326 & 0,37999 & $-0,29102$ \\
\hline UMMZ156835 & Colaptes rupicola puna & 0,96895 & 0,71374 & $-0,43586$ & $-1,77663$ & $-0,11695$ & 0,89725 & 0,88071 & 0,64548 \\
\hline AMNH4212 & Celeus flavescens ochraceous & $-0,82348$ & $-2,15995$ & $-0,54602$ & $-0,21043$ & 0,17305 & 0,97634 & $-0,22077$ & 1,48909 \\
\hline MZUSP89470 & Celeus flavescens & $-0,02065$ & $-1,8799$ & $-1,72201$ & 0,71911 & $-0,50835$ & $-0,51303$ & 0,6551 & $-0,81389$ \\
\hline MZUSP89471 & Celeus flavescens & 0,58762 & $-0,85015$ & $-2,10499$ & $-0,78417$ & 1,72684 & $-0,49729$ & $-1,25767$ & 0,74616 \\
\hline MZUSP89472 & Celeus flavescens & 0,37906 & $-1,49608$ & $-2,13214$ & $-0,00887$ & $-0,00916$ & $-0,52514$ & 1,00544 & $-0,45867$ \\
\hline MZUSP89473 & Celeus flavescens & 0,39667 & $-1,66324$ & $-2,0423$ & 0,4723 & 0,24843 & $-0,39432$ & 0,58698 & 0,24425 \\
\hline AMNH6915 & Celeus lugubris & 0,00898 & $-1,27468$ & $-0,04715$ & $-0,43014$ & $-1,13252$ & 0,12078 & 0,94511 & 1,11413 \\
\hline AMNH14781 & Geocolaptes olivaceus & $-0,35174$ & 1,64861 & $-2,0798$ & 0,97795 & $-2,01122$ & 3,85239 & $-3,45513$ & $-1,13243$ \\
\hline UMMZ212934 & Geocolaptes olivaceus & $-0,30898$ & 1,02066 & $-1,17872$ & $-0,02426$ & 0,41158 & 1,72651 & 1,57085 & 0,80549 \\
\hline UMMZ212935 & Geocolaptes olivaceus & $-0,45892$ & 1,38277 & $-0,72246$ & $-0,32726$ & 1,04852 & 0,93189 & 1,49013 & $-0,95914$ \\
\hline AMNH5297 & Dryocopus lineatus & 2,11995 & $-1,60513$ & 1,65453 & $-0,97125$ & $-1,85343$ & 0,93587 & 0,60654 & $-3,30414$ \\
\hline AMNH5341 & Dryocopus lineatus & 0,77942 & $-1,38637$ & 0,12357 & $-0,4833$ & $-1,74433$ & 0,16995 & $-0,25915$ & 0,19182 \\
\hline AMNH5345 & Dryocopus lineatus & 1,61825 & $-1,14667$ & 1,17555 & $-0,64841$ & 0,64214 & 0,58221 & $-0,5736$ & 1,16675 \\
\hline AMNH6668 & Dryocopus lineatus erythrops & 1,85423 & $-1,04598$ & 1,44819 & $-0,10914$ & 0,27726 & $-0,16531$ & $-1,2909$ & 1,02501 \\
\hline MZUSP89447 & Dryocopus lineatus & 1,582 & $-1,4626$ & 0,52737 & 1,20502 & 0,5693 & 0,53155 & $-1,83667$ & 0,10312 \\
\hline
\end{tabular}

Tabela 11: Índices dos fatores extraídos pela análise de componente principal geral das escalas logarítmicas das medidas ósseas dos exemplares. 


\begin{tabular}{cccc}
\hline Medidas & Fator $\mathbf{1}$ & Fator $\mathbf{2}$ & Fator $\mathbf{3}$ \\
\hline cmaxi & 0,9587 & $-0,1720$ & 0,0132 \\
pcran & 0,9463 & $-0,0088$ & 0,0795 \\
Icran & 0,9385 & 0,1468 & $-0,0143$ \\
dpmed & 0,9202 & $-0,1506$ & $-0,0288$ \\
cmaxs & 0,9176 & $-0,1134$ & $-0,0480$ \\
dcondp & 0,8904 & $-0,1492$ & $-0,2124$ \\
acran & 0,8818 & 0,3665 & 0,0709 \\
amaxs & 0,8413 & 0,1760 & $-0,1461$ \\
dapm & 0,8400 & $-0,2396$ & 0,0294 \\
lamaxi & 0,8125 & 0,3199 & 0,0510 \\
\hline Imaxs & 0,7991 & 0,5151 & 0,0072 \\
cnar & 0,7834 & $-0,4684$ & 0,0424 \\
cjug & 0,7218 & $-0,3752$ & 0,1795 \\
dintn & 0,5817 & 0,7430 & $-0,0208$ \\
Inar & 0,5584 & $-0,5844$ & 0,0052 \\
dppteri & 0,0203 & 0,0568 & 0,9861 \\
\hline \hline
\end{tabular}

\begin{tabular}{cccc}
\hline Medidas & Fator $\mathbf{1}$ & Fator $\mathbf{2}$ & Fator $\mathbf{3}$ \\
\hline cum & 0,9885 & 0,0416 & $-0,0632$ \\
culn & 0,9635 & 0,0956 & $-0,0724$ \\
crad & 0,9584 & 0,0810 & $-0,0681$ \\
ccora & 0,9514 & 0,1849 & $-0,0812$ \\
cpig & 0,9468 & $-0,0634$ & 0,1634 \\
\hline Iproxum & 0,9446 & 0,0030 & $-0,1541$ \\
cfem & 0,9351 & $-0,0560$ & $-0,0759$ \\
apig & 0,9292 & 0,0079 & 0,1819 \\
ddiag & 0,9124 & 0,0499 & $-0,1882$ \\
\hline acris & 0,9123 & $-0,0394$ & 0,0101 \\
aace & 0,9114 & $-0,1911$ & $-0,0103$ \\
\hline lace & 0,9110 & $-0,2282$ & 0,1254 \\
Iptbt & 0,9035 & 0,2012 & 0,1678 \\
\hline ctbt & 0,8942 & 0,0410 & $-0,2172$ \\
\hline cproc & 0,8889 & $-0,2680$ & 0,1761 \\
Itroc & 0,8886 & $-0,1087$ & 0,1923 \\
\hline cqui & 0,8643 & 0,3140 & $-0,2430$ \\
aqui & 0,8162 & 0,4227 & $-0,1787$ \\
\hline Ipig & 0,8000 & $-0,2189$ & 0,3462 \\
\hline Iproc & 0,7202 & $-0,5867$ & 0,1147 \\
\hline eum & 0,5219 & 0,2042 & $-0,2737$ \\
\hline etbt & 0,1162 & 0,6797 & 0,6852 \\
\hline \hline
\end{tabular}

Tabela 12: Matriz de componentes redimensionados da análise do crânio, mostrando os valores associados a cada medida e fator, com os cinco maiores (fundo sólido) e cinco menores (fundo hachurado) valores em evidência.

Tabela 13: Matriz de componentes redimensionados da análise do pós-crânio, mostrando os valores associados a cada medida e fator, com os cinco maiores (fundo sólido) e cinco menores (fundo hachurado) valores em evidência. 


\begin{tabular}{|c|c|c|c|c|c|c|c|}
\hline Tombo & Táxon & F. cran. 1 & F. cran. 2 & F. cran. 3 & F. p-cran. 1 & F. p-cran. 2 & F. p-cran. 3 \\
\hline MZUSP89471 & Celeus flavescens & 0,7283 & 1,1657 & $-0,8311$ & 0,3885 & $-2,1553$ & $-0,4746$ \\
\hline MZUSP89472 & Celeus flavescens & 0,2768 & 1,3071 & $-1,3288$ & 0,1491 & $-2,3704$ & $-0,2032$ \\
\hline MZUSP89470 & Celeus flavescens & $-0,4076$ & 1,4574 & $-0,8604$ & $-0,0609$ & $-2,7119$ & $-0,1424$ \\
\hline MZUSP89473 & Celeus flavescens & 0,2081 & 1,8257 & $-0,8275$ & 0,2389 & $-2,0988$ & $-0,4439$ \\
\hline AMNH4212 & Celeus flavescens ochraceous & $-1,7177$ & 1,1876 & $-0,9004$ & $-0,7552$ & $-1,5522$ & 1,3180 \\
\hline AMNH6915 & Celeus lugubris & $-0,4247$ & 0,7083 & $-0,5201$ & 0,1061 & $-0,8493$ & 1,6421 \\
\hline AMNH6912 & Colaptes atricollis & $-0,5682$ & 0,0453 & $-1,1409$ & $-1,3538$ & $-1,5229$ & 0,7809 \\
\hline AMNH24055 & Colaptes campestris & 0,9233 & $-0,5415$ & $-0,0459$ & 1,0718 & $-0,9454$ & $-2,1727$ \\
\hline NMNH630185 & Colaptes campestris & 0,4449 & $-0,0977$ & 0,9266 & 0,3092 & 0,8947 & $-0,1273$ \\
\hline NMNH614654 & Colaptes campestris & 0,9952 & $-0,6255$ & 1,2742 & 0,9011 & 0,9120 & 0,3539 \\
\hline NMNH614655 & Colaptes campestris & 0,4777 & $-0,9012$ & $-0,3402$ & 0,7907 & 0,6665 & $-0,3542$ \\
\hline AMNH6648 & Colaptes campestris & 0,9917 & $-0,9931$ & 2,6730 & 0,9091 & 1,0544 & $-0,0006$ \\
\hline MZUSP89449 & Colaptes campestris & 0,1913 & $-0,8084$ & 0,4999 & 0,4646 & $-0,9173$ & $-2,0518$ \\
\hline MZUSP90432 & Colaptes campestris & 0,4010 & $-0,9635$ & 0,4554 & 0,2867 & $-0,1384$ & $-2,7174$ \\
\hline MZUSP89451 & Colaptes campestris & 0,4358 & 0,7265 & 1,1499 & 0,7737 & $-0,5013$ & $-2,3063$ \\
\hline NMNH227387 & Colaptes campestris campestroides & 0,4069 & $-0,3386$ & 0,3303 & 0,5017 & 0,4065 & 0,0367 \\
\hline AMNH16571 & Colaptes chrysoides & $-0,2882$ & $-0,7855$ & $-3,1618$ & $-0,2943$ & $-0,4057$ & $-0,1955$ \\
\hline AMNH16572 & Colaptes chrysoides & $-0,0811$ & $-1,0996$ & $-0,4582$ & $-0,5189$ & $-0,1553$ & $-0,4770$ \\
\hline UMMZ200723 & Colaptes melanochloros & $-0,1269$ & $-0,5399$ & 0,0013 & $-0,1551$ & 0,9384 & 0,1291 \\
\hline UMMZ158658 & Colaptes melanochloros & $-0,4827$ & 0,6884 & 0,2460 & $-0,1405$ & 1,0925 & 0,2570 \\
\hline NMNH490026 & Colaptes melanochloros melanochloros & $-0,6510$ & 0,5994 & $-0,9804$ & $-0,3681$ & 0,4048 & 0,0985 \\
\hline AMNH23990 & Colaptes melanochloros melanolaimus & $-0,4626$ & $-0,8889$ & 1,9790 & $-0,6379$ & 0,2232 & 0,1558 \\
\hline AMNH23912 & Colaptes melanochloros melanolaimus & $-0,7464$ & $-0,3784$ & $-1,6335$ & $-1,0266$ & 0,2902 & 0,1812 \\
\hline NMNH614653 & Colaptes melanochloros melanolaimus & $-0,3442$ & $-0,3076$ & $-0,2332$ & $-0,2495$ & 0,7832 & $-0,4835$ \\
\hline NMNH614652 & Colaptes melanochloros melanolaimus & $-0,7193$ & $-0,3896$ & $-0,6205$ & $-0,6189$ & 1,1118 & $-0,5104$ \\
\hline UMMZ202079 & Colaptes melanochloros melanolaimus & $-0,3635$ & $-0,5707$ & 0,7354 & $-0,4056$ & 0,0194 & 0,2653 \\
\hline
\end{tabular}




\begin{tabular}{|c|c|c|c|c|c|c|c|}
\hline Tombo & Táxon & F. cran. 1 & F. cran. 2 & F. cran. 3 & F. p-cran. 1 & F. p-cran. 2 & F. p-cran. 3 \\
\hline UMMZ202080 & Colaptes melanochloros melanolaimus & $-0,1058$ & $-0,0028$ & 0,0132 & $-0,1826$ & 1,0195 & 0,3339 \\
\hline UMMZ202081 & Colaptes melanochloros melanolaimus & $-0,2204$ & $-0,0897$ & 0,3370 & $-0,0978$ & 0,9540 & $-0,1157$ \\
\hline UMMZ202082 & Colaptes melanochloros melanolaimus & $-0,6468$ & $-0,1320$ & 0,2226 & $-0,3460$ & 0,6167 & 0,1319 \\
\hline UMMZ157049 & Colaptes melanochloros melanolaimus & $-0,8008$ & 0,0323 & 0,6949 & $-0,3416$ & 0,0124 & 0,0106 \\
\hline UMMZ157050 & Colaptes melanochloros melanolaimus & $-0,6438$ & $-0,7694$ & 0,9507 & $-0,3455$ & 0,8043 & $-0,1874$ \\
\hline NMNH227386 & Colaptes melanochloros nigroviridis & $-0,7173$ & $-0,0390$ & 0,4122 & $-0,4461$ & 0,1781 & 0,4206 \\
\hline AMNH5293 & Colaptes pitius & 0,7562 & $-1,1718$ & $-0,2228$ & 0,4364 & 1,0793 & $-0,3924$ \\
\hline AMNH6712 & Colaptes pitius & 1,0653 & $-0,8894$ & $-0,2245$ & 0,5310 & 0,7859 & 0,0419 \\
\hline UMMZ157725 & Colaptes pitius & 0,4294 & $-1,4965$ & $-0,2236$ & 0,1244 & 0,9700 & $-0,4250$ \\
\hline AMNH6913 & Colaptes punctigula & $-2,3856$ & 0,3184 & 0,8616 & $-2,1349$ & $-0,3143$ & 0,2481 \\
\hline UMMZ156145 & Colaptes punctigula & $-2,6663$ & 0,6659 & 0,8980 & $-3,0451$ & 0,1404 & 0,8438 \\
\hline UMMZ157645 & Colaptes punctigula & $-2,9306$ & 0,6077 & 0,8863 & $-2,5418$ & $-0,3776$ & 0,6301 \\
\hline AMNH7089 & Colaptes rupicola & 1,1124 & $-0,5543$ & $-1,4583$ & 0,4587 & 0,0474 & 0,7041 \\
\hline AMNH7090 & Colaptes rupicola & 0,9946 & $-0,4819$ & $-0,8951$ & 0,5890 & $-0,1777$ & 0,7006 \\
\hline UMMZ156835 & Colaptes rupicola puna & 1,3671 & $-0,2885$ & $-0,6596$ & 0,7286 & 0,5459 & 0,9305 \\
\hline AMNH5345 & Dryocopus lineatus & 1,2727 & 1,9068 & 0,7288 & 1,5707 & 0,2535 & 0,9918 \\
\hline AMNH5341 & Dryocopus lineatus & 0,6139 & 1,4933 & $-0,5463$ & 0,7360 & $-0,5940$ & 1,7444 \\
\hline AMNH5297 & Dryocopus lineatus & 1,6413 & 2,1354 & 0,8095 & 2,0720 & 0,2346 & 2,2825 \\
\hline MZUSP89447 & Dryocopus lineatus & 1,2023 & 1,9045 & 1,2836 & 1,6783 & $-1,2162$ & $-0,1906$ \\
\hline AMNH6668 & Dryocopus lineatus erythrops & 1,4338 & 1,4409 & 0,3658 & 2,0850 & 0,1459 & 1,3889 \\
\hline AMNH14781 & Geocolaptes olivaceus & 0,0429 & $-1,4249$ & $-0,6775$ & $-0,4557$ & 1,3874 & $-2,1279$ \\
\hline UMMZ212934 & Geocolaptes olivaceus & 0,0757 & $-1,0344$ & $-0,0568$ & $-0,6652$ & 0,5538 & $-0,3360$ \\
\hline UMMZ212935 & Geocolaptes olivaceus & 0,0127 & $-1,6122$ & 0,1125 & $-0,7134$ & 0,4773 & $-0,1863$ \\
\hline
\end{tabular}

Tabela 14: Índices dos fatores extraídos pela análise de componente principal da análise de crânio e pós-crânio das escalas logarítmicas das medidas ósseas dos exemplares. 